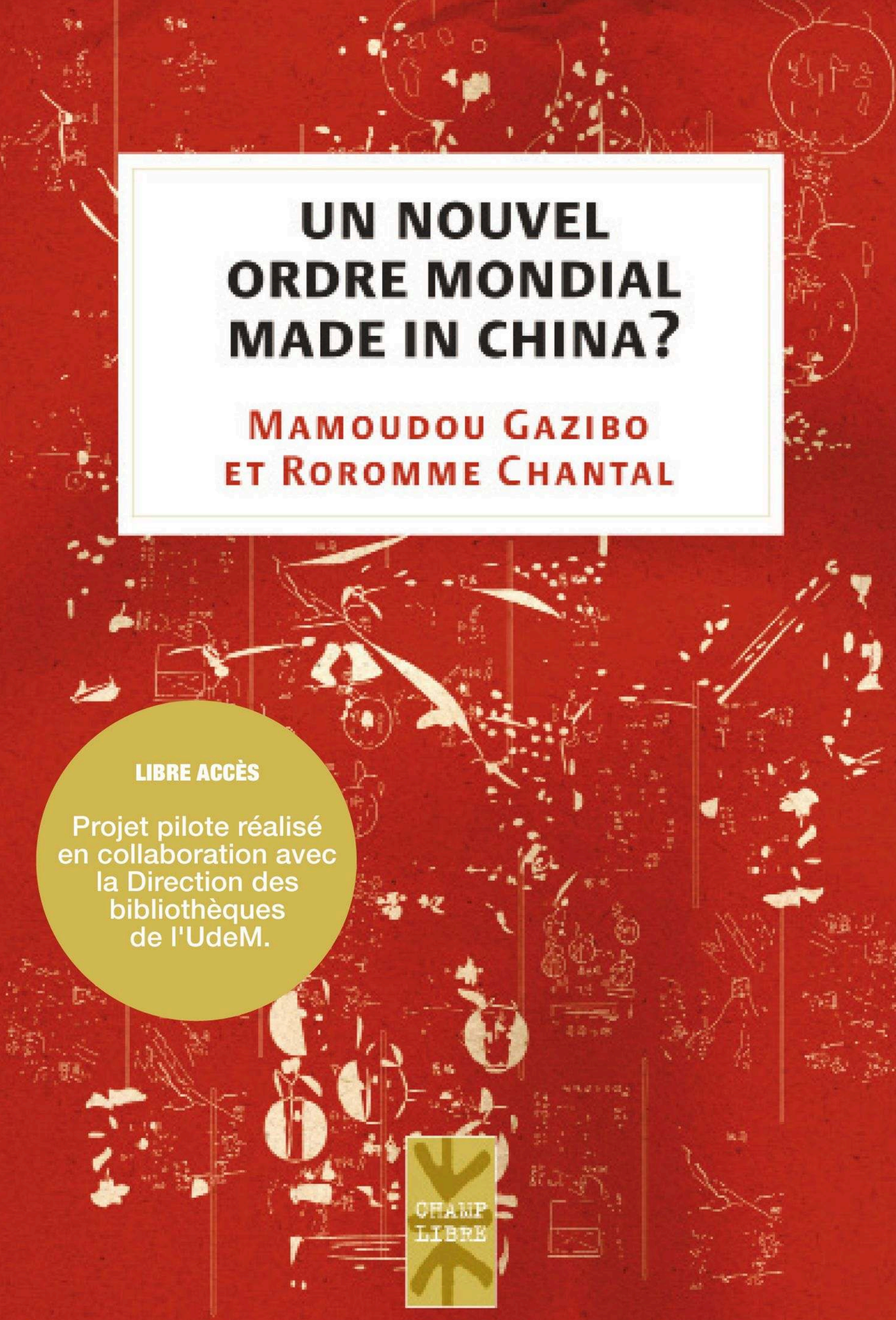




\section{Un nouvel ordre mondial made in China?}

\section{Mamoudou Gazibo et Roromme Chantal}

Éditeur : Presses de l'Université de Montréal

Lieu d'édition : Montréal

Année d'édition : 2011

Date de mise en ligne : 23 janvier 2018

Collection : Champ libre

EAN électronique : 9782821897656

\section{OpenEdition}

Books

https://books.openedition.org

Édition imprimée

EAN (Édition imprimée) : 9782760626737

Nombre de pages : 173

\section{Référence électronique}

GAZIBO, Mamoudou; CHANTAL, Roromme. Un nouvel ordre mondial made in China ? Nouvelle édition [en ligne]. Montréal : Presses de l'Université de Montréal, 2011 (généré le 29 janvier 2022). Disponible sur Internet : <http://books.openedition.org/pum/4440>. ISBN : 9782821897656.

(c) Presses de l'Université de Montréal, 2011

Conditions d'utilisation :

http://www.openedition.org/6540 


\section{RÉSUMÉS}

Le XXI ${ }^{\mathrm{e}}$ siècle sera-t-il chinois ? Bien des signes le laissent penser. En quelques décennies, le pays a su rattraper son retard en dépassant toutes les prédictions. Son influence économique, stratégique, diplomatique et idéologique est partout croissante - dans le tiers-monde, en particulier. L'Occident, et au premier titre les États-Unis, observe cette résurgence avec une défiance manifeste. A-t-on raison de s'inquiéter ? Et comment, au juste, cette transition est-elle pilotée?

Le meilleur moyen de le savoir, c'est d'inscrire l'analyse dans la longue durée et de prêter l'oreille aux discours des spécialistes et des acteurs chinois. Depuis Deng Xiaoping, Beijing a fait du pragmatisme un principe de gouvernement fondamental. C'est l'ère de l'« ascension pacifique ", qui opère un savant dosage entre l'assurance d'une puissance qui entend faire sa marque et le doigté d'un partenaire d'affaires raisonnable et rassurant. 


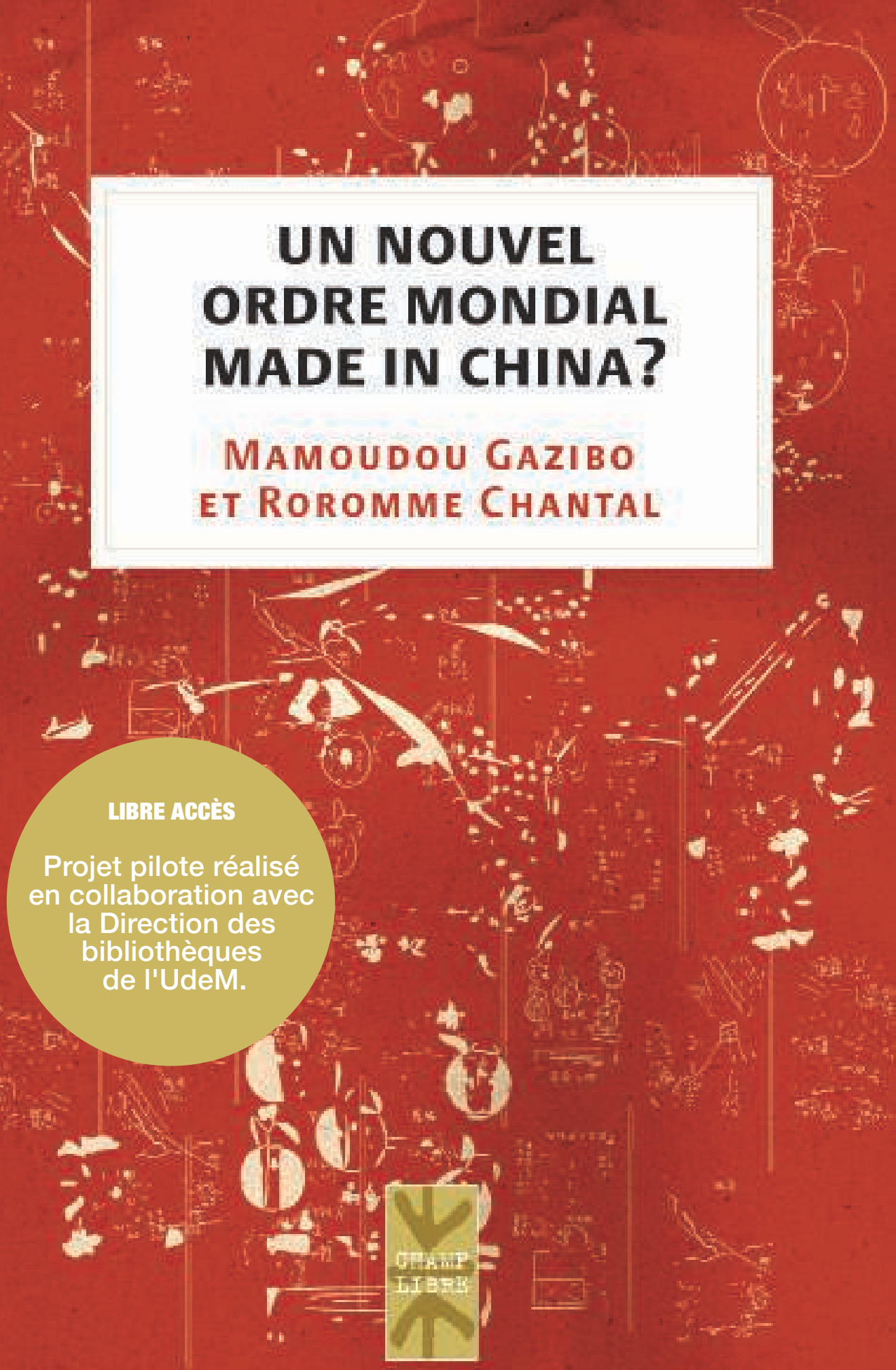



UN NOUVEL ORDRE MONDIAL MADE IN CHINA? 



\section{MAMOUDOU GAZIBO \\ ROROMME CHANTAL}

\section{UN NOUVEL ORDRE MONDIAL MADE IN CHINA?}


Catalogage avant publication de Bibliothèque et Archives nationales du Québec et Bibliothèque et Archives Canada

Gazibo, Mamoudou

Un nouvel ordre mondial made in China?

(Champ libre)

Comprend des réf. bibliogr.

ISBN 978-2-7606-2250-O

1. Chine - Conditions économiques - 2000- .

2. Chine - Relations extérieures.

3. Pouvoir économique - Chine.

4. Nouvel ordre économique international.

5. Grandes puissances.

I. Chantal, Roromme. II. Titre. III. Collection: Champ libre (Presses de l’Université de Montréal).

HC427.95.G39 2011 33O.951'O6 C2O1O-94261O-X

ISBN (version imprimée) 978-2-7606-2250-O

ISBN (version numérique PDF) 978-2-7606-2673-7

Dépôt légal : $1^{\text {er }}$ trimestre 2011

Bibliothèque et Archives nationales du Québec

(C) Les Presses de l'Université de Montréal, 2011

Les Presses de l'Université de Montréal reconnaissent l'aide financière du gouvernement du Canada par l'entremise du Fonds du livre du Canada pour leurs activités d'édition.

Les Presses de l'Université de Montréal remercient de leur soutien financier le Conseil des Arts du Canada et la Société de développement des entreprises culturelles du Québec (SODEC).

IMPRIMÉ AU CANADA EN FÉVRIER 2011 


\section{INTRODUCTION}

Considérée désormais comme le principal rival de l'hégémonie mondiale des États-Unis, la République populaire de Chine (RPC) entre dans le $\mathrm{XxI}^{\mathrm{e}}$ siècle avec devant elle un défi à la mesure de ses ambitions. Depuis l'implosion de l'Union soviétique, au tournant de la décennie 1990, les États-Unis exercent en effet une domination sans précédent sur le système international. L'économie de la seule «hyperpuissance» pèse pour plus du quart dans l'économie mondiale, équivalente à celles réunies de l'Allemagne, du Japon, de la Grande-Bretagne, de la France et de l'Italie. Quant à ses dépenses militaires, elles sont plus importantes que celles de tous les autres pays du monde additionnées ${ }^{1}$. Dans l'histoire moderne, aucun autre État n'a eu une telle prépondérance en termes de richesse, de puissance et d'influence.

La Chine, de son côté, a pour elle ses 1,3 milliard d'habitants - soit environ un cinquième de la population

1. Susan L. Shirk, China: Fragile Superpower, Oxford University Press, 2007, p. 10. 
mondiale et plus de quatre fois celle des États-Unis -, une croissance économique qui se maintient aux environs de 9,4\% depuis trois décennies et son arsenal nucléaire. Elle est la principale puissance émergente, et on lui reconnaît couramment aujourd'hui le potentiel de rivaliser avec les États-Unis dans les affaires mondiales.

Mais vu l'énorme écart qui sépare encore la Chine de son rival, la question de sa suprématie se pose sous la forme d'une équation dont la variable clé est la force de l'adversaire. Elle doit penser une stratégie de puissance qui évite de provoquer la seule superpuissance du globe. Comment la Chine conçoit-elle et met-elle en œuvre cette stratégie?

Dans ce livre, nous proposerons des éléments de réponse en analysant l'émergence de la Chine du double point de vue des circonstances historiques et du réalisme offensif, une variante de la théorie réaliste qui met l'accent sur le caractère expansionniste des États dans un système international anarchique. Nous nous intéresserons en particulier à la stratégie d'affirmation de puissance de Beijing, fondée sur l'une des armes les plus redoutables de l'ère post-guerre froide, la force économique. En examinant la conversion de cette force en ressources militaires, politiques et diplomatiques, nous tenterons d'en évaluer les implications pour l'ordre mondial en mutation.

Nous verrons d'abord comment, sous diverses facettes, la montée en puissance de la Chine bouleverse l'ordre mondial actuel. Nous verrons ensuite dans quelle mesure le leadership chinois a pu utiliser efficacement le soft power (la puissance économique et l'influence politique), à défaut de disposer encore du hard power nécessaire (la puissance militaire), dans le cadre d'une stratégie visant à remettre 
en question l'hégémonie américaine en Asie et au niveau global. À cet effet, nous analyserons ce qui nous paraît constituer les piliers essentiels de la stratégie d'affirmation de puissance de la Chine: une conscience historique qui l'incline à renouer avec une grandeur perdue, mais à sa manière; l'équilibrage interne (internal balancing), qui renvoie aux dimensions économique et militaire; et l'équilibrage externe (external balancing), qui concerne les dimensions politiques et diplomatiques de cette montée en puissance. Nous verrons que tout en étant largement explicable sous l'angle du réalisme offensif, la montée en puissance de la Chine redessine l'ordre mondial en dérogeant à maints égards aux schémas classiques. 



\section{L’ordre mondial bousculé}

L'ascension de la Chine au rang de grande puissance bouscule à plusieurs égards l'ordre mondial centré sur la superpuissance américaine. Ce nouveau statut sur la scène internationale est le résultat de l'ingéniosité du peuple chinois, mais aussi et surtout de la stratégie de son leadership. Pour reprendre les termes du général Jean Salvan, la stratégie peut être définie comme «l'ensemble des méthodes et moyens permettant d'atteindre les fins exigées par le politique ${ }^{1}$ ».

En reprenant l'analyse de Christopher Layne, Tanguy Struye de Swielande définit la grande stratégie comme un processus en trois temps: détermination des intérêts sécuritaires vitaux d'un État; identification des menaces qui pèsent sur ces intérêts; allocation des ressources politiques, militaires et économiques de l'État nécessaires à leur protection ${ }^{2}$.

1. Cité dans Tanguy Struye de Swielande, «Les États-Unis et le nouvel ordre mondial émergent», Les Cahiers du RMES, vol. 5, nº 1, 2008, p. 78.

2. Christopher Layne, «From preponderance to offshore balancing», International Security, vol. 22, $\mathrm{n}^{\circ}$ 1, 1997, p. 88. 
La stratégie intégrale, prise dans cette acception, articulerait «la sécurité extérieure aux facteurs d'ordre interne que sont tant les ressources économiques et la capacité de production des acteurs que leur culture ou idéologie et les institutions politiques qui les expérimentent». Dans ces circonstances, comme le souligne Swielande, «la grande stratégie d'un État représente donc une feuille de route délimitant les grands objectifs de la politique étrangère. Bien que cela lui soit difficile, il est donc fondamental pour un État d'établir une stratégie générale, une grille de lecture qui lui permette de définir ou de redéfinir ses priorités par rapport au monde.»

Sur un plan plus opérationnel, la grande stratégie serait alors la combinaison particulière des moyens militaires, politiques et économiques par lesquels un État tente de faire prévaloir ses intérêts nationaux. Une telle approche implique une sorte d'équilibre entre soft et hard power dans la politique étrangère des États; l'équilibre entre ces deux sources de l'influence nationale traduisant concrètement la grande stratégie de l'État ${ }^{3}$.

\section{Une stratégie d'affirmation de puissance}

Les analyses qui précèdent correspondent, croyons-nous, au comportement de la Chine sur la scène internationale au cours des dernières décennies. En effet, les observateurs sont de plus en plus nombreux à penser que la Chine, à l'instar de n'importe quel autre État, poursuit actuellement une grande stratégie dictée essentiellement par son

3. Ben D. Mor, «Public diplomacy in grand strategy», Foreign Policy Analysis, vol. 2, n² 2, 2006, p. 158. 
expérience historique, ses intérêts politiques et son environnement géostratégique 4 . Avery Goldstein observe qu'au sortir de la guerre froide, période au cours de laquelle la Chine a fait face aux défis de l'unilatéralisme américain, un consensus s'est dégagé parmi ses leaders. Ce consensus constitue de facto une grande stratégie édictant les grandes lignes de sa politique étrangère ${ }^{5}$.

Cette grande stratégie peut se définir comme la poursuite de ce que Beijing perçoit comme ses intérêts eu égard aux ressources dont elle dispose et au contexte contraignant dans lequel ces objectifs doivent être atteints. En analysant la portée de sa grande stratégie, on prête couramment à ce pays l'intention de se propulser au statut de grande puissance dans un contexte unipolaire dominé par la superpuissance américaine.

Dans les milieux plus conservateurs en Occident, où les moindres faits et gestes de la Chine sont passés au peigne fin, les observateurs sont encore plus radicaux. En 2009, un spécialiste de l'Asie déclarait au Congrès américain: «Je partage l'opinion, nourrie par 25 ans d'études de la RPC, que le leadership du PCC a toujours eu une grande stratégie. En outre, il me semble évident [que les dirigeants chinois] continuent d'avoir une grande stratégie aujourd'hui. C'est une grande stratégie d'intimidation, d'expansion, d'affirmation et de domination sur le plan global. C'est une stratégie qui vise à rattraper, à surpasser et finalement à éclipser la superpuissance régnante, les

4. Michael D. Swaine et Ashley J. Tellis, Interpreting China's Grand Strategy: Past, Present, and Future, Santa Monica, RAND, 2000, p. 8.

5. Avery Goldstein, Rising to the Challenge. China's Grand Strategy and International Security, Stanford University Press, 2005, p. 12. 
États-Unis d'Amérique. En un mot, c'est une stratégie d'hégémonie ${ }^{6}$.»

Bien entendu, la perspective officielle chinoise oppose à cette conception, jugée biaisée, la thèse du développement pacifique. À la tête de cette contre-offensive, le premier ministre Wen Jiabao a, depuis 2004, entrepris d'expliquer que la Chine «n'émergera au détriment d'aucun autre pays, ne se mettra en travers du chemin d'aucun autre pays, ni ne constituera une menace pour aucun autre pays».

Cela étant dit, dans son livre blanc sur la défense, Beijing formule des objectifs en matière de sécurité qui pourraient trahir ses véritables ambitions. Ceux-ci visent, entre autres, à mettre le pays à l'abri de menaces externes, à freiner le séparatisme, en prévénant en particulier une déclaration de jure d'indépendance de Taiwan, et à préserver l'ordre intérieur et la stabilité sociale. Discernant les implications de tels objectifs, sinologues et stratèges s'accordent généralement pour dire que la Chine se doit de développer des capacités politiques, militaires et économiques adéquates afin de protéger ses intérêts. Autrement dit, elle doit émerger.

\section{Du potentiel latent à la puissance effective}

La Chine a généralement été une grande nation dans le système international: histoire de puissance plusieurs fois millénaire, grand territoire, vastes ressources et population immense. Après deux siècles de déclin, son poids est à

6. Steven W. Mosher, «Does the PRC have a Grand strategy of hegemony?», Washingon, US House of Representatives, 14 février 2006. 
présent sans cesse grandissant dans la balance de la politique mondiale. En effet, les réformes lancées en 1978 par Deng Xiaoping ont rapidement transformé un potentiel latent en puissance effective. Oubliant progressivement les vicissitudes de l'ère Mao, marquée par l'échec dramatique de la Révolution culturelle, la Chine a réussi en l'espace de quelques décennies ce qui est, à plusieurs égards, son vrai «Grand bond en avant». Ce processus est important en raison de ses répercussions sur le système international, qu'il transformerait profondément s'il aboutissait.

Dès les années 1990, l'ascension de la Chine revenait au centre de l'attention du monde occidental. Mais l'ampleur du phénomène, souvent annoncé comme le plus important du $\mathrm{XXI}^{\mathrm{e}}$ siècle, semble aller au-delà de toutes attentes. Aujourd'hui, il ne serait pas exagéré de dire que Washington vit dans la crainte constante que cette Chine montante ne rattrape les États-Unis dans un avenir encore plus proche qu'on ne l'imaginait, voire ne l'évince, pour devenir la première puissance mondiale. Martin Wolf, reconnu comme l'un des plus brillants analystes de l'économie mondiale, n'hésite pas à écrire dans le Financial Times que «la Chine change le monde entier ${ }^{7}$ ».

La guerre des pronostics prédisant que la Chine serait dans quelques années la première économie au monde a déjà commencé, tant, friande de records, elle fait pâlir même les plus optimistes des projections sur son évolution. Il en découle que son émergence n'est plus aujourd'hui une promesse, mais un fait. Il ne reste plus que quelques incrédules pour faire peu de cas qu'elle affiche

7. Cité dans Adama Gaye, «La nouvelle donne chinoise en Afrique», en ligne, Fondation Gabriel Péri, 〈www.gabrielperi.fr〉, 2008. 
la croissance la plus rapide au monde et qu'elle possède la deuxième réserve mondiale de devises étrangères, essentiellement des dollars.

La Chine possède aussi la plus grande armée du monde (2,5 millions d'hommes) et le quatrième budget de défense, lequel connaît une croissance annuelle de l'ordre de $10 \%$. La question n'est pas de savoir si et quand elle rattrapera les États-Unis, mais plutôt de se préparer à composer avec elle sur la scène globale. De l'aveu même de l'ancien secrétaire d'État britannique aux Affaires étrangères, David Miliband, elle est en train de devenir la «nation indispensable du XXI ${ }^{\mathrm{e}}$ siècle», ce qui n'est pas sans rappeler que la même formule était jadis employée par Madeleine Albright et Bill Clinton à propos des États-Unis.

Il est par conséquent légitime d'affirmer que la Chine émerge comme un peer competitor des États-Unis, c'est-àdire, dans la définition donnée par les réalistes, comme un État ayant «la puissance et la motivation de confronter les États-Unis à une échelle internationale de façon soutenue et à un niveau susceptible de rendre l'issue d'un conflit incertaine même si les États-Unis emploient leurs ressources de façon effective et appropriée ${ }^{8} »$.

\section{S'affirmer sans claironner}

Dans sa fameuse stratégie des 24 caractères, le père du «socialisme aux caractéristiques chinoises», Deng Xiaoping, exhortait en ces termes ses concitoyens: «Observons calmement; affinons notre position; abordons les affaires

8. Thomas S. Szayna, The Emergence of Peer Competitors: A Framework for Analysis, Santa Monica, RAND, 2001, p. 7-8. 
calmement; dissimulons nos capacités et attendons notre temps; ingénions-nous à garder un profil bas et ne revendiquons jamais le leadership.»

Dans leur comportement, les dirigeants chinois actuels restent, à plusieurs égards, fidèles à cette philosophie, en particulier en ce sens qu'ils n'ont jamais explicitement divulgué de «grande stratégie» détaillant leurs objectifs et les moyens dont ils disposeraient en vue de les atteindre. Mais, comme l'interprète le département américain de la Défense dans ses rapports annuels sur la puissance militaire chinoise, ce flou résulterait d'un effort délibéré pour dissimuler les véritables intentions et capacités du pays.

Conscientes des remous provoqués par leur montée en force et de la perception consécutive, particulièrement en Occident, d'une menace, les autorités de Beijing ont entrepris d'apaiser l'atmosphère. Ils ont emballé leur grande stratégie dans le nouveau concept de «développement pacifique» (heping fazhan), qui résulte d'un débat académique en Chine sur le remplacement de l'expression «ascension pacifique» (heping jueqi) qu'avait introduite le théoricien Zheng Bijan lors du Forum pour la réforme de la Chine de 2003.

Le nouveau leadership chinois, sous $\mathrm{Hu}$ Jintao et le premier ministre Wen Jiabao, a ouvertement endossé la stratégie du développement pacifique. En décembre 2005, le Conseil d'État de la RPC a publié un livre blanc dans lequel sont précisées les grandes lignes de la Chine en matière de politique étrangère. Le titre du document, China's Peaceful Development Road, n'est en rien anodin. «Paix» et «développement»y reviennent sous la forme des deux faces d'une même médaille quoique, relèvent 
certains analystes, «depuis la seconde moitié de 2004, le discours sur la diplomatie coopérative a été contrebalancé par celui qui met l'accent sur la difficulté de la lutte de la Chine pour prévenir la déclaration d'indépendance de Taiwan et protéger ses intérêts nationaux ${ }^{9}$ ».

Il en ressort, du point de vue de Beijing, que le concept de développement pacifique n'implique nullement une acceptation de l'ordre mondial made in USA. À cet égard, la plupart des stratèges chinois font valoir non sans raison que leur pays, tout en étant le premier consommateur d'acier et le deuxième plus grand consommateur de pétrole dans le monde en 2003, n'influait pourtant que très faiblement sur les mécanismes internationaux de fixation des prix. Rien d'étonnant, par conséquent que la Chine affirme sa volonté de participer à la régulation, au contrôle et à la réforme du système économique international de même qu'à l'établissement d'un ordre économique international plus juste.

Par conséquent, le discours (officiel) sur la politique étrangère et les comportements actuels de la Chine sur la scène internationale participeraient d'un effort concerté pour dissiper ce qu'il convient d'appeler le «dilemme de sécurité» généré par son accession au statut de grande puissance. Force est de reconnaître également que la notion de développement pacifique contraste aussi bien avec les intentions perçues de la Chine qu'avec son application à développer ses capacités économiques, militaires, technologiques, etc.

9. Yong Deng et Fei-Ling Wang (dir.), China Rising: Power and Motivation in Chinese Foreign Policy, Lanham, Rowman \& Littlefield, 2005, p. 4. 
La plus mordante critique vient de l'autre côté du détroit: le Taipei Times accuse ainsi Beijing de vouloir entretenir une «paix de façade» au sein de la communauté internationale. C'est peu dire que l'ascension pacifique n'a rien fait pour pacifier les relations entre la Chine communiste réunificatrice et l'île capitaliste indépendantiste ${ }^{10}$. Le Pentagone ne rate aucune occasion pour réitérer sa conviction que la nécessité «pour la Chine de se préparer de manière à parer adéquatement à toutes hostilités dans le détroit de Taiwan, lesquelles entraîneraient presqu'inévitablement une intervention des États-Unis, est la principale raison derrière l'entreprise de modernisation de sa puissance militaire ${ }^{11}$ ».

\section{Réalisme et pragmatisme}

D'un point de vue théorique, on peut affirmer qu'il y a deux approches principales quant au rôle de la puissance dans les relations internationales ${ }^{12}$. La première, le réalisme défensif, est illustrée par les travaux de Kenneth Walt $^{13}$. Dégageant certaines régularités dans le comportement international des puissances, le réalisme défensif affirme que celles-ci ont tendance à «balancer» la puissance des autres États. Faute de le faire, elles risquent d'être éliminées du système.

10. Voir Abanti Bhattacharya, «China's foreign policy challenges and evolving strategy», Strategic Analysis, vol. 30, n 1, 2006, p. 182-204.

11. Rapport du département américain de la Défense sur la puissance militaire chinoise, 2008, <www.defenselink.mil/pubs/pdfs $>$.

12. Voir Richard Rosecrance, «Power and international relations: The rise of China and its effects», International Studies Perspectives, vol. 7, 2006, p. 31.

13. Kenneth Waltz, Theory of International Politics, Reading, Addison Wesley, 1979. 
La seconde approche, celle du réalisme offensif, a été développée par John Mearsheimer ${ }^{14}$. S'inscrivant dans la lignée de Thucydide, Mearsheimer cherche à prédire le comportement des nations lorsqu'elles font face à des puissances rivales. Les nations qui éprouvent un sentiment d'agression, dit-il, opteront soit pour la stratégie du «balancing», soit pour le «buck-passing», mais jamais pour le «bandwagoning» ${ }^{15}$. Chaque puissance cherchera à dominer sa région et à devenir une puissance hégémonique régionale. ${ }^{16}$

Il est évident que l'on ne se trouve pas aujourd'hui dans le cas d'un «équilibre des puissances», pierre angulaire du réalisme défensif imaginé par Kenneth Waltz, en tout cas pas au sens d'une parité dans les rapports des forces en présence. En plus de la configuration complexe caractéristique du système international émergent, les États ne choisissent pas la voie prédite par Waltz, qui consisterait, pour les puissances moyennes en particulier,

14. Voir John Mearsheimer, The Tragedy of Great Power Politics, New York, W. W. Norton, 2001.

15. L'équilibrage, ou balancing, renvoie en théories des R.I. (réalistes, en particulier) au fait pour un État de se trouver pour des raisons stratégiques et de sécurité dans l'obligation de se joindre à une coalition d'autres États faibles pour contrer l'influence d'un État fort ou d'une coalition. Le terme vient de la notion d'équilibre des puissances (balance of power). Le buck-passing consiste quant à lui en l'action de transférer ses responsabilités à un État tiers qui se charge d'équilibrer la puissance hégémonique. Le bandwagoning, enfin, est l'opposé du balancing. Cette notion que l'on pourrait traduire par «suivisme» désigne les États faibles qui rejoignent un État plus fort ou sa coalition. Le phénomène se produit lorsque des États faibles estiment que le coût de l'opposition à un État plus fort l'emporte sur les bénéfices à en attendre. Les États forts peuvent inciter les plus faibles à les rejoindre par divers moyens: promesse de cession de territoire, accords commerciaux préférentiels, etc. Le terme a été utilisé par Quincy Wright, avant d'être popularisé par Kenneth Waltz.

16. Richard Rosecrance, op. cit. 
à se ranger aux cotés du plus fort (bandwagoning) ou à rétablir l'équilibre des forces en se coalisant (balancing).

La Chine n'a d'ailleurs jamais été au-delà de quelques déclarations d'intention en faveur d'un monde multipolaire pour éventuellement entreprendre de former une coalition rivale, hostile aux États-Unis. Si l'on tient compte des dimensions économique, militaire et politique de la grande stratégie de la Chine, nous pouvons affirmer en revanche que son émergence peut être analysée du point de vue du réalisme offensif. Selon cette théorie, les États qui augmentent leur puissance relative sont a priori préoccupés par la répartition des ressources matérielles. En particulier, ils essaient d'accumuler autant d'avantages que possible en termes de puissance sur leurs rivaux.

La théorie du réalisme offensif met par ailleurs l'accent sur les capacités militaires des grandes puissances. Mearsheimer souligne ainsi que «pour mériter la qualification de grande puissance, un État doit posséder des atouts militaires suffisants pour livrer une bataille sérieuse dans le cadre d'une guerre conventionnelle contre l'État le plus puissant au monde». En outre, précise-t-il, si «les grandes puissances cherchent à devenir riches - en fait, plus riches que leurs rivales, [c'est] parce que la puissance militaire a un fondement économique ${ }^{17}$ ».

Plusieurs éléments concourent à valider cette hypothèse. Un indicateur couramment cité est que la Chine met à profit sa croissance économique pour investir dans ses capacités militaires. À ce sujet, le département américain de la défense estime qu'elle dispose du plus grand potentiel pour affronter les États-Unis militairement et

17. John Mearsheimer, op. cit., p. 5 et 29. 
mettre en place des technologies militaires qui, à terme, pourraient dépouiller les États-Unis de leur avantage traditionnel en Asie.

Ses progrès sur le plan économique sont encore moins discutables. En 2008, elle a éclipsé la France comme quatrième économie mondiale et, en 2009, a ravi à l'Allemagne sa troisième place. En termes de volume, le commerce chinois arrive en deuxième position derrière les ÉtatsUnis, avec une réserve de devises étrangère évaluée à 1,95 billion de dollars ${ }^{18}$. La Chine représente le troisième plus grand récipiendaire d'investissements directs étrangers au monde après le Royaume-Uni et les États-Unis (attirant 72 milliards de dollars en 2005), tout en étant elle-même un grand investisseur à l'étranger $(50$ milliards annuellement). Cette performance spectaculaire amène certains analystes à projeter que, avec un taux de croissance avoisinant les $9 \%$, le PNB chinois peut dépasser celui des États-Unis d'ici 10 à 15 ans.

Ces dernières années, les dirigeants chinois ont pu se permettre le luxe d'investissements massifs dans l'acquisition d'équipements militaires. Ils ont soit importé des armes sophistiquées de fournisseurs étrangers, en particulier de la Russie, soit développé les technologies nécessaires afin de monter leurs propres systèmes. Considérant le processus de modernisation accélérée de son armée, certains analystes croient que la Chine sera en mesure de développer et de construire des systèmes militaires ultraperformants dans les années à venir ${ }^{19}$.

18. Wang Biqiang, "China's foreign reserves: Which button to press?», Economic Observer, <www.eeo.com.cn/ens/>.

19. Voir, par exemple, Aaron L. Friedberg «The future of U.S.-China relations: Is conflict inevitable?», International Security, vol. 30, n 2, p. 18. 
Cela dit, personne ne connaît aujourd'hui avec une certitude absolue l'état de sa puissance militaire conventionnelle, qui fait l'objet de toutes sortes de spéculations. D’un côté, obsédés par la «menace chinoise», certains milieux en Occident tendent parfois à en exagérer l'ampleur tandis que, de l'autre, Beijing, calculateur, s'emploie à l'évidence à dissimiler ses capacités réelles. Toutefois, quels que soient les progrès accomplis par une puissance émergente sur le plan de la modernisation militaire stricto sensu, ils ne seront vraisemblablement pas suffisants pour remettre radicalement en question la suprématie militaire des États-Unis dans un avenir proche, si l'on s'en tient aux standards conventionnels de la puissance militaire.

Pour autant, loin d'être défaitistes, les officiels chinois ne renoncent pas à leur projet historique de modernisation militaire qui, seule, permettra le «retour à la grandeur» de l'«Empire du Milieu». En effet, aucune analyse sérieuse de la montée en puissance de la Chine ne peut se faire sans un retour sur l'Histoire, qui montre que ce qu'on nomme la grande stratégie chinoise de puissance est un projet cohérent et inévitable à mesure que la Chine se développe. À défaut de pouvoir réaliser une «révolution dans les affaires militaires» à l'occidentale, les décideurs chinois s'ingénient à en promouvoir une version plus adaptée à leur réalité, c'est-à-dire, une «révolution militaire avec des caractéristiques chinoises».

En complément de leur entreprise de transformation accélérée de l'Armée populaire de libération (APL) en une force moderne, apte à mener des combats dans un environnement de hautes technologies, ils développent une stratégie de défense dite asymétrique. Inspirée de Mao et du stratège Sun Tzu, une telle stratégie vise essentiellement 
une combinaison efficace des technologies de l'information avec celles militaires conventionnelles afin de défier un «ennemi supérieur».

Les Chinois démontrent déjà une telle maîtrise dans l'«information warfare» (la guerre basée sur l'information) que l'issue d'une éventuelle bataille de ce type entre la Chine et les États-Unis paraît aujourd'hui de moins en moins certaine. En Occident, le génie chinois est redouté dans tous les compartiments de la puissance, mais l'est encore plus pour ce qui est de l'usage des technologies de l'information à des fins militaires dont aucune puissance - même pas les États-Unis - n'a le monopole en ce moment.

Il en résulte que la question importante est maintenant de savoir ce que la Chine fera de sa puissance. L'histoire des relations internationales enseigne que les grandes puissances nourrissent la plupart du temps des intentions révisionnistes jusqu'à ce qu'elles parviennent à un certain degré de puissance sinon d'hégémonie mondiale. Dans cette perspective, affirment les réalistes, ce sont plutôt leurs capacités que leurs intentions qui comptent car les États ne peuvent pas deviner les intentions des autres. Les puissances montantes sont généralement surveillées par les plus grandes car elles tendent à bousculer l'ordre international existant et sont sont peu enclines à accepter les contraintes institutionnelles, les délimitations des frontières et les hiérarchies de prestige politique héritées d'une époque où elles étaient encore relativement faibles.

Il ne manque pas d'exemples historiques qui prouvent que les puissances émergentes cherchent souvent à changer, voire parfois à chambarder le statu quo, et à établir de nouveaux arrangements qui reflètent plus adéquatement leur nouvelle conception d'eux-mêmes et de leurs préfé- 
rences dans le monde. Ainsi, afin de rétablir l'équilibre du système, les puissances émergentes - dont la Chine - risquent-elles de se retrouver en porte-à-faux vis-à-vis des États-Unis. Leur objectif, en attendant l'hégémonie, est de créer un monde multipolaire qui affaiblirait la puissance américaine. Aussi, selon certains chercheurs, la question n'est pas de savoir si d'autres puissances chercheront à rétablir un équilibre, mais plutôt quand elles y parviendront.

Depuis la fin de la guerre froide, il n'y a pas eu de signe avéré d'un mouvement de hard balancing (utilisation de la force) contre les États-Unis. Néanmoins, certains internationalistes rejettent l'idée que les puissances montantes ont renoncé aux efforts visant à incliner la balance de la puissance en leur faveur, mais suggèrent qu'elles ont plutôt changé de stratégie en raison de la prédominance américaine. La Chine, comme l'explique par exemple un spécialiste, balance la puissance américaine «in a smart manner ${ }^{20} »$.

Si l'on revient brièvement aux précédentes considérations, de nature purement stratégique, cela signifie que pour parvenir à leur objectif ultime qui est l'hégémonie, les États disposeraient, entre autres options, du balancing (équilibrage) ou du buck-passing (transfert de responsabilité). Tandis que le buck-passing est la stratégie favorite des États dans un système multipolaire, ils lui préfèrent l'approche balancing dans un contexte bipolaire. La raison: dans ce second cas de figure, il est difficile de trouver un

2O. Yuan-Kang Wang, «China's grand strategy and U.S. primacy: Is China balancing American power?», Washington, CNAPS, Brookings, 2006, p. 1. 
État désireux de jouer le rôle de buck-catcher (un État prêt à accepter la responsabilité de l'équilibrage).

En dépit de la prééminence américaine, nous postulons ici que le système qui prévalait à l'ère de la guerre froide reste essentiellement le même dans le contexte actuel: il existe aujourd'hui une superpuissance, les ÉtatsUnis, et une superpuissance en devenir, la Chine. Certes, pourrait-on objecter, la Chine n'est pas l'URSS de la guerre froide, de même que de nos jours l'accent n'est plus placé sur la stricte compétition militaire. Il n'en demeure pas moins que les États continuent de rivaliser pour la puissance, dans d'autres domaines et sur d'autres valeurs.

Cela revient à affirmer, de l'avis de plusieurs analystes, que nous vivons aujourd'hui au niveau systémique toujours dans un monde anarchique hobbesien ou en tout cas lockien, caractérisé par une relation de rivalité. Par conséquent, il importe peu que les États-Unis se considèrent ou non comme un empire, le risque est grand qu'ils soient perçus comme tel, et une telle perception de la surperpuissance américaine conditionne en retour la réaction de ses rivaux dans le monde.

Le département américain de la Défense s'inquiète souvent de ce que la Chine serait en train de construire un arsenal offensif à même de répondre aux forces navales américaines, et qu'elle déploie des anti-missiles et des sous-marins de combat. C'est au point que, une fois le président George W. Bush arrivé à la Maison Blanche, la doctrine dite préventive est devenue une caractéristique dominante dans la conception de la politique étrangère des États-Unis. Mais la Chine ne se contente pas de se développer économiquement et militairement. Tandis qu'elle s'assure de pouvoir devenir la puissance hégémo- 
nique en Asie du Sud-Est, elle est aussi en train d'utiliser son soft power afin de déployer ses réseaux partout, au grand dam de Washington.

\section{Une diplomatie centrée sur l'économie}

La Chine n'est certes pas le seul nouvel acteur important sur l'échiquier géopolitique de l'ère post-guerre froide. Parmi les aspirants au statut de grande puissance les plus couramment mentionnés figurent également l'Union européenne, l'Allemagne, le Japon et, dans un horizon plus lointain, la Russie, l’Inde ou le Brésil. Avec les États-Unis et l'Union européenne, la Chine forme toutefois ce qu'il est convenu d'appeler un «triangle stratégique» auquel analystes et décideurs sont de plus en plus attentifs. On estime en effet que ces trois puissances continentales possèdent de façon croissante l'essentiel de la puissance économique et militaire, et de l'influence politique et normative ${ }^{21}$.

Parmi les puissances émergentes, la Chine apparaît indéniablement comme le candidat qui se rapproche le plus du statut de grande puissance. Car, s'il est vrai que l'Union européenne, par exemple, est une puissance économique affirmée, elle reste un conglomérat d'États politiquement hésitant. La Chine, par contre, entend jouer un rôle moteur et n'entend pas se limiter à être une puissance dominante en Asie. Elle affiche aussi son ambition d'avoir une fonction stratégique, face à l'Europe, face à l'Amérique, seul vrai concurrent mondial aux yeux de Pékin,

21. David Shambaugh, «The new strategic triangle: US and European reactions to China's rise», The Washington Quarterly, été 2005, vol. 28, $\mathrm{n}^{\circ} 3$, p. 7-25. 
et face au reste du monde: Amérique latine, Afrique et Moyen-Orient. Autant de régions qui l'intéressent économiquement ${ }^{22}$.

Analysant l'effet de sa montée en puissance sur la diplomatie globale, Joshua Kurlantzick écrit: «Pour la première fois depuis des siècles, la Chine est en train de devenir une puissance internationale, avec des ambitions de politique étrangère globales. En fait, la Chine peut devenir la première nation depuis la chute de l'Union soviétique qui pourrait sérieusement défier les États-Unis pour le contrôle du système international ${ }^{23}$.»

Cette perspective est d'autant plus sérieuse qu'elle bénéficie d'une attention soutenue dans les milieux stratégiques occidentaux. Selon certains analystes, elle occupe même la première place sur l'agenda des priorités stratégiques à Washington, devant la guerre contre Al-Qaïda et le terrorisme. De toutes les puissances émergentes, la Chine est la seule à offrir une alternative idéologique pertinente aux États-Unis, son ascension s'érigeant contre le mythe fondateur même de l'Amérique hégémonique: il n'est pas indispensable d'être «politiquement démocratique» pour être «économiquement prospère».

$\mathrm{Au}$ cours de cette première décennie du XXI $\mathrm{I}^{\mathrm{e}}$ siècle qui s'achève, et vingt ans après la chute du mur de Berlin et l'effondrement du communisme, la «nouvelle architecture internationale» reflète en effet une nouvelle division du monde caractérisée par deux idéologies contradictoires. Selon George Soros, célèbre financier américain et fin

22. Voir Philippe Le Corre, «La Chine, nouvel acteur des relations internationales», SER-SA/Études 2006/10, tome 405, p. 307-318.

23. Joshua Kurlantick, «Cultural revolution: How China is changing global diplomacy», The New Republic, 27 juin 2005. 
analyste du système international, le monde fait face à deux modèles d'organisation diamétralement opposés: «Le capitalisme international et le capitalisme d'État ${ }^{24}$ ». Sur les plans politique et économique, on parle d'«une guerre sans limite» entre les deux principaux géants de la planète pour décrocher la suprématie mondiale.

Ce constat n'occulte nullement le fait que les deux puissances restent liées par une «interdépendance complexe»: les États-Unis, en proie à une balance commerciale déficitaire chronique vis-à-vis de la Chine, en ont besoin pour relancer leur économie; la Chine a besoin des capitaux américains pour maintenir sa croissance. Mais après avoir utilisé l'économie comme principal levier pour se lancer vers les sommets de la puissance, la crainte est maintenant que Beijing n'agite au besoin le «spectre de la terreur financière» pour achever un adversaire déjà économiquement à genoux.

Forte de son succès, elle est de plus en plus confiante sur la scène internationale. Après une période de suspicion vis-à-vis des instances multilatérales, elle les intègre tout en menant une diplomatie bilatérale des plus actives à travers des partenariats stratégiques avec les «puissances moyennes» et les «États faibles».

La politique étrangère de la Chine implique de lier le développement intérieur à l'ouverture sur le monde extérieur, en arrimant son développement à celui des autres parties du monde. À titre d'illustration, nous citerons son engagement accru en Afrique, comme en témoignent les fréquentes visites de hauts dignitaires sur

24. George Soros, «A new world architecture», Project Syndicate, 2009, <www.project-syndicate.org〉. 
le continent, qui ont captivé l'attention du monde ces dernières années.

Le troisième Sommet Chine-Afrique tenu à Beijing en novembre 2006 avec la participation de dirigeants représentant pas moins de 48 nations africaines, ainsi que le quatrième sommet tenu en novembre 2009 au Caire, fournissent une preuve tangible de la vitalité des relations avec le continent.

La Chine est l'un des premiers partenaires de l'Afrique en matière d'aide au développement, avec notamment d'importants projets d'infrastructures, et des investissements significatifs en santé publique et en éducation. Ainsi, «le rôle complexe et croissant de la Chine en Afrique présente des défis et opportunités pour les intérêts occidentaux et africains et impose une analyse beaucoup plus nuancée et approfondie car les intérêts chinois en Afrique vont au-delà des richesses et ressources du continent et incluent des aspects politiques et diplomatiques impor$\operatorname{tants^{25}}$ ».

Par ailleurs, les relations sino-latino-américaines se trouvent aujourd'hui dans une phase nouvelle de développement rapide. Pourquoi, se demande-t-on, la Chine s'estelle ingéniée au fil des ans à consolider sa coopération multilatérale avec le sous-continent, arrière-cour de Washington, sans être très active au sein du Forum de Cooperation Asie-Pacifique (APEC), mais avec un statut d'observateur à l'Organisation des États américains (OEA), et en mettant en place des mécanismes comme le Forum

25. Bates Gill et James Reilly, «The tenuous hold of China Inc. in Africa», The Washington Quarterly, vol. 30, n 3, p. 37. 
Chine-Amérique latine, le Dialogue Chine-Mercosur ou les consultations Chine-Communauté andine?

La réponse est à trouver dans le contexte international dans lequel elle évolue. Consciente du retard considérable à combler, elle a entrepris de balancer la superpuissance américaine d'une manière pragmatique. À cet effet, elle a conçu une stratégie qui comprend deux grands piliers: sur le plan interne, des réformes économiques et militaires; sur le plan externe, une diplomatie dynamique et efficace en adéquation avec ses ambitions de puissance. Une telle stratégie vise à éviter pour le moment tout risque de confrontation directe qui aurait pour principal effet de nuire à son ascension. Cependant, à mesure que sa puissance s'accroît, elle pourrait bien afficher une posture plus agressive, quitte à engager également, avec la seule superpuissance du monde, des compétitions de nature sécuritaire en Asie et au-delà de cette région. 



\section{La puissance chinoise dans la longue durée}

Depuis le début des années 2000, chercheurs et praticiens de la politique internationale s'étonnent des progrès fulgurants réalisés par la Chine dans tous les domaines, notamment économique et militaire. Si l'on s'en tient au court terme, on peut considérer que tout a commencé à la fin des années 1970 avec l'arrivée au pouvoir de Deng Xiaoping qui, rompant avec la politique idéologique de Mao, fit prendre au pays la voie pragmatique des réformes.

À partir de 1978, il mit en œuvre la doctrine des «quatre modernisations» présentée dès 1975 par son mentor, le premier ministre Zhou Enlai, mais restée jusqu'alors lettre morte. Il s'agissait de faire de l'industrie, de l'agriculture, des sciences et technologies et de la défense nationale les piliers de la modernisation de la Chine. Quelques décennies plus tard, la prophétie prêtée à Napoléon selon laquelle «quand la Chine s'éveillera, le monde tremblera» prend tout son sens.

Quel que soit le critère que l'on choisit, la Chine se qualifie comme puissance: elle est en passe de devenir la seconde économie du monde derrière les États-Unis; elle 
est le pays qui modernise le plus rapidement et massivement son arsenal militaire après les États-Unis; elle dispose de l'arme nucléaire et vient d'entrer dans le club select des puissances spatiales. En Occident notamment, on s'émeut de ces transformations rapides et profondes qui altèrent l'ordre mondial contemporain, car l'histoire des États nous apprend que les puissances émergentes sont habituellement révisionnistes et leur ascension, généralement belligène.

Avant de s'étonner de cette montée en puissance et de tirer des conclusions sur son impact sur l'ordre mondial, notamment en ce qui a trait à la relation avec les ÉtatsUnis, il est nécessaire de faire un détour par l'histoire ${ }^{1}$. Loin d'être un pays qui s'éveille à sa puissance, la Chine renoue avec elle. Cette réalité historique nous aide à mieux comprendre son comportement contemporain.

\section{Une puissance historique}

Pour mieux appréhender l'émergence de la Chine, il faut placer l'analyse dans une perspective de long terme. L'idée d'une Chine qui s'éveille laisse imaginer un pays endormi alors que, comme le rappelle Warren Cohen, ce qui s'y passe en ce $\mathrm{XXI}^{\mathrm{e}}$ siècle doit être vu comme une forme de résurrection et non comme un phénomène inédit dans son histoire. Même si les trente dernières années ont été déterminantes, la montée en puissance actuelle est en

1. Pour une discussion sur ce sujet mais qui soutient la thèse contraire, voir John Cranmer-Byng, "The Chinese view of their place in the world: An historical perspective», China Quarterly, n50, 1973, p. 67-79. 
réalité le produit d'un long processus d'expansion ${ }^{2}$. Ce processus a connu des périodes d'interruption, mais il n'a rien d'une nouveauté et ce, que la dimension prise en compte soit économique, industrielle, militaire ou culturelle.

Les historiens s'accordent pour reconnaître que pendant longtemps et jusqu'au XVIII ${ }^{\mathrm{e}}$ siècle, la Chine était en avance sur le reste du monde, y compris l'Occident, dans la plupart des domaines. Dans le domaine des techniques, John Fairbank rappelle ainsi:

Il ne fait guerre de doute que la civilisation chinoise, telle qu'elle se présente à l'époque des dynasties T'ang et Sung, du $\mathrm{VII}^{\mathrm{e}} \mathrm{au} \mathrm{XII}^{\mathrm{e}}$ siècle, était supérieure à celle de l'Europe. On en trouve la preuve non seulement dans les peintures de paysage Sung et dans la philosophie néo-confucéenne de Chu Hsi et d'autres, mais aussi dans la longue série d'inventions technologiques chinoises. Comme a pu le remarquer Francis Bacon voilà bien longtemps, les trois prouesses techniques qui ont façonné l'histoire européenne moderne sont l'invention de l'imprimerie, le compas de navigation et la poudre à canon. Tous trois apparurent d'abord en Chine ${ }^{3}$.

À ces trois prouesses, il faut aussi ajouter des inventions capitales sans lesquelles la modernité n'aurait pas été concevable telles que le papier et l'acier et, dans une moindre mesure, les feux d'artifice, la soie, ou encore les allumettes... Sur le plan technologique et sur bien d'autres, la Chine ancienne a donc été un moteur essentiel des jalons qui ont fondé le monde contemporain.

2. Warren I. Cohen, «China's rise in historical perspective», Journal of Strategic Studies, vol. 30, $\mathrm{n}^{\text {os }} 4-5$, 2007, p. 683.

3. John King Fairbank, La grande révolution chinoise: 1800-1989, Paris, Flammarion, 1989, p. 23. 
Les innovations ont transformé très tôt le domaine de la guerre, en particulier à travers l'utilisation des explosifs et des canons. Joseph Needham, l'un des plus grands spécialistes des innovations technologiques dans la Chine ancienne, estime qu'en cherchant à produire du sulfate de potassium, un savant chinois a mené dès le VII ${ }^{\mathrm{e}}$ siècle, sans s'en rendre compte, la première expérience de préparation d'un mélange produisant une déflagration; expérience inédite dans l'histoire des civilisations humaines.

La référence explicite à la poudre à canon apparaît dans un ouvrage du $\mathrm{IX}^{\mathrm{e}}$ siècle dans lequel l'auteur, tentant de mettre en garde contre des mixtures dangereuses, évoque ce mélange dont la déflagration a brûlé les visages et les mains des alchimistes et même incendié leurs maisons. On assistera, dès le $\mathrm{x}^{\mathrm{e}}$ siècle, aux premières utilisations militaires de cette invention dans des lance-flammes, des bombes et des grenades ${ }^{4}$. Il faut attendre la fin du XIII ${ }^{\mathrm{e}}$ siècle environ - l'époque de la dynastie des Yuan pour que cette technologie soit transmise aux pays européens et arabes.

Les innovations mentionnées plus haut, notamment l'invention de la boussole, vont aussi révolutionner la maîtrise des mers. L'expertise des Chinois dans le domaine de la navigation remonte à avant l'ère chrétienne. Au $\mathrm{I}^{\text {er }}$ siècle av. J.-C., ils avaient développé de vastes connaissances, notamment le gouvernail placé dans l'axe de la quille, la boussole et les cartes maritimes. Les progrès dans ce dernier domaine et l'utilisation de la boussole, aussi tôt qu'au début du viII ${ }^{\mathrm{e}}$ siècle, permirent à la Chine,

4. Joseph Needham, Science in Traditional China: A Comparative Perspective, Harvard Universty Press, 1981, p. 30-31. 
sous la dynastie des Tang (618-908) déjà, d'envoyer des expéditions lointaines, notamment à des fins diplomatiques avec l'Afrique du Nord ${ }^{5}$.

L'utilisation de la boussole se généralisa sous les Song (960-1276) mais, nous rappelle Philip Snow, c'est vraiment dans la seconde partie du règne de cette dynastie connue comme la période des Song du Sud (1127-1279) que la Chine devint une puissance. Cela s'explique par la perte de la moitié nord de son territoire aux mains des Tartares qui obligea les Song du Sud à se tourner vers le commerce maritime. C'est l'époque d'apparition d'immenses bateaux comportant jusqu'à six mats et capables de transporter des centaines de personnes sur de longues distances ${ }^{6}$.

Cependant, le moment phare de la marine chinoise se situe à l'époque des Ming (1368-1644) et reste symbolisée par les sept expéditions maritimes de l'amiral Zeng He entre 1405 et 1423 à l'instigation de l'empereur Yong'le. Naviguant trois quarts de siècle avant Christophe Colomb, il est présenté tantôt comme son équivalent, mais souvent comme lui étant bien supérieur. Un auteur britannique, Gavin Menzies, le présente même comme le vrai découvreur de l'Amérique dès $1421^{7}$.

Si cette thèse est contestée, tous les protagonistes s'accordent pour reconnaître que le seul pays qui avait à l'époque la technologie et l'expérience pour faire des expéditions de la taille de celle de l'amiral Zheng He était la Chine. Son navire amiral était quatre à cinq fois plus

5. Yuan Wu, La Chine et l'Afrique, Beijing, China Continental Press, 2006, p. 20-21.

6. Philip Snow, The Star Raft. China's Encounter with Africa, Ithaca, Cornell University Press, 1988, p. 8.

7. Gavin Menzies, 1421, l'année où la Chine a découvert l'Amérique, Paris, Éditions Intervalles, 2007. 
grand que celui de Colomb. La Chine était la première puissance navale au monde avant que, à la suite de la mort de l'empereur Yong'le, son successeur ne mette fin à des expéditions jugées trop coûteuses.

Cette position dominante de la Chine était aussi perceptible dans le domaine industriel et économique. Citant Paul Bairoch, Philip Golub rappelle que «en 1750, la part relative de la production manufacturière chinoise était de $32,8 \%$, alors que celle de l'Europe était de $23,2 \%$ - leurs populations respectives étant estimées à 207 millions et 130 millions de personnes. Prises ensemble, les parts de l'Inde et de la Chine atteignaient $57,3 \%$ de la production manufacturière globale [...]. Le produit intérieur brut par habitant en Chine s'élevait à 228 dollars (valeur de 1960), contre 150 à 200 dollars selon les pays en Europe ${ }^{8}$ ».

Le domaine du textile, aujourd'hui au cœur de débats sur «l'inondation» des autres pays par les produits manufacturés chinois, était déjà dominé par la Chine dans l'Antiquité à travers notamment la route de la soie. À cela, s'ajoute le commerce des épices. Pour John Fairbank,

sur le plan des relations économiques mondiales, l'expansion européenne qui ouvre l'époque moderne est le produit d'une réaction non seulement au commerce des épices avec l'archipel des Indes orientales, mais également au thé et à la soie, à la céramique et aux autres objets d'art ou denrées de luxe, tous produits du commerce extérieur de la Chine. Que les européens aient ouvert les premiers le commerce avec les Indes, puis la Chine et le Japon, ne prouve qu'une chose, c'est que les européens étaient des peuples démunis ${ }^{9}$.

8. Philip S. Golub, «Quand la Chine et l'Inde dominaient le monde», Manière de voir, $\mathrm{n}^{\circ}$ 9, 2006, p. 9.

9. John King Fairbank, op. cit., p. 25. 
Comme le rappelle Philip S. Golub, sur le plan de la production manufacturière globale, «Si l'on ajoute à l'Inde et à la Chine les parts des pays d'Asie du Sud-Est, de Perse et de l'Empire ottoman, la part de l'Asie au sens large (à l'exclusion du Japon) avoisinait les $70 \%{ }^{10}$ ».

On estime ainsi que depuis le début de l'ère chrétienne, la Chine a occupé une position dominante dans le monde pendant la majeure partie du temps. Selon Joseph Needham, «les Chinois [...] furent, entre le $\mathrm{I}^{\mathrm{er}}$ et le $x v^{\mathrm{e}}$, généralement bien en avance sur l'Europe, et il fallut attendre la révolution scientifique de la fin de la Renaissance pour que l'Europe prenne soudain la tête ${ }^{11}$ ».

Pour prendre la mesure de cette position dominante à l'échelle du temps, il suffit de penser que les États-Unis ne le sont que depuis 60 ans à peine puisquau début de la Seconde Guerre mondiale, ils étaient seulement la $5^{\mathrm{e}}$ puissance militaire derrière la Grande-Bretagne, l'Allemagne le Japon et la France. On ne comprend pas la stratégie actuelle d'affirmation de puissance de la Chine si on ne revient pas sur cette position dominante longtemps détenue dans l'histoire, les conditions dans lesquelles elle a été perdue et le désir ardent de renouer avec le passé. Nous y reviendrons au dernier point de ce chapitre.

\section{État, pouvoir et puissance dans la Chine ancienne}

Une fois la domination historique de la Chine dite, et dans la perspective d'une compréhension de ce que

10. Philip S. Golub, op. cit., p. 9.

11. Joseph Needham, La science chinoise et l'Occident, Paris, Seuil, 1973, p. 9 . 
certains auteurs ont appelé sa grande stratégie d'affirmation de puissance ${ }^{12}$, il est utile de s'interroger sur la manière dont elle s'est comportée lorsqu'elle était en position de force. Il ne s'agit pas d'extrapoler à partir de l'histoire et de tirer des conclusions sur le comportement à venir de la Chine bien que cette tendance est celle qui guide de nombreuses études en relations internationales, notamment les réalistes depuis Thucydide et sa chronique de la guerre du Péloponnèse. Il s'agit plus simplement d'exposer des faits et de revenir sur différentes interprétations qui ont pu être proposées par les auteurs pour montrer la banalité de la Chine qui obéirait, comme tout pays, aux règles de la recherche de puissance, mais surtout pour insister sur des traits distinctifs.

En revenant sur les péripéties ayant marqué l'empire d'une dynastie à l'autre d'une part, et, accessoirement, sur celles de la Chine depuis l'instauration de la République d'autre part, nous nous interrogerons sur son comportement dans ses relations internationales en espérant dégager quelques pistes permettant d'éclairer les processus contemporains découlant de la remontée en puissance de ce pays.

À l'instar de la plupart des empires comme la Macédoine ou Rome, l'ancienne Chine s'est construite essentiellement par la force. Il ne s'agit pas ici de refaire l'histoire de la formation de la Chine, mais d'insister sur quelques moments clés susceptibles d'éclairer la question de la puissance dans la Chine contemporaine. W. Cohen montre comment le processus de construction de «l'État»

12. Voir David M. Lampton, The Three Faces of Chinese Power: Might, Money and Minds, Berkeley, University of California Press, 2008, p. 25-32. 
commence trois millénaires av. J.-C. ${ }^{13}$. Au début, vers 2100, à l'époque de l'âge de bronze chinois, il y avait la dynastie des Xia, petite entité dans le Nord-Est de la Chine actuelle.

À la suite de la défaite des Xia, les vainqueurs, les Shang, entreprennent d'asseoir leur domination sur un espace plus vaste, comprenant «l'ensemble du monde civilisé » et délimité par les zones habitées par les «barbares». Le territoire s'agrandit et le pouvoir se stabilise relativement puisque les Shang et leurs successeurs, les Zhou, règnent près de deux millénaires durant jusqu'à l'arrivée de la dynastie des Qin en 221 av. J.-C., puis des Han seulement quinze ans après. Plusieurs autres dynasties vont se succéder jusqu'à la dernière, la dynastie Mandchoue, mais quelques-unes sont particulièrement importantes pour notre propos ${ }^{14}$.

Il y a d'abord la dynastie des Qin, connue pour avoir initié la construction de la grande muraille de Chine. Bien qu'elle ne dure qu'une quinzaine d'années, elle est cruciale à trois niveaux. En premier lieu, sous la houlette de Qin Shi Huangdi qui en est le fondateur (resté dans l'histoire avec l'armée en terre cuite de Xi'an), elle met fin à près d'un demi-millénaire de conflits et de divisions symbolisés notamment par la période dite «des printemps et des automnes» et celle des «royaumes combattants».

En second lieu, elle unifie la Chine (qui tire son nom du royaume du premier empereur Qin, victorieux des autres royaumes combattants) et marque le début de l'empire. En troisième lieu, les troubles qui précèdent la victoire du

13. Warren I. Cohen, op. cit.

14. Voir Catherine Coulomb, Chine: le nouveau centre du monde?, Éditions de l'Aube, p. 49-117; Danielle Élisseeff, Histoire de la Chine, Paris, Éditions du Rocher, 1997. 
royaume de Qin marquent un tournant aussi bien dans l'art de la guerre que dans le développement de la pensée philosophique chinoise puisque les principales écoles comme le confucianisme et le taoïsme en particulier, apparaissent à ce moment-là en réaction au chaos ambiant. Comme nous le verrons plus bas, ces deux aspects resteront cruciaux tout au long de l'histoire qui suivra, y compris dans la Chine contemporaine.

Il y a ensuite la dynastie des Han, qui dura quatre siècles et qui fut celle de la route de la soie, de plusieurs des inventions mentionnées plus haut et aussi de l'adoption du confucianisme. Selon W. Cohen, les Han régnèrent sur un espace centralisé, au moyen d'une force militaire effective constituant avec Rome, l'Inde et Parthes, une des puissances de l'Antiquité. La Chine devint alors l'empire que l'on combat ou dont on recherche l'amitié et la protection, y compris en lui payant tribut ${ }^{15}$. D'un point de vue territorial, l'empire est presque à son apogée, n'étant dépassé en taille que par l'empire des Yuan (les Mongols) et celui des Qing (les Mandchous).

Il convient de mentionner également la dynastie des Ming (1368-1644), dont les vestiges sont encore clairement visibles dans la périphérie de Pékin où un immense espace abrite les tombeaux de treize des seize empereurs qui se sont succédé. La Chine est alors à l'apogée de sa puissance. On estime que son armée compte en ce temps plus d'un million d'hommes. C'est l'époque des grandes explorations maritimes décrites plus haut et d'une supériorité sur les pays européens dans presque tous les domaines.

15. Warren I. Cohen, op. cit., p. 685. 
Cette position dominante sera encore conservée deux siècles après l'arrivée au pouvoir de la dynastie Mandchoue des Qing qui furent militairement très entreprenants, portant les limites de l'empire à leur maximum en étendant leur domination au Xinjiang musulman, au Tibet, à la Mongolie et à Taiwan. Sous l'empereur Qianlong (17361795) la Chine est à l'apogée de la puissance comme le démontrent les statistiques exposées plus haut.

La question qui se pose ici est de savoir comment la Chine s'est comportée dans ces moments différents par rapports à ses voisins. Pour certains auteurs, elle s'est toujours comportée suivant les diktats du réalisme. Y.-K. Wang estime ainsi que le comportement de la Chine ancienne illustre parfaitement les propositions des réalistes qui, suivant Thucydide, estiment que les États veulent maximiser leur puissance et tendent à se comporter de manière agressive lorsqu'ils sont puissants. Selon lui, la Chine adoptait une posture plus offensive lorsque sa puissance augmentait et prenait une posture plus défensive quand sa puissance déclinait. Les décideurs n’hésitaient jamais à utiliser la force lorsque leurs adversaires étaient faibles et qu'ils étaient capables d'en tirer parti. Mais, flexibles, ils évaluaient toujours la faisabilité de leur action et s'abstenaient lorsque le rapport de forces n'était pas à leur avantage.

Par ailleurs, historiquement, ce pays se serait toujours préparé pour parvenir à une position dominante en Asie de l'Est. Quand elle parvenait à cette position dominante, elle tendait à adopter une politique expansionniste et contraignante $^{16}$. Ce qui est plus intéressant encore, c'est

16. Yuan-Kang Wang, «Offensive realism and the rise of China», Issues and Studies, vol. 4O, n 1, 2004, p. 189. 
que selon Wang, les dirigeants de la Chine impériale semblaient accommoder leurs adversaires lorsqu'ils étaient en position de faiblesse. Ils se donnaient ainsi le temps de procéder aux réformes politiques et économiques internes permettant de consolider l'économie et renforcer l'armée ${ }^{17}$. Fait intéressant, cette analyse est faite par plusieurs auteurs en ce qui concerne la stratégie accommodante adoptée par la Chine contemporaine...

À cet égard, les différentes dynasties chinoises se sont illustrées dans l'utilisation de la force pour agrandir leur royaume ou empire au détriment des voisins. W. Cohen rappelle que dans ce processus de construction de l'État, les Chinois n'étaient ni moins arrogants, ni moins rudes que leurs homologues européens, japonais ou américains ${ }^{18}$. Les exemples qu'il fournit sont nombreux. Ainsi, le cinquième empereur de la dynastie des Han, Han Wudi, est présenté comme un des plus grands impérialistes de tous les temps, lui qui a construit un empire plus vaste que Rome à son apogée. Durant son règne, la conquête chinoise s'est étendue à la Corée, la Mongolie, le Vietnam et une bonne partie de l'Asie centrale.

Kubilai Khan, le premier empereur de la dynastie mongole des Yuan, ne tolérait pas de remise en cause de son pouvoir qu'il voulait universel, attaquant le Japon à deux reprises, mais aussi la Corée et plusieurs parties de l'Asie du Sud-Est incluant Java et Sumatra.

Quant aux Qing, la dernière des dynasties, elle mena la plus grande entreprise d'expansion depuis les Mongols, dominant une bonne partie de l'Asie centrale, mais aussi

17. Ibid., p. 189-190.

18. Warren I. Cohen, op. cit., p. 683. 
les Birmans, les Mongols, les Vietnamiens, les Coréens ${ }^{19}$... Tout cela conduit l'auteur à tirer la conclusion qu'il n'y a aucune raison, culturelle ou génétique, de penser qu'une Chine puissante se comporterait autrement.

Les choses ne sont sans doute pas aussi simples et déterministes pour deux raisons au moins. D'une part, historiquement, la Chine n'a pas misé que sur la force dans ses rapports internationaux et d'autre part, le contexte dans lequel la Chine agit aujourd'hui est bien différent, exigeant une diversification et une adaptation selon des méthodes que nous exposerons aux chapitres suivants et qui n'obéissent pas à la seule logique militaire classique.

Dans une perspective historique d'abord, la position dominante chinoise reposait aussi déjà sur ce que Joseph Nye a conceptualisé sous le nom de soft power, et Cohen lui-même le souligne. Il montre que si la Chine était crainte, elle était aussi admirée par des peuples qui étaient en dehors de sa zone d'influence et qui, pourtant, adoptaient ses pratiques politiques et culturelles. Mais il y a mieux encore. Nous avons vu plus haut que durant l'époque dite «des royaumes combattants», le confucianisme se développa pour apporter une réponse au chaos et fut adopté sous les Han comme idéologie d'État. J. Needham attire notre attention sur l'importance de cet esprit confucéen dans la conduite des affaires en Chine, en particulier lorsqu'il s'agit de l'utilisation de la force.

Il existerait une «croyance chinoise suivant laquelle l'épée ne peut que conquérir ce que le logos seul peut garder». Et de citer cette adresse d'un philosophe de la cour à un des empereurs Han: «Vous avez conquis l'empire à 
cheval, mais du haut de votre cheval, vous ne réussirez pas à le gouverner». Autrement dit, la force ne peut pas être une fin en soi, et ce serait «pour cette raison que les confucéens insistèrent tant sur la persuasion [...] C'est ce qui explique qu'on rencontre souvent ce qu'on pourrait appeler de la «propagande» (pas nécessairement dans un sens péjoratif) dans les textes classiques chinois et dans les textes d'histoire». En définitive, conclut Needham, «la force fut toujours considérée comme une mauvaise voie pour accomplir les choses: ce qui revient à dire que la persuasion civile, beaucoup plus que la persuasion militaire, était la bonne voie pour accomplir quoi que ce $\operatorname{soit}^{20}$ ».

Le discours officiel chinois contemporain épouse beaucoup cette position pacifiste, inventant le concept «d'émergence pacifique» (peaceful rise), puis, le mot «rise» faisant peur, de «développement pacifique». Il insiste aussi sur le fait, souligné par des auteurs indépendants, que la Chine a peu profité de sa position dominante, dans le domaine naval en particulier, pour coloniser d'autres peuples. À propos des relations entretenues par la flotte de l'amiral Zheng He avec les populations africaines, P. Snow remarque qu'elles étaient bien différentes de celles des Européens qui arriveront soixante-dix ans plus tard.

À l'inverse des Portugais, note-t-il, les Chinois n'ont ni détruit, ni conquis aucune ville. En conséquence, ils étaient acceptés sur les côtes de Mogadiscio car ils traitaient avec courtoisie et retenue des peuples pourtant plus faibles $^{21}$. Selon un analyste contemporain, la Chine fait preuve, de nos jours, de beaucoup de respect à l'égard des

2O. Joseph Needham, op. cit., p. 128-129.

21. Philip Snow, The Star Raft, p. 29. 
nations les plus petites: le dirigeant d'un minuscule pays comme Saint Kitts and Nevis, en visite à Pékin, a droit à des égards dont il ne pourrait que rêver à Washington ${ }^{22}$. Nous y reviendrons au chapitre 6 pour montrer comment en Afrique et en Amérique latine, cette façon de faire vaut bien des amitiés à la Chine.

Bien entendu, cela n'implique nullement un pacifisme à tout prix, que ce soit dans la gestion des affaires intérieures ou externes. Pour s'en convaincre, il suffit de rappeler le processus exposé plus haut de formation de l'empire d'une dynastie à l'autre, qui s'est fait, comme partout ailleurs, au détriment des voisins; la guerre civile entre nationalistes et communistes ayant abouti à l'instauration de la République populaire en 1949 ou encore la violente répression des manifestants de la place Tiananmen en 1989.

Dans une perspective plus contemporaine ensuite, le comportement actuel de la Chine intrigue. Contrairement à ce qui est dit de la Chine impériale qui était agressive quand elle était puissante et accommodante quand elle était faible, la Chine populaire semble suivre le chemin inverse. La République populaire a mené des guerres parfois sanglantes contre ses voisins à l'instar du Vietnam ou de la Corée du Sud, en a intimidé d'autres comme les Philippines et a soutenu des mouvements rebelles partout en Asie du Sud-Est jusqu'aux années 1980. Mais depuis qu'elle monte en puissance, elle tend à devenir une «puissance responsable». Sans doute, cela est calculé.

22. Joshua Kurlantzick, Charm Offensive: How China's Soft Power is Transforming the World, New Haven et Londres, Yale University Press, 2007, p. 58. 
D'une part, la Chine craint que sa fulgurante progression inquiète ses voisins et les incite à se liguer avec les États-Unis pour la contenir ${ }^{23}$. D'autre part, elle est consciente que pour accéder au statut de grande puissance, elle a besoin d'alliés, que ce soit pour s'approvisionner en matières premières stratégiques ou pour avoir des votes favorables dans les instances internationales. Il n'en demeure pas moins qu'elle est devenue incroyablement accommodante pour un pays de son rang. Signe des temps, en dépit de la rhétorique qui fait de l'intégrité du territoire national un principe quasi sacré, la Chine se montre disposée dans le cas de contentieux territoriaux à accepter des compromis qui lui sont manifestement défavorables si cela contribue à rassurer ses voisins ${ }^{24}$.

Comme on le sait, dans le passé comme dans le présent, le comportement de l'État n'est pas déterminé seulement par les professions de foi des leaders ou par une pratique séculaire, notamment parce qu'il dépend de celui des autres États et des perceptions réciproques. Or cellesci peuvent changer selon les circonstances. Dans le cas de la Chine, il n'est pas possible de comprendre sa stratégie actuelle d'affirmation de puissance si on ne revient pas sur cette position dominante longtemps détenue dans l'histoire, les conditions dans lesquelles elle a été perdue et le désir ardent de renouer avec le passé, mais de manière durable cette fois...

23. Susan L. Shirk, China: Fragile Superpower, Oxford University Press, 2007, p. 111.

24. Ibid., p. 112. 


\section{Le syndrome de l'humiliation}

Pour comprendre la stratégie actuelle d'affirmation de puissance de la Chine, il faut revenir sur ce que l'on pourrait appeler le syndrome de l'«humiliation»subie par un pays tombé un moment de son piédestal et les défis auxquels il fait face.

L'humiliation, comme on le répète dans le discours officiel car le répéter est rassembleur, renvoit en premier lieu à l'occupation de larges pans du territoire de la Chine pendant la période de semi-colonisation et à l'appauvrissement qui s'en est suivi. Il y a aussi, au-delà de l'occupation elle-même, les conditions qui l'ont rendue possible, notamment l'affaiblissement du pouvoir central au début du XIX ${ }^{\mathrm{e}}$ siècle, faiblesse que le pouvoir actuel veut dorénavant conjurer.

Il est étonnant en effet qu'après avoir dominé le monde de l'Antiquité à la fin de la Renaissance, la Chine en soit arrivée à être dominée par l'Occident qui doit beaucoup de ses technologies à ses innovations. J. Fairbank pense que la Chine s'est laissée distancer par l'Occident au moment du tournant industriel en raison d'une «répugnance compréhensible à changer ses valeurs sociales, sa culture et ses institutions ${ }^{25}$ ». L'interdiction des expéditions maritimes après la mort de l'empereur Yong'le en 1424 qui a mis fin à la suprématie chinoise sur les mers en serait un exemple. À cela s'ajoutent les agitations politiques et les efforts de guerre qu'elles ont nécessité, qui ont contribué à affaiblir la dynastie des Qing.

25. John King Fairbank, op. cit., p. 19. 
C'est dans ces conditions que la Chine connut en 1840 une défaite dans la guerre de l'opium contre l'Angleterre. Ce n'était là que la première d'une série de déconvenues des armées chinoises, face à la France et au Japon en particulier dans la dernière moitié du XIX ${ }^{\mathrm{e}}$ siècle. Cela résulta en la cession aux Occidentaux de concessions territoriales sur la côte Est et, en 1931, l'invasion de la Mandchourie par le Japon qui réinstaura la monarchie abolie depuis la proclamation de la République en $1911^{26}$.

Les conséquences de cette semi-colonisation du pays furent désastreuses, car elles conduisirent à sa désindustrialisation. Celle-ci, nous dit Philip Golub, s'explique par l'avance industrielle de l'Europe, qui rendait les produits chinois moins compétitifs, mais aussi par le libre-échange à sens unique imposé aux Chinois, obligés d'ouvrir leur marché aux produits occidentaux sans contrepartie. Le résultat est que la Chine s'est rapidement appauvrie: «alors que la Chine et l'Inde représentaient $53 \%$ de la production manufacturière mondiale en 1800, elles ne comptaient plus que pour 7,9\% en 1900 . Et si, au début du XIX ${ }^{\mathrm{e}}$ siècle, le PNB par habitant en Europe et en Asie était à peu près équivalent [...] dès 1860 , ce ratio est passé de 2 à 1 , et même de 3 à 1 dans le cas de la Grande-Bretagne ${ }^{27}$.» Pour un pays qui a occupé une position dominante pendant dix-huit siècles, la dégringolade est aussi inédite que terrible, d'autant que la population chinoise est sortie appauvrie en termes absolus de ce processus.

L'humiliation telle qu'elle est ressentie dans un pays au nationalisme à fleur de peau, c'est aussi le défi, pour

26. Jian Bozan et al., Histoire générale de la Chine, Pékin, Éditions en langues étrangères, 1985, p. 105-162.

27. Philip S. Golub, op. cit., p. 10. 
le moment insurmontable, de récupérer l'île rebelle de Taiwan. Cette île a régulièrement entretenu des relations difficiles avec le continent depuis la chute de la dynastie des Ming quand les partisans de l'empereur déchu voulurent l'utiliser comme base arrière en vue de reconquérir le pouvoir. Mais l'invasion menée par la nouvelle dynastie Qing en 1683 ramena l'île dans le giron continental. À la suite de la première guerre sino-japonaise, la Chine «cède» l'île au Japon qui la contrôlera jusqu'à sa défaite à la Seconde Guerre mondiale.

Mais le retour de Taiwan comme province administrée effectivement par le gouvernement central ne durera que jusqu'en $1949^{28}$. La prise du pouvoir par les communistes provoqua le repli sur l'île du gouvernement nationaliste de Chiang Kai Chek. Au début, il n'était pas question d'indépendance puisque, avec l'appui notamment des États-Unis, le gouvernement en place à Taiwan continua de représenter la Chine dans les instances internationales comme l'ONU jusqu'en 1971.

La Chine envisage même une action militaire pour récupérer l'île dès le début des années 1950. Mais la dégradation des relations sino-américaines notamment à la suite de la guerre de Corée rend cette entreprise impossible militairement au regard du rapport des forces largement défavorable à la Chine. Comme nous le rappelle Susan Shirk, actuellement, les dépenses militaires américaines sont plus importantes que celles de l'ensemble des autres pays du monde et celles de la Chine, que l'on dit cependant sous-estimées, n'en représentent qu'un sixième environ ${ }^{29}$.

28. Jian Bozan et al., op. cit., p. 132.

29. Susan L. Shirk, op. cit., p. 10. 
Les Chinois vivent cette quasi-indépendance et la présence de la $7^{e}$ flotte américaine jusque dans les eaux stratégiques taiwanaises (donc chinoises) comme un affront. Échaudés entre autres par la vive tension de 1996 consécutive à la vente d'armes américaines à Taiwan, ils pensent que si leur pays se dote des moyens appropriés, il leur sera possible de récupérer Taiwan de gré ou de force car ils voient mal les États-Unis, qui se sont toujours opposés à l'indépendance de l'île, risquer une guerre pour la défendre si le rapport des forces actuel était significativement altéré.

À ces défis, il faut également ajouter la rivalité séculaire avec le Japon et la crainte qu'inspire ce pays high-tech qui revient de nouveau sur la scène militaire internationale et questionne désormais ouvertement les clauses antimilitaristes inscrites dans sa Constitution à l'instigation des Américains au sortir de la deuxième Guerre mondiale.

Enfin, le contrôle des mers et des voies d'approvisionnement maritimes par les différentes flottes américaines est vécu comme un carcan pouvant étouffer le développement de la Chine. Bien qu'elle soit devenue la troisième du monde en tonnage et qu'elle commence à s'engager sur des mers lointaines (comme les côtes somaliennes en appui aux actions anti-piraterie), elle reste loin derrière celle des Américains. Cette situation aussi explique grandement la recherche de voies nouvelles de modernisation militaire engagée par la Chine sur laquelle nous reviendrons.

Il est impossible de comprendre la stratégie de puissance de la Chine que nous avons assimilée au réalisme offensif sans intégrer ces facteurs tissés par l'histoire. Dans le même temps, c'est un réalisme renouvelé. Par exemple, si les débuts de la République populaire ont été 
souvent conflictuels - pensons à la guerre de Corée, aux conflits avec l'Inde et le Vietnam -, le leitmotiv est aujourd'hui au «développement pacifique» et à l'offensive de charme. Ces facteurs, qui renvoient aussi à l'histoire de la Chine ancienne, transparaissent dans la pensée des dirigeants récents. Deng Xiaoping conseillait ainsi à ses successeurs d'adopter un profil bas et de cacher les capacités du pays; et son successeur Jiang Zemin estimait qu'il faut «séduire et non intimider ${ }^{30}$ ».

Le contexte et les défis ont aujourd'hui changé. Ils expliquent pourquoi la Chine, tout en obéissant globalement au réalisme offensif dans un environnement qu'elle n'a pas choisi et qui le lui impose en un sens, conduit une stratégie diversifiée et, sur bien des plans, originale. Elle tente de se doter des outils nécessaires à l'exercice du hard power (la puissance militaire), mais elle ne le fait pas de manière purement conventionnelle. À cela, s'ajoute un investissement important dans la mise en place d'un soft power (diplomatie, culture, commerce et aides) qui est vu, à la manière confucéenne, comme encore plus efficace, seul ou en combinaison avec le hard power redéfini.

30. Joshua Kurlantzick, op. cit., p. 38. 



\section{La dimension économique de la stratégie chinoise de puissance}

La stratégie économique actuellement poursuivie par la Chine est souvent considérée comme une étape préliminaire dans sa stratégie de «balancing», d'où le terme de «prebalancing» utilisé pour la qualifier ${ }^{1}$. Dans ce contexte, les efforts de Beijing afin de projeter son émergence au statut de grande puissance comme un «développement pacifique» exprimeraient la crainte des dirigeants chinois de voir les États-Unis chercher à contenir leur essor avant qu'ils ne puissent développer pleinement leur potentiel économique et le convertir en puissance militaire.

Il est évident que les chances de la Chine d'émerger au rang de grande puissance et, ultimement, de devenir la puissance hégémonique en Asie dépendront d'abord de sa capacité à bâtir une puissance économique. C'est pourquoi Beijing a inscrit le développement économique au premier plan de ses priorités. Dans le cadre de son processus d'«ascension pacifique» dans le contexte post-guerre

1. Voir par exemple Christopher Layne, «The unipolar illusion revisited: The coming end of the United States' unipolar moment», International Security, vol. 31, n² 2, 2006, p. 9. 
froide, sa grande stratégie consiste à trouver un équilibre optimal entre «les canons et le beurre» (guns and butter $)^{2}$.

L'objectif de ce chapitre est de voir comment la Chine a fait de la réforme économique le pilier central de sa stratégie de puissance. Ensuite, il s'agira d'expliquer dans quelle mesure, à défaut de pouvoir utiliser le «hard power», c'est-à-dire le pouvoir militaire, Beijing fait un usage efficace du hard economic power, sa puissance économique, comme arme principale dans sa bataille contre l’hégémonie américaine.

\section{La nouvelle idéologie du « développement pacifique»}

La stratégie économique que la Chine met en œuvre est aussi une réponse aux contraintes imposées par l'environnement géopolitique international au seuil de la décennie 1990. À cette époque, le point de vue qui prévalait chez les analystes chinois reflétait grosso modo la position des partisans de la thèse du déclin en théories des relations internationales. Ceux-ci projetaient une puissance américaine sur la pente descendante et prédisaient l'émergence imminente d'un système international multipolaire.

Dans son China Debates the Future Security Environment (2000), Michael Pillsbury a bien scruté le bouillant débat qui a vu le jour dans ce contexte ${ }^{3}$. Vers le milieu de la décennie 1990, à la surprise des dirigeants chinois, il paraissait plutôt de plus en plus évident que les États-Unis tenaient bon et qu'ils gagnaient même davantage en puissance. Dans ce contexte, une des conclusions auxquelles

2. Yuan-Kang Wang, «China's grand strategy and U.S. primacy», op. cit.

3. Cité dans Warren I. Cohen, "China's power paradox», The National Interest, 2006, <nationalinterest.org〉. 
les Chinois sont arrivés est la suivante: «À long terme, le déclin de la suprématie des États-Unis et la transition consécutive vers un monde multipolaire sont inévitables; mais à court terme, la puissance de Washington ne déclinera vraisemblablement pas, et son poids dans la balance des affaires mondiales demeurera intact ${ }^{4}$.»

Face à un tel constat, il devenait alors évident que la Chine n'aurait d'autre choix que de s'atteler à réaliser ses objectifs dans le contexte d'un monde unipolaire sous domination américaine et où les États-Unis sont perçus comme une menace à l'ascension chinoise. Deng Xiaoping s'identifiait d'ailleurs très clairement à cette ligne de pensée. C'est pourquoi il a instruit ses camarades du leadership communiste de dissimuler les capacités de la Chine, de construire discrètement sa puissance nationale.

Le message est on ne peut plus clair: une Chine relativement faible doit, autant que faire se peut, éviter toute provocation tandis que son économie se développe et sa force s'accroît. En fait foi, dans son fameux discours devant le leadership du Parti Communiste en 1990, il prévient: «Si la Chine veut évacuer la pression inhérente à l'impérialisme et la politique de puissance et préserver le système socialiste, il est crucial pour nous de réaliser une croissance économique rapide et exécuter notre stratégie de développement ${ }^{5} »$.

Comme le remarque avec justesse David Lampton, le développement économique devient dans ce contexte la tâche principale du Parti Communiste: «Encore plus importants pour la grande stratégie de la Chine sont ses

4. Voir Wang Jisi, «China's search for stability with America», Foreign Affairs, vol. 84, $\mathrm{n}^{\circ}$ 5, 2005.

5. Yuan-Kang Wang, op. cit., p. 16. 
efforts en vue de consolider sa puissance économique et construire ce que Beijing espère être une classe moyenne stabilisée $e^{6} »$.

$\mathrm{Au}$ cours des dernières décennies, la Chine a notamment conduit des réformes aux niveaux social, culturel et politique. La stratégie de la croissance économique arrive cependant en tête des priorités du Parti Communiste. Comme le notent Yong Deng et Fei-Ling Wang, il sagit pour le régime communiste d'une question de survie depuis les années 1980. «Deng Xiaoping a isolé le développement économique comme la «tâche centrale» pour le Parti communiste chinois au cours des cent prochaines années ${ }^{7} »$. De sorte que, pour les Chinois, faire de l'argent est devenu non seulement une politique en soi mais aussi une nouvelle quasi-religion.

Pour la plupart des observateurs, la tendance la plus importante dans le débat sur la Chine est qu'elle est aujourd'hui l'économie la plus convaincante dans le monde, avec une croissance soutenue depuis plusieurs décennies. Aujourd'hui, en raison de ses performances économiques, la Chine est largement considérée comme une étoile montante de la politique internationale avec les États-Unis pour principal adversaire.

\section{Un impératif de sécurité intérieure et extérieure}

Ayant donc compris que le développement économique est le seul moyen pouvant lui permettre de relever un

6. David M. Lampton, The Three Faces of Chinese Power: Might, Money, and Minds, Berkeley, University of California Press, 2008, p. 120.

7. Voir à ce sujet Yong Deng et Fei-Ling Wang, Rising China: Power and Motivation in Chinese Foreign Policy, op. cit., p. 32. 
certain nombre de défis pressants auxquels elle faisait face, la Chine a articulé sa stratégie autour de cet objectif central depuis trois décennies. Cela implique, d'une part, de maîtriser l'environnement sécuritaire pour s'assurer de pouvoir se concentrer sur son développement économique, social et politique ${ }^{8}$ puisque Beijing mise premièrement sur ses ressources internes afin de balancer la puissance des États-Unis ${ }^{9}$.

D'autre part, à un moment où les populations paraissent de moins en moins friandes du communisme, l'économie (avec le nationalisme) est forcément un impératif pour la légitimité et la stabilité du régime. Sur le plan intérieur, Beijing se doit de promouvoir une croissance économique soutenue et un climat serein pour se concentrer sur la construction de sa puissance ${ }^{10}$.

De la sorte, «la stratégie nationale de la Chine est conçue de façon à favoriser sa croissance économique rapide, laquelle constitue le principal facteur de légitimité pour le régime hormis le nationalisme; attirer les ressources maximum (technologie, investissement et ressources matérielles stratégiques) vis-à-vis du système international; et réduire les menaces externes qui pourraient absorber ses ressources. Après le pari de Mao sur la puissance coercitive et de Deng sur la puissance économique, la

8. Zhang Yunling et Tang Shiping, «China's regional strategy», dans David Shambaugh (dir.), Power Shift: China and Asia's New Dynamics, Berkeley, University of California Press, 2005.

9. Robert S. Ross, «Bipolarity and balancing in East Asia», dans T. V. Paul, James J. Wirtz (dir.), Balance of Power: Theory and Practice in the 21st Century, p. 288.

10. Yuan-Kang Wang, op. cit., p. 9. 
Chine cherche maintenant un mélange plus équilibré qui procède également de "la puissance des idées"11».

Au cours des dernières décennies, la Chine a accompli des progrès significatifs en vue de la transformation d'un système bureaucratique d'État planifié en un régime ouvert sur l'économie de marché. D'un système autarcique, elle s'est donc muée en un moteur alimentant la globalisation en Asie et au-delà. Pratiquant une politique d'ouverture, la Chine a graduellement libéralisé ses politiques commerciales et d'investissement. Elle peut compter sur une diplomatie agressive qu'elle a ingénieusement mise au service de son économie.

Depuis la fin de la guerre froide, la politique étrangère de la Chine est inextricablement liée à la promotion de son économie. La nouvelle approche chinoise privilégie la réalisation d'un développement qui soit bénéfique pour la Chine et ses partenaires à travers des inter-échanges économiques croissants rendus possibles par la globalisation ${ }^{12}$.

En cela, la politique étrangère de Beijing reflète parfaitement sa stratégie d'affirmation de puissance. À l'ère de la globalisation, ses interactions avec le monde extérieur se font essentiellement à travers les échanges économiques, cristallisés par un engagement accru dans les organisations internationales (OI). À ce sujet, après un long moment de débat et d'incertitude, le leadership chinois, dans le contexte post-guerre froide, s'entend finalement sur une ligne de politique étrangère vers le milieu de la décennie 1990.

11. David M. Lampton, op. cit., p. 117-118.

12. Robert G. Sutter, Chinese Foreign Relations: Power and Policy Since the Cold War, Lanham, Rownan \& Littlefield, 2008, p. 7. 
Selon plusieurs sinologues, c'est cette politique qui précise les contours d'une grande stratégie en matière de politique étrangère pour le présent et le futur. Le but ultime d'une telle stratégie (axée sur l'économie) est de propulser le pays au statut de grande puissance. Cette stratégie est conçue de manière à créer les conditions requises pour poursuivre la modernisation économique et militaire, ainsi que pour minimiser les risques que les États-Unis, entre autres, perçoivent la Chine comme une menace à contenir ou à détruire.

Dans son ouvrage sur les nouvelles relations étrangères chinoises, Robert Sutter résume ce qu'il relève comme étant les deux composantes essentielles de cette stratégie. D'une part, établir des partenariats variés avec des puissances mondiales, en créant des liens qui fassent de la Chine un acteur indispensable - ou du moins attrayant - de telle sorte que les acteurs clés du système renonceraient à miner ses intérêts. D'autre part, devenir un activiste de l'agenda international en se faisant une réputation d'acteur responsable et un membre de la communauté internationale. L'objectif est de faire taire les inquiétudes largement répandues quant à la façon dont elle pourrait utiliser sa puissance croissante et, ainsi, éviter que d'autres puissances se liguent contre elle ${ }^{13}$.

Grâce aux fruits des réformes qu'elle a initiées, la Chine réalise progressivement la dimension économique de ce que le lexique spécialisé désigne par une puissance nationale intégrale. En l'occurrence, ce concept réfère particulièrement à la puissance économique, militaire et politique indispensable pour jouer un rôle de leader dans

13. Robert G. Sutter, op. cit., p. 7. 
les affaires asiatiques et mondiales ${ }^{14}$. Les chiffres parlent d'eux-mêmes.

Depuis le lancement des reformes économiques en 1978, le produit intérieur brut a été multiplié par quatre et, selon certaines estimations, il pourrait doubler vers le milieu de la seconde décennie du XXI ${ }^{\mathrm{e}}$ siècle. Mais, s'il en était besoin, comme la dernière récession qui a menacé l'économie mondiale en 2009 pourrait le rappeler, ce qui est particulièrement impressionnant à propos de l'économie chinoise est non seulement la vitesse à laquelle elle croît mais aussi son potentiel énorme et croissant. La Chine dispose en effet d'un atout naturel non négligeable en la taille de sa population et, la modernisation aidant, la productivité progressive de ses ouvriers. Ainsi, prédit-on, la Chine peut-elle un jour retrouver sa place historique comme la première économie mondiale, dans un horizon qu'elle ne fait de raccourcir jour après jour.

\section{Le moteur du commerce mondial}

La Chine est devenue, selon la métaphore désormais à la mode, l'«atelier du monde», c'est-à-dire, la plus grande plate-forme mondiale de production pour l'exportation. Elle est, à ce titre, le pivot d'une segmentation régionale des processus de production ${ }^{15}$. Depuis un quart de siècle, les échanges extérieurs de la Chine se développent à un rythme exceptionnellement rapide: leur montant en dol-

14. Robert G. Sutter, «Durability in China's strategy toward central Asia - reasons for optimism», China and Eurasia Forum Quarterly, vol. 6, n ${ }^{\circ}$, 2008, p. 3.

15. Pour approfondir le sujet, voir: «Chine: le prix de la compétitivité», La lettre du CEPII, n 254, mars 2006, p. 1. 
lars a augmenté de plus de $15 \%$ par an en moyenne de 1980 à 2006. D'acteur marginal dans le commerce mondial en 1980 , elle est devenue la troisième puissance commerciale en $2005^{16}$. Au cours de l'année 2006, ses exportations ont dépassé celles des États-Unis.

En Asie, elle est déjà la première puissance commerciale et a dépassé le Japon depuis 2004. Les chiffres affichés sont tout simplement époustouflants. Elle est la deuxième économie mondiale en termes de parité du pouvoir d'achat derrière les États-Unis (qu'elle pourrait bientôt dépasser), et a contribué plus de $10 \%$ à l'économie mondiale en 2007 et 2008. Elle s'impose par conséquent comme un maillon clé dans la relance de l'économie mondiale.

Entre 2000 et 2005, la croissance économique de la Chine a avoisiné une moyenne de 9,5\% en termes réels; ses importations ont triplé, passant de 225 milliards de dollars en 2000 à 660 milliards en $2005^{17}$. À elle seule, la Chine comptait déjà pour $12 \%$ de la croissance du commerce mondial, ce qui constituait une augmentation impressionnante, vu qu'en 2000 elle en représentait moins de 4\%. En 2006, les statistiques disponibles montraient que le produit intérieur brut chinois, converti en dollars au taux de change $(8,1$ yuan pour un dollar américain selon le taux de l'époque), représentait environ $5 \%$ du PIB mondial.

Après un quart de siècle de croissance à marche forcée, la Chine a attiré des centaines de milliards de dollars en

16. Françoise Lemoine, «La montée en puissance de la Chine et l'intégration économique en Asie», Hérodote, nº 125, 2007.

17. C. Fred Bergsten et al., China: The Balance Sheet, New York, Public Affairs, 2006, p. 73. 
investissements étrangers et plus d'un trillion de dollars en investissements internes en à peine une douzaine d'années. Elle a clairement émergé comme une force motrice tirant l'économie mondiale. Par exemple, en 2006 les seuls gains annuels des États-Unis en provenance de leurs interactions avec la Chine se chiffraient autour de 70 milliards de dollars ${ }^{18}$.

\section{Le réveil du « Dragon »}

Depuis le lancement des réformes à la fin de la décennie 1970, la Chine a réussi à réduire l'écart abyssal qui séparait son économie de celle des États-Unis. Ainsi, calcule-t-on, si l'économie américaine valait 31,5 fois celle de la Chine à l'époque, en 2002, la taille de l'économie américaine (9,2 billions de dollars) valait «seulement» 7,6 fois celle de la Chine $(1,21 \text { billion de dollars })^{19}$. Si la tendance se maintient, l'écart devrait encore se résorber. En effet, selon certaines prédictions, l'économie de la Chine devrait dépasser celle du Japon, la deuxième économie mondiale, vers $2 \mathrm{O}^{20}$. Déjà, la Chine a pendant plusieurs années été considérée comme le premier producteur mondial d'acier, de cuivre, d'aluminium, de ciment et de charbon.

En tant que consommateur, la Chine a surpassé le Japon comme deuxième plus grand importateur de pétrole du globe en 2005. En 2006, la Chine a surpassé le Japon comme le deuxième marché mondial de l'automobile, avec des ventes totales de 7,2 millions de véhicules et la produc-

18. Ibid., p. 116.

19. Voir Yuan-Kang Wang, op. cit., p. 17.

2O. James F. Hoge, «A global power shift in the making», Foreign Affairs, juillet-août 2004. 
tion de 7,3 millions. En 2007, la Chine est également devenue le premier producteur mondial de navires marchands. Bref, conclut un analyste, on n'a besoin d'aucune donnée de la Banque Mondiale pour savoir que la Chine est une superpuissance économique ${ }^{21}$. Autrement dit, on ne lui promet plus un réveil hypothétique mais, avec un peu de présomption, le rang de première puissance économi$q^{2} e^{22}$. Le réveil de la Chine est un phénomène unique dans l'histoire mondiale par son ampleur.

Dans Le grand échiquier, Zbigniew Brzezinski soulignait au tournant de la décennie 2000 les prouesses de l'économie chinoise. S'appuyant sur l'analyse factuelle des économistes, il rappelle que dans la phase initiale de l'industrialisation, il a fallu à la Grande-Bretagne plus de cinquante ans et à peine moins aux États-Unis pour doubler leur production respective par habitant, alors qu'il a suffi d'une dizaine d'années à la Chine pour obtenir le même résultat ${ }^{23}$. Dans un sens, le seul exemple qui s'y apparente - mais comme cette comparaison vient de démontrer, de loin - est la montée en puissance de l'Amérique après sa guerre civile. En effet, écrit un autre analyste,

Au milieu de la pire crise économique depuis la Grande Dépression, un nouvel ordre est en train d'émerger - avec son centre de gravité vers la Chine... Le Fonds monétaire international prédit que le produit intérieur brut (PIB) mondial chutera d'un alarmant $1,3 \%$ cette année [2009]. Mieux, défiant cette tendance globale, la Chine espère une croissance économique annuelle de $6,5 \%$ à $8,5 \%$. Au cours du premier trimestre de

21. John Tkacik, «China's superpower economy», Webmemo, n 1762 , 28 décembre 2007.

22. Bruno Cabrillac, Économie de la Chine, PUF, 2003, p. 1.

23. Zbigniew Brzezinski, Le grand échiquier. L’Amérique et le reste du monde, Hachette, 1997, p. 199. 
2009, les principaux marchés boursiers mondiaux combinés ont chuté de 4,5\%. En contraste, l'indice du marché de change de Shanghai a grimpé de $38 \%$. En mars, les ventes de véhicules en Chine battaient des records atteignant 1,1 million, surpassant les États-Unis pour le troisième mois successivement ${ }^{24}$.

Face à cette énigme que constitue le succès de l'économie capitaliste la plus florissante au monde tenue par un régime communiste, Deng Xiaoping répondait, non sans candeur: «Peu importe que le chat soit blanc ou noir, seul un chat intelligent attrapera la souris. Le succès est notre devise.» Décembre 2008 a vu le trentième anniversaire de la réforme chinoise. Une occasion pour l'actuel président $\mathrm{Hu}$ Jintao d'en expliciter le sens: «La Chine a utilisé la réforme et l'ouverture comme une force motrice puissante pour pousser vers des réalisations et accomplissements qui captivent l'attention du monde.»

C'est en effet de ce rôle central dans l'économie mondiale que résulte son statut d'acteur stratégique incontournable, occupant une place de premier ordre sur l'échiquier international. Au vu de la performance affichée par ses principaux indicateurs macro-économiques - performance soutenue depuis plus de trente ans -, d'aucuns soutiennent qu'il est déjà tout à fait justifié de considérer la Chine comme une superpuissance économique. Sa croissance économique est à ce point spectaculaire qu'elle génère presqu'autant d'appréhensions que ses capacités militaires.

Il y a en effet de plus en plus d'inquiétudes que, soit à travers la domination économique ou militaire ou une combinaison des deux, elle n'entende devenir la puissance

24. Dilip Hiro, «The world's new superpower», Salon, 5 mai 2009, <www.salon.com>. 
hégémonique du xxI ${ }^{\mathrm{e}}$ siècle ${ }^{25}$. Certes, seul le cours des événements, sur le double plan interne et externe, déterminera les orientations stratégiques que l'actuel leadership communiste ainsi que les prochaines générations de dirigeants chinois seront susceptibles de suivre. Néamnoins, comme nous le verrons dans le prochain chapitre, la Chine devrait continuer à développer significativement sa puissance militaire en parallèle avec sa puissance économique et politique. D'où la question récurrente qui consiste à se demander si elle est également en train de devenir une superpuissance militaire.

25. Voir à ce sujet: June Teufel Dreyer, «China's power and will: The PRC's military strength and grand strategy», p. 651, 〈www.fpri.org〉. 



\section{CHAPITRE 4}

\section{La modernisation militaire conventionnelle de la Chine}

Si l'émergence progressive de la Chine au rang de superpuissance militaire ne fait plus de doute, l'orientation stratégique du programme de modernisation militaire qu'elle met en œuvre reste à préciser. Dans ce chapitre, nous ne tenterons pas de dresser un bilan exhaustif ni de trancher l'épineux débat sur l'exactitude des chiffres avancés de toutes parts. Notre ambition sera plutôt de dégager certaines tendances.

Dans un premier temps, nous reviendrons brièvement sur l'esprit général qui préside aux mutations dans le domaine militaire. Nous verrons ensuite les actions dans la conquête spatiale dont Beijing semble faire un nouveau champ de manœuvre. Nous proposerons par ailleurs une revue factuelle et analytique du budget de la Défense et des acquisitions d'armements sophistiqués.

\section{Des ambitions militaires nettement relevées}

Aujourd'hui, les aspirations de la RPC au statut de superpuissance militaire ne souffrent guère d'ambiguïté. Forte 
de sa robustesse économique, elle est de plus en plus confiante dans l'affirmation de sa puissance, affichant clairement un potentiel croissant et une volonté à peine dissimulée d'assumer son rôle comme principal concurrent des États-Unis ${ }^{1}$.

L'Armée populaire de libération (APL) boucle actuellement sa deuxième décennie de réformes et de modernisation, sans précédent dans son histoire et révolutionnaire par sa nature. Grosso modo, ces changements sont de trois ordres. D'une part, d'une force militaire conçue traditionnellement pour livrer des combats au sol, l'armée chinoise accorde dorénavant une égale importance aux forces navales et aériennes. Ensuite, d'une force armée préparée à livrer de longues batailles de libération dans l'hypothèse d'invasions ennemies sur son territoire, elle s'est transformée en une puissance militaire prête à engager des guerres de haute intensité, dotée d'une capacité de projection et de plus en plus orientée vers la défense des intérêts nationaux chinois au-delà de ses frontières.

Enfin, d'une armée qui misait sur un personnel pléthorique afin de compenser ses carences technologiques, elle s'est muée en une puissance militaire pourvue de «poches d'excellence» technologiques n'ayant pas beaucoup à envier au savoir-faire conventionnel des autres puissances militaires. Autant de facettes qui viennent révéler la nature de la nouvelle mission qui incombe à l'armée chinoise et dont le caractère stratégique semble largement déborder le focus traditionnel mis sur le détroit

1. Pour une perspective militaire chinoise à ce sujet, voir entre autres Lieutenant General Li Jijun, Traditional Military Thinking and the Defensive Strategy of China, Carlisle, Strategic Studies Institute, 1997. 
de Taiwan comme principal argument de ses efforts de modernisation militaire ${ }^{2}$.

Comme nous le soulignions aussi plus haut, l'armée chinoise a entrepris de développer un éventail de systèmes stratégiques, se transformant progressivement en une force jugée aujourd'hui suffisamment fiable afin de remettre en question la traditionnelle suprématie militaire américaine en Asie. Loin de l'en dissuader, l'avance militaire apparemment incommensurable des puissances rivales, en particulier celle des États-Unis, a au contraire dopé la Chine dans ses efforts en vue de se munir au plus vite d'une force militaire conventionnelle à la dimension de son statut de principale puissance émergente ${ }^{3}$.

Les événements militaires survenus au cours des trois dernières décennies - qui ont renseigné les Chinois sur la nette supériorité de l'Occident en la matière - ont contribué à renforcer la perception déjà bien ancrée à Beijing qu'une force militaire adéquate et moderne est un élément essentiel au statut de «grande puissance» auquel aspire le leadership communiste. En réponse, ce dernier a réussi à promouvoir un consensus susceptible de favoriser les conditions nécessaires à la croissance économique et la modernisation militaire tenant compte du contexte unipolaire dominé par les États-Unis dans lequel il évolue ${ }^{4}$.

2. Pour une analyse récente sur le sujet, voir Roy Kamphausen, David Lai et Andrew Scobell (dir.), Beyond the Strait, PLA Missions Other Than Taiwan, Carlisle, Strategic Studies Institute, 2009.

3. Voir sur cette question James C. Mulvenon et al., Chinese Responses to U.S. Military Transformation and Implications for the Department of Defense, Santa Monica, RAND, MG-340-OSD, 2006.

4. Kevin Pollpeter, Building for the Future: China's Progress in Space Technology During the Tenth 5-Year Plan and the U.S. Response, Carlisle, Strategic Studies Institute, 2008. 
Ainsi, vers la fin de la décennie 1990, le programme de modernisation militaire chinois, lancé environ dix ans plutôt, a-t-il connu une nouvelle impulsion, en réponse aux défis inhérents au nouvel environnement sécuritaire post-guerre froide. Au-delà de la rhétorique en faveur de l'émergence d'une société internationale harmonieuse dont Beijing se veut le promoteur, deux tendances sont généralement relevées comme preuves de sa résolution à parachever un agenda militaire inavoué.

D'une part, des investissements soutenus, en particulier dans son arsenal militaire et ses capacités stratégiques, aux fins du relèvement des capacités de projection de l'armée chinoise au-delà de ses frontières asiatiques. D'autre part, depuis 1996, et à l'exception de 2003, son budget de Défense a, en termes réels, augmenté significativement d'au moins $10 \%$ annuellement. À l'évidence, ces indicateurs inaugurent une nouvelle ère dans la stratégie de défense dite active. Pour le moins, ils scellent une nette rupture avec la politique suivie dans le contexte des «quatre modernisations», dont la défense ne représentait que le dernier des quatre piliers - à côté de l'agriculture, de l'industrie et de la technologie ${ }^{5}$.

Dans ce contexte, sa stratégie d'affirmation de puissance post-guerre froide peut se présenter sous la forme d'un triangle dont la puissance militaire, avec celle écono-

5. Lancé en 1975 par Zhou Enlai, ce programme était conçu afin de faire de la Chine une superpuissance économique au tournant du XXI ${ }^{\mathrm{e}}$ siècle. Ce programme mettait l'emphase sur l'autosuffisance économique de la Chine, par l'accroissement du volume d'investissements directs étrangers (IDE) par l'ouverture du marché chinois au monde extérieur. Pour une revue exhaustive du concept, voir: Immanuel C. Y. Hsü, The Rise of Modern China (6 ${ }^{\mathrm{e}}$ éd.), New York, Oxford University Press, 2000; Richard Evans, Deng Xiaoping and the Making of Modern China, London, Penguin Books, 1995, p. 10. 
mique et politique, constitue une des trois pierres angulaires. Pour ce qui est du volet militaire, les versions 2004 et 2006 du livre blanc sur la défense traduisaient déjà, de manière manifeste, les ambitions de Beijing. L'aventure à laquelle est conviée l'armée y est décrite sous la forme d'une entreprise devant aboutir à une «révolution dans les affaires militaires avec des caractéristiques chinoises». Ce document définit par ailleurs un horizon temporel dans lequel concrétiser la plupart des buts fixés. En un mot, ceux-ci consistent à jeter une solide fondation d'ici 2010, essentiellement parvenir à maîtriser la mécanisation afin de progresser vers l'informatisation vers $202 \mathrm{O}$ et, ultimement, atteindre l'objectif de modernisation de la défense nationale et des forces armées vers le milieu du XXI ${ }^{\mathrm{e}}$ siècle.

Mais, il importe de le préciser, si l'armée a épousé le slogan de «révolution dans les affaires militaires avec des caractéristiques chinoises», c'est en guise de "raccourci» conceptuel - c'est-à-dire, probablement à défaut de mieux - afin de traduire ses efforts visant à développer une force militaire d'une taille relativement réduite en comparaison avec les versions précédentes de l'armée nationale, mais qui en même temps, aurait la faculté d'être plus flexible, agile et efficace. Sur un plan opérationnel, ces changements revêtent trois caractéristiques essentielles.

Dans un premier temps, il s'agit de réduire la taille de l'APL et rendre plus efficaces l'industrie militaire et le système de recherche et de défense. Une deuxième étape consiste à introduire les services militaires dans l'ère des opérations interarmes rendues possibles par les technologies de l'information et de la communication. Finalement, selon plusieurs études, Beijing entend d'entretenir une puissance nucléaire dissuasive susceptible de remettre en 
question la prééminence américaine dans la mesure du possible.

À défaut d'informations crédibles, les stratèges occidentaux devinent que l'une des priorités de l'APL est, à brève échéance, d'accumuler une puissance de projection au-delà de l'Asie et de chercher à se donner les moyens de barrer aux États-Unis les voies d'accès à l'Asie Centrale. Le département américain de la Défense paraît prendre ce scenario avec le plus grand sérieux, confirmant dans ses derniers rapports rendus publics que le programme de modernisation militaire de la Chine a enregistré des progrès considérables, avec des implications stratégiques en Asie.

\section{L'espace comme nouveau champ de manœuvre}

Pour un coup d'essai, ce fut un coup de maître. Le 11 janvier 2007, emblématique de ses efforts de modernisation militaire, la Chine réussit à détruire un de ses anciens satellites en orbite (la collision a eu lieu à quelque $800 \mathrm{~km}$ au-dessus de la terre) au moyen d'un missile lancé depuis son territoire. Cette information, révélée avec un empressement compréhensible par la Maison Blanche, mais dans un premier temps non confirmée (ni démentie) par les autorités chinoises, n'a depuis cessé de faire des vagues.

Jusque-là, seuls les États-Unis et l'ex-Union soviétique avaient démontré leur capacité de détruire des objets dans l'espace. L'entrée confirmée de la Chine dans ce club très fermé n'a pas manqué de relancer le débat sur la militarisation de l'espace et d'alimenter les éditoriaux dans les journaux et revues spécialisés. 
Mais au-delà du succès incontestable de l'opération et de son caractère révolutionnaire dans le contexte de l'entreprise de modernisation militaire chinoise, ce sont surtout les messages sibyllins qu'elle lance qui constitueront le fond des réflexions stratégiques. Lance Gatling, exofficier américain et expert des questions aérospatiales à Tokyo, estime ainsi que cet essai relance les craintes d'une militarisation de l'espace et démontre clairement que, dorénavant, les satellites espions ne sont plus à l'abri d'une destruction par un pays hostile. Mais surtout, estimet-il, les Chinois montrent clairement leur intention de poursuivre leur programme militaire spatial comme ils l'entendent, et qu'ils sont même prêts à en assumer les conséquences.

Qu'en est-il en réalité? La réponse est loin d'être évidente même s'il paraît certain que, si les États-Unis misent sur l'espace pour des raisons à la fois commerciales et militaires, la conquête spatiale signifie pour Beijing un «retour à la gloire». En Occident, et en particulier aux États-Unis, une telle situation amplifie les préoccupations suscitées par l'émergence d'un pays aux ambitions géopolitiques jadis dormantes, mais aujourd'hui supposément réveillées.

Ce test spatial réussi, discerne-t-on, ne restera pas sans suite et l'expérimentation de cette arme antisatellite participe forcément d'un programme plus vaste visant le développement d'autres armes de ce type, incluant des «ground-based lasers» et «jammers». Si celles-ci étaient développées avec succès, prédit-on, elles mettraient à coup sûr à risque les satellites américains, c'est-à-dire, la base même de la suprématie militaire américaine dans la région asiatique. 
D'autres systèmes potentiels d'armements pourraient être à même de perturber l'usage de satellites placés en orbite à une altitude supérieure, y compris le système de géopositionnement sattélitaire mondial. Les spécialistes font remarquer que la perte de ces atouts dans l'espace serait de nature à affecter la plupart des opérations militaires américaines dans le Pacifique, incluant des interventions dans l'hypothèse d'un conflit sur la question de Taiwan.

Ce qui ne fait pas de doute, c'est que cette opération spatiale peut tout simplement vouloir dire que l'effort de modernisation militaire entrepris avec la transformation accélérée de l’Armée populaire de libération, a porté ses fruits. Plusieurs évidences montrent en effet que le programme spatial de la Chine a accompli des progrès spectaculaires au cours des dernières années. Depuis 2003, la Chine a entrepris des missions spatiales habitées et lancé une navette spatiale sur la lune ${ }^{6}$. Ces réussites spectaculaires ont été obtenues grâce à des progrès importants dans une large gamme de technologies spatiales qui comprennent les programmes de lancement, les satellites et le vol spatial habité.

Il faut par conséquent remettre cet effort spatial dans le contexte de ce qu'il convient d'appeler une double modernisation militaire: conventionnelle et non conventionnelle. En effet, ce bond remarqué de la Chine dans l'espace est cohérent avec la modernisation non conventionnelle qu'elle a entreprise parallèlement. Parmi les auteurs au sein de l'armée chinoise, il semble qu'est largement partagée l'idée que c'est seulement en établissant une domina-

6. Douglas C. Lovelace Jr., préface de Kevin Pollpeter, op. cit., p. v. 
tion spatiale qu'il serait possible de maîtriser pleinement les systèmes modernes de commande, contrôle, communications, ordinateurs, renseignement, surveillance et reconnaissance (C4ISR en anglais). Ceci est nécessaire si l'on veut rendre opérationnelles les fonctions de commande et de contrôle indispensables aux guerres dans un environnement informatisé (wars under informationalized conditions).

Selon certains experts chinois, de son habilité à mener ces types de guerres dépend la chance de l'armée chinoise d'accomplir ses «missions historiques». Elle disposerait par ailleurs d'un atout considérable en cela que les forces spatiales peuvent venir en appui aux forces terrestres, aériennes et navales en fournissant un support en information et même en engageant des attaques au sol.

C'est ainsi qu'il faut comprendre les actions visant à intégrer des capacités militaires traditionnelles à son arsenal stratégique. Celles-ci incluent des missiles balistiques, entre autres armes conventionnelles à très longue portée ${ }^{7}$. Depuis plus d'une décennie maintenant, les stratèges militaires et des scientifiques de l'aérospatial s'ingénient à concevoir un modèle pour asseoir une domination dans l'espace. Par conséquent, équiper ce qui est désigné par les stratèges comme le «Space Theater of Global War» (que nous traduisons par: Théâtre spatial de la Guerre Globale) dictera les priorités technico-militaires de l'industrie de défense de la Chine au début du XXI ${ }^{\mathrm{e}}$ siècle $^{8}$.

7. Brad Roberts, «Strategic deterrence beyond Taiwan», dans Roy Kamphausen, David Lai et Andrew Scobell (dir.), Beyond the Strait, PLA Missions Other Than Taiwan, Strategic Studies Institute, 2009, p. 169-170.

8. Mary C. Fitzgerald, «China's military modernization and its impact on the United States and the Asia-Pacific», déclaration devant la US-China 


\section{Un budget militaire en adéquation avec des ambitions de puissance}

La hausse substantielle et constante du budget militaire chinois ne fait plus partie des secrets d'États, jalousement entretenus par Beijing. Connues généralement pour leur discrétion, des voies autorisées assument désormais volontiers la part de lion que se taille la défense dans la répartition des ressources chinoises. «Nous devons augmenter notre budget militaire, car il est important pour la sécurité nationale. L'armée chinoise doit se moderniser. Dans l'ensemble, notre budget de la défense est inadéquat ${ }^{9}{ }$. Ces déclarations attribuées à un porte-parole de l'armée chinoise en font foi; elles traduisent bien les ambitions de la Chine à l'aube du nouveau millénaire. Tandis que la puissance chinoise continue de s'amplifier globalement, lui faisant miroiter un plus grand rôle dans les affaires mondiales, Beijing a aussi compris qu'il lui sera indispensable de disposer d'une armée à la dimension de ses ambitions géopolitiques. Elle ne lésine pas sur les moyens que lui procure son économie en plein essor. Elle a pu se payer le luxe de consentir des investissements significatifs dans un programme de modernisation tous azimuts. Celui-ci est axé sur une professionnalisation accrue de ses forces armées, sans pour autant nuire à son ascension économique, contrairement à ce qui s'est passé pour l'URSS en son temps.

Economic and Security Review Commission, Hudson Institute, 30 mars 2007.

9. Jiang Enzhu, porte-parole de l'Assemblée nationale populaire. Ces propos ont été rapportés dans Jim Yardley et David Lague, «Beijing accelerates its military spending», The New York Times, 5 mars 2007, p. A-8. 
La Chine continue d'investir des sommes conséquentes dans son système de défense, en particulier dans son arsenal et ses capacités stratégiques. La RPC est le pays au monde qui augmente son budget militaire dans les proportions les plus considérables. En 2009, elle a annoncé une augmentation de son budget militaire de $14,9 \%$, soit la $19^{\mathrm{e}}$ hausse à double chiffres en 20 ans. Même s'il accuse une baisse par rapport aux années précédentes (17,6\% en 2008 et $17,8 \%$ en 2007), pris dans le contexte mondial caractérisé par une sévère récession économique, cette allocation qui totalise $6,3 \%$ de son budget national fournit tout de même une preuve de l'importance que la Chine accorde à la question militaire.

Ce faisant, elle confirme son ambition de rendre ses forces armées plus compétitives en les élevant au niveau de celles d'autres grandes puissances rivales. Les chiffres disponibles pour 2007 attiraient déjà l'attention en cela qu'ils représentaient la plus grande rallonge depuis plusieurs années. Qui plus est, ces augmentations s'opèrent au grand dam des pays occidentaux, en quête d'informations quasi introuvables sur la justification de ces dépenses en nette croissance.

En réaction à ces hausses budgétaires répétées, Washington a régulièrement, mais en vain, encouragé Beijing à ouvrir ses secrets militaires à plus d'examens. Stratégiques, les dirigeants chinois dénoncent une campagne de désinformation, rejetant toujours d'un revers de main la moindre suggestion que les dépenses militaires consenties puissent traduire une menace de quelque nature pour d'autres pays, et défendant au contraire qu'une bonne partie du budget de la défense est destinée à financer les salaires de ses 2,5 millions de soldats. Li Zhaoxing, porte- 
parole du Congrès National du Peuple, va jusqu'à qualifier le budget de la défense de la Chine de «modeste», en comparaison par exemple avec celui des États-Unis dont il est vrai qu'il ne représente qu'environ un dixième.

Quoique Beijing justifie ses efforts, les rangeant systématiquement dans le cadre d'actions visant son «développement pacifique» ainsi que le renforcement de sa défense nationale, ses dépenses militaires constituent une des principales évidences corroborant la thèse de «la menace chinoise».

À cet égard, le rapport annuel 2007 du département américain de la défense donne toute la mesure de la vigilance de Washington vis-à-vis de Beijing. Les dirigeants américains s'accordent avec la plupart des analystes pour penser que les officiels chinois font généralement mystère sur leurs réels investissements militaires. Ainsi, les propos de Jiang Enzhu, porte-parole de la première session de la $11^{\mathrm{e}}$ Assemblée populaire nationale (APN), qui a indiqué que la Chine comptait augmenter son budget de la défense de $17,6 \%$ à 417,8 milliards de yuans $(57,2$ milliards de dollars) en 2008, bien que déjà très important, seraient-ils loin de refléter la réalité.

Le Pentagone chiffrait entre 97 et 139 milliards de dollars l'enveloppe militaire de la Chine en 2007, ce qui a finalement acculé Beijing à concéder que l'augmentation était de 19,5\% en 2006. C'est aussi seulement à cette occasion que l'on connaîtra le montant (revu à la hausse) pour 2008 , soit une hausse de 17,6\% équivalant à 57,2 milliards de dollars. Selon certaines déductions couramment utilisées, les dépenses chinoises peuvent être jusqu'à deux ou trois fois plus élevées que les chiffres officiels. Cela placerait les 44 milliards de dollars chinois à 67 milliards, mon- 
tant comparable aux 65 milliards dépensés par la Russie, aux 43 milliards du Japon et aux 38 milliards du Royaume$\mathrm{Uni}^{10}$. Entre 2000 et 2005, le budget de la défense a doublé, s'élevant à 247,7 milliards de yuans, soit 30,7 milliards de dollars contre 120 milliards de yuans (14,5 milliards de dollars) cinq ans auparavant ${ }^{11}$.

Les dépenses militaires officielles ont donc crû remarquablement, à un rythme annuel effréné de deux chiffres depuis le début des années 1990 ${ }^{12}$. Déjà en 2005, un rapport du Pentagone estimait que les dépenses militaires chinoises se chiffraient à plus de 90 milliards de dollars, soit le plus important budget militaire d'Asie et le troisième du monde après ceux des États-Unis et de la Russie. Certains calculs faisaient mention, pour la même année, de 104 milliards de dollars, ce qui en ferait le deuxième budget militaire mondial derrière uniquement les États-Unis ${ }^{13}$.

Certains relèvent même que, en termes de parité du pouvoir d'achat (PPA), les dépenses militaires effectives dépassent de loin les 45 milliards de dollars (chiffre annoncé en 2007 par la Chine), ou même les 105 milliards estimés par le département américain de la Défense. Ces dépenses militaires se situeraient autour de 450 milliards en termes de PPA, ce qui mettrait la Chine au même niveau que les États-Unis. Ce montant ne serait pas à minimiser

10. Adam Segal (dir.), Chinese Military Power, New York, Council on Foreign Relations, 2003, p. 5.

11. Voir Jean-Pierre Cabestan, «Chine, des armes pour quoi faire?», Politique internationale, $\mathrm{n}^{\circ}$ 110, 2005-2006, Paris; Jean-Pierre Cabestan, «Hu Jintao et l'armée: quelles évolutions?», Centre Études Asie, <www.centreasia. org>.

12. Robert G. Sutter, «Why does China matter?», The Washington Quarterly, vol. 27, nº 1, 2003-2004, p. 80.

13. Liselotte Odgaard, "China's premature rise to great power status», AlterNet, 〈www.alternet.org >. 
selon les analystes qui rappellent qu'un milliard de dollars peut procurer beaucoup plus en Chine qu'aux États-Unis...

Tenant compte du fait que ces augmentations soutenues du budget militaire de la Chine interviennent au cours de la période post-guerre froide, marquée par des efforts de désarmement multilatéraux, certains analystes continuent de s'interroger sur les véritables motivations de Beijing. Quand on tient compte du rythme de croissance du PIB de la Chine, on peut prévoir que, sur les 10 à 20 prochaines années, même si Beijing devait maintenir un budget de la défense relativement «modeste», comme le prétend un de ses porte-parole, cela n'empêcherait pas une croissance rapide de ses dépenses militaires réelles, qui, ainsi, continuerait à pourvoir sans difficulté à son armement ${ }^{14}$.

Dans l'espace d'une décennie, sinon beaucoup plus tôt, la Chine sera le premier rival mondial des États-Unis pour ce qui est de l'influence militaire et stratégique ${ }^{15}$. D'aucuns pensent que son budget militaire fournit une claire indication des efforts entrepris par l’Armée Populaire de Libération afin de se transformer d'une force excessivement peuplée en une armée restructurée, basée sur l’information et s'appuyant sur un personnel fait de soldats et d'officiers hautement qualifiés ${ }^{16}$.

On estime généralement que des dépenses militaires significatives pourraient ne pas apparaître dans le budget

14. Voir à ce sujet Robert $S$. Ross, «A realist policy for managing USChina competition», Policy Analysis Brief, novembre 2005, <www.stanleyfdn. org>.

15. Bill Gertz, «China expands sub fleet», The Washington Times, 2 mars 2007, p. A-1.

16. Richard Halloran, «China's missing military spending», <www. realclearpolitics.com>. 
de la défense annoncé par Beijing. Selon certaines estimations parmi les plus prudentes, ces coûts invisibles, quoique difficiles à calculer, comprennent l'acquisition d'armements de l'étranger; des subventions à l'industrie de la défense - incluant l'Armée populaire de libération et les groupes paramilitaires -; des projets de construction liés à la défense; etc.

Les chiffres officiels omettent volontiers les coûts relatifs à certaines autres rubriques importantes comme la démobilisation et la pension, l'entretien des réserves et de la police de l'armée populaire (PAP), et les revenus provenant d'échanges commerciaux ${ }^{17}$. En conclusion, cette élévation sans précédent du budget militaire de la Chine est un des indicateurs de sa puissance et en font surement ce qu'on qualifie en Occident de «top global power».

\section{Une superpuissance militaire en devenir}

Si l'on tient compte de tous les critères pertinents de la puissance, la Chine s'impose aujourd'hui comme une superpuissance militaire potentielle. À termes, estimet-on, elle disposera d'une puissance militaire en adéquation avec son statut global et des options militaires envisagées vis-à-vis de Taiwan. Depuis 1990, elle a en effet dramatiquement redressé ses ressources militaires terrestres, navales et spatiales et, plus récemment, elle a entrepris de développer des capacités de projection au-delà de l'Océan Pacifique par le biais d'une flottille de petits bateaux de guerres dans le golfe d'Aden dans le cadre

17. The IISS Military Balance 2006, Routledge, 2006, p. 253. 
d'efforts internationaux visant à combattre la piraterie somalienne.

En août 2009, le ministre de la défense, Liang Guanglie, dont les déclarations ont été relayées par la presse internationale, tout en réitérant que l'armée chinoise se développera pacifiquement, a tenu à préciser que celle-ci intensifierait aussi sa coopération avec des forces armées étrangères afin de remplir ses obligations internationales. La raison se trouve dans l'inquiétude qu'elle suscite et dans le besoin de la calmer.

En 2008, le Pentagone a tiré la sonnette d'alarme sur les efforts militaires de la Chine. Cette version de son Annual Report on the Military Power of the People's Republic of China dépeignait au Congrès, comme celles plus récentes, un tableau très factuel de la modernisation en mode accéléré des capacités militaires de ce pays. Les experts américains ont, en substance, mis l'accent sur le fait que la Chine était non seulement en train de se doter de capacités militaires de projections au-delà de ses frontières asiatiques dans les domaines terrestre, naval et aérien, mais surtout qu'elle se concentrait sur l'intégration des différentes composantes de ses forces armées à des fins supposées d'opérations conjointes.

Les rapports officiels du département américain de la Défense méritent attention même si, à n'en pas douter, ils présentent la perspective officielle américaine sur la question avec un risque connu d'exagération. Cette précaution observée, il ne fait aujourd'hui guère de doute que l'APL met le cap sur le concept présenté plus haut de «guerre locale dans un environnement informatisé». Dans cette perspective, deux objectifs stratégiques seraient poursuivis par la Chine qui peuvent se résumer en deux mots: 
«coercition» vis-à-vis de Taiwan et «dissuasion» quant à tout éventuel soutien des États-Unis en faveur de l'île.

Par ailleurs, la Chine partage des frontières avec 15 autres pays en Asie, plusieurs desquels posent, selon elle, de sérieux problèmes de sécurité. Taiwan, la Corée du Nord, le Pakistan et l'Inde représentent tous des défis pour la sécurité régionale.

Cela dit, le Pentagone reconnaît que la capacité de la Chine à projeter sa puissance militaire sur des théâtres éloignés demeure limitée pour le moment, mais, s'empresse-t-il d'ajouter, comme noté dans le Quadrennial Defense Review Report de 2006, elle a «le plus grand potentiel afin de rivaliser militairement avec les États-Unis et concevoir des technologies militaires susceptibles de retirer à terme aux États-Unis leurs avantages militaires traditionnels à l'étranger».

Les indices montrant que la Chine poursuit la construction d'une force armée à vocation offensive ne manquent pas. Les militaires chinois acquièrent de nouveaux systèmes d'armements et ont mis à jour leur doctrine et formation afin de permettre à l'armée de projeter sa puissance au-delà de ses frontières et de défendre ses forces déployées sur des théâtres de combats. Ils sont déjà prêts à affronter des d'attaques de nature variée, impliquant les avions, les sous-marins et les missiles ${ }^{18}$. Le pays est aujourd'hui dotée d'une force navale jugée digne de ce nom, équipée de plus de 55 sous-marins de combat, entre autres vaisseaux navals incluant des missiles localisés sur les zones côtières du sud et de l'est. 
La Chine investit aussi, de manière soutenue, dans l'acquisition d'un système d'armement sophistiqué, incluant des missiles balistiques de moyenne portée, des avions de combat, et des systèmes de surveillance actualisés. Le défi vise, avant toute chose, à mettre à mal le fonctionnement du système d'information americain dans l'eventualité d'un conflit armé impliquant Washington.

La coopération militaire avec d'autres pays, en particulier la Russie ${ }^{19}$, a permis à la Chine de développer sa puissance aérienne et spatiale. Comme cela été bien documenté par plusieurs institutions de recherches en Occident, dont l'Institut de recherche international pour la paix de Stockholm (SIPRI), l'armée chinoise a dépensé une part significative de son budget de la Défense pour acquérir des systèmes d'armement perfectionnés de la Russie.

Selon les données disponibles, depuis le milieu des années 1990, elle a dépensé en moyenne 2,5 milliards \$ par année dans l'achat d'armements conventionnels avancés (pour la plupart, des avions et bateaux de combat). De tels investissements la propulsent au sommet de la liste du SIPRI parmi les pays les mieux cotés en acquisition de systèmes d'armements conventionnels importants au cours de ces dernières années ${ }^{20}$.

Parallèlement, la Chine a accompli des étapes importantes vers le développement, lentement mais sûrement, de

19. Voir Jean-Pierre Cabestan, «La politique étrangère chinoise: une Chine sans ennemis n'est pas forcément une Chine rassurante», Hérodote, $\mathrm{n}^{\circ} 125,2007, \mathrm{p} .11-27$. Selon cet auteur, la Russie est le principal fournisseur d'armements de la Chine avec 2 milliards de dollars de ventes annuelles en moyenne depuis les années 1990.

20. Roy Kamphausen, David Lai et Andrew Scobell (dir.), Beyond the Strait: PLA Missions Other than Taiwan, Carlisle, Strategic Studies Institute, 2009, p. 6. 
sa propre «defense industrial base» ou «weapons-building capability». En effet, comme le souligne Kamphausen, l'acquisition d'armes sophistiquées de la Russie peut ne pas être représentative de ses efforts de réarmement militaire accéléré. L'armée a aussi investi des ressources considérables sur le plan interne afin de relever sa puissance militaire globale. Comme le note aussi Ross, la modernisation de son économie favorisera le développement de l'industrie aux fins de la production sur place de systèmes d'armements sophistiqués ${ }^{21}$. On estime que l'Armée populaire de libération a déjà réussi à améliorer significativement la qualité de ses usines de fabrication et sa capacité à intégrer les technologies de pointe.

Selon une analyse du Lexington Institute réalisée en 2006, l'APL se donne ainsi les moyens de contester l'hégémonie américaine au-delà de l'Asie ${ }^{22}$. Cette analyse semble corroborée par la tendance à consacrer une attention soutenue à l'acquisition d'armes conçues pour des guerres asymétriques. Les récentes acquisitions militaires chinoises ainsi que celles en cours - des missiles balistiques mobiles, des forces aériennes et navales améliorées et capables de mener toute une gamme d'opérations seraient ainsi à même de permettre à la Chine de conduire des opérations militaires partout.

Il serait erroné d'interpréter la rapide croissance observée de la puissance militaire de la Chine comme une menace seulement envers Taiwan. Elle a aussi des implications pour les États-Unis et leurs alliés dans la région

21. Robert S. Ross, «A realist policy for managing US-China competition», 〈www.stanleyfoundation.org $>$.

22. «China's military power: Shadow over central Asia», <lexington institute.org>. 
pacifique. Pris ensemble, des budgets accrus de Défense, l'acquisition de systèmes d'armement les plus avancés, et certaines affirmations du leadership plaident en faveur du «scénario de la menace» (threat scenario).

La Chine a des ambitions régionales, voire globales, et se dote d'une armée de première classe afin de réaliser ces ambitions. Ce serait par conséquent, préviennent certains spécialistes en Occident, commettre une erreur stratégique grossière que d'interpréter la construction de cette puissance militaire comme participant «uniquement» de préparatifs pour une invasion de Taiwan, éventualité dans laquelle elle aurait en effet à envisager de neutraliser les forces militaires américaines dans la région.

Lactivisme militaire trahit selon plusieurs, ses véritables ambitions en matière stratégique qui semblent déborder le cadre de ses périphéries asiatiques et, pour ainsi dire, ne viseraient pas la simple préservation de son territoire, de son espace maritime et aérien et de la sauvegarde de ses intérêts nationaux. Il s'inscrirait dans une perspective globale ${ }^{23}$. Certains décrivent tout simplement un pays qui passe à l'offensive et proposent de voir dans cette perspective la construction de bases navales dans l'Océan indien. À ce rythme, on anticipe que dans une décennie, et peut-être plus tôt, elle deviendra le seul compétiteur mondial des États-Unis d'Amérique en termes d'influence militaire et stratégique.

Les dirigeants américains se retrouvent chaque fois devant un véritable mur du silence dans leurs tentatives d'obtenir des explications auprès d'un régime communiste

23. Kamlesh Kumar Agnihotri, «White paper - “China's national defense in 2008”: An analysis», Maritime Affairs, vol. 5, $\mathrm{n}^{\circ} 1$. 
qui se contente de distiller ses informations au comptegoutte. «Nous pensons qu'il est important que dans notre dialogue, nous comprenions l'agenda et les intentions de la Chine», lançait, impuissant, le sous-secrétaire d'État de George Bush ${ }^{24}$. John Negroponte avait aussi alerté en des termes clairs la Commission du renseignement du Sénat américain: «la puissance de la Chine s'accroît rapidement et s'accompagne d'une influence globale croissante qui en fait à certains égards le peer competitor des États-Unis ${ }^{25}$ ».

Perplexe, l'ancien secrétaire d'État américain à la Défense Donald Rumsfeld se demandait quant à lui : «Pourquoi tous ces investissement croissants? Pourquoi toutes ces vastes acquisitions?» L'interrogation sousjacente est de savoir pourquoi un pays qui ne fait face à aucune menace militaire sérieuse investit autant dans l'armée, si ce n'est qu'il entend utiliser la force, ou l'intimidation, pour atteindre certains objectifs intérieurs et internationaux.

En juin 2005, c'était au tour de la Secrétaire d'État Condoleezza Rice, d'exhorter les États-Unis à faire le nécessaire afin de faciliter l'assimilation par la Chine des règles de l'économie mondiale avant qu'elle ne devienne une «superpuissance militaire». Sa prise de position paraît des plus avisées, à écouter les déclarations du général chinois Zhu Chenghu aux micros des reporters en 2005, indiquant que la Chine n'hésiterait pas à utiliser ses armes nucléaires en réponse à l'usage de missiles conventionnels

24. Voir Edward Cody, «China boosts military spending: senior U.S. official presses Beijing to clarify "plans and intentions" », Washington Post, 5 mars 2007.

25. John D. Negroponte, «Annual Threat Assessment of the Director of National Intelligence for the Senate Select Committee on Intelligence», Office of the Director of National Intelligence, 2 fév. 2006. 
par les États-Unis contre la Chine dans un conflit éventuel avec Taiwan.

Quelques années plus tôt, le général Xiong Guangkai menaçait aussi d'utiliser les armes nucléaires chinoises contre Los Angeles si les États-Unis s'avisaient d'épauler Taiwan en cas d'invasion chinoise sur l'île rebelle ${ }^{26}$. C'est pourquoi, préviennent Ashley Tellis et Michael D. Swaine, «à long terme, sa croissance économique et militaire massive fera de la Chine une puissance agressive en matière de politique internationale. Il n'est pas garanti que la Chine sera une puissance pacifique ${ }^{27}$.»

L'objectif à long terme de la Chine, devine Lonnie Henley, «[est] de se hisser au même niveau économique, diplomatique et militaire que la première puissance mondiale, c'est-à-dire, les États-Unis d'Amérique ${ }^{28}$ ». Thomas J. Christensen, dont les analyses des questions stratégiques chinoises sont réputées, conclut: «il existe vraisemblablement un large consensus parmi les analystes chinois que la Chine devrait sans délai construire sa puissance militaire et liquider plusieurs conflits liés à sa souveraineté dans l'Est et le Sud de la côte maritime, manu militari si nécessaire ${ }^{29}{ }^{2}$.

\section{Une puissance militaire révisionniste?}

À l'évolution rapide de son programme de modernisation militaire s'ajoute le flou supposé entretenu par Beijing autour de ses objectifs stratégiques à long terme. Il s'agit,

26. Voir Bill Gertz, op. cit.

27. Interpreting China's Grand Strategy, op. cit.

28. Bates Gill et Lonnie Henley, «China and the revolution in military affairs», rapport, Carlisle, Strategic Studies Institute, p. 30.

29. Thomas F. Christensen, «Chinese realpolitik», Foreing Affairs, vol. 75, $\mathrm{n}^{\circ} 5,1996$, p. 44. 
à l'évidence, de deux sujets de première préoccupation risquant d'enlever - ne serait-ce que pour quelque temps encore - leur sommeil aux stratèges américains ${ }^{30}$. Chacun y va de son expertise dans l'explication des initiatives militaires chinoises.

James Mulvenon range les motivations probables chinoises pour la poursuite d'objectifs militaires dans deux catégories d'éléments qu'il qualifie d'«actifs» et de «réactifs». Dans le premier cas, il invoque la volonté de multiplier ses options militaires afin d'exercer une influence dans ses périphéries - en particulier le détroit de Taiwan et la mer du sud de la Chine. Dans le second cas, il y a la crainte de rester en marge de la course globale à la modernisation militaire, une préoccupation que les enseignements tirés de la Guerre du Golfe en 1991 et de l'Operation Iraqi Freedom en 2003 n'ont fait que renforcer ${ }^{31}$.

Gennady Chufrin, professeur à l'Institute of World Economy and International Relations (russe), est de ceux qui interprètent les actions de la Chine comme une réponse directe aux opérations militaires conduites par les Américains au cours de ces dernières années. La présence militaire des États-Unis en Asie centrale, qui naguère aurait été impensable, a littéralement créé un «scénario catastrophe» en matière sécurité. Ce facteur étant considéré comme fournissant le cœur des rivalités sino-américaines en Asie de l'Est, il n'est dès lors pas étonnant que la Chine essaye

30. À ce sujet, voir l'excellente analyse de Jonathan D. Pollack, «Chinese military power: What vexes the United States and why?», 〈www.fpri.org〉.

31. James C. Mulvenon et al., Chinese Responses to U.S. Military Transformation and Implications for the Department of Defense, Santa Monica, RAND, 2006, 〈www.rand.org>. 
par tous les moyens de renverser la situation ou, à tout le moins, d'en minimiser l'impact ${ }^{32}$.

En dépit du discours sur le développement pacifique épousé par le leadership du Parti Communiste, les investissements sans précédents dans l'expansion des capacités militaires de la Chine trahissent, à l'analyse, une claire intention de remettre en question la suprématie des ÉtatsUnis dans le Pacifique Ouest et de s'établir comme la puissance militaire de la région. Un analyste observait en 2007 que la Chine émerge comme une superpuissance militaire et principal challenger des États-Unis en Asie de l'Est, qu'elle pourrait dominer au XXI ${ }^{\mathrm{e}}$ siècle à mesure que décroîtra l'influence américaine ${ }^{33}$.

Larry Wortzel, un éminent spécialiste de l'Asie, déclarait pour sa part: «Nous ignorons les intentions de la Chine, mais en observant ses capacités et doctrine militaires, nous savons que l'armée chinoise agit comme en prévision d'une guerre contre les États-Unis ${ }^{34}$.»Un point de vue qu'un dignitaire de haut rang se charge de transmettre en mains propres aux membres du Congrès lors d'une audition en 2007. Il affirme que les Chinois sont en train de «construire leur armée pour, à son avis, atteindre un certain degré de parité avec les États-Unis», ajoutant qu'ils représentent une menace aujourd'hui, et qu'ils seront une menace grandissante avec le temps ${ }^{35}$.

32. Gennady Chufrin, «The changing security model in post-Soviet central Asia», The Quaterly Journal, $\mathrm{n}^{\circ}$ 1, 2003, p. 4.

33. John J. Tkacik J $\mathrm{r}$, «Hedging against China», 〈www.heritage.org〉.

34. Larry M. Wortzel, remarques dans le cadre du débat «The implications of China's military modernization: Reframing China policy», Washington, Carnegie Endowment for International Peace, 6 février 2007, $<$ www.carnegieendowment.org $\rangle$.

35. Ces propos sont ceux du Director of National Intelligence, Michael McConnell. Voir John J. Tkacik Jr, op. cit., p. 1. 
Cependant, une catégorie d'analystes minimise la thèse de la menace chinoise, arguant que la Chine, en dépit de percées militaires incontestables, équivaut en termes stratégiques bien moins à l'Union soviétique des années 1950 qu'à l'Irak des années 1990: une menace régionale aux intérêts de l'Ouest, mais pas un rival idéologique mondial nécessitant des réactions d’urgence. Sans cependant nier les velléités militaires de la Chine, ils suggèrent plutôt une appréciation plus nuancée de ses capacités réelles en matière de puissance conventionnelle. Leur argumentaire s'appuie, pour l'essentiel, sur le fait avéré que la Chine accuse un retard d'au moins plusieurs décennies à combler avant de constituer une menace sérieuse pour les intérêts américains ${ }^{36}$.

Beijing s'est, de son côté, toujours inscrit en faux contre toute allégation d'expansionnisme militaire et circonscrit son programme de modernisation militaire au titre de son «développement pacifique». En effet, conscients des remous provoqués par leurs efforts militaires, les officiels chinois ont savamment entrepris d'apaiser les craintes: «la Chine n'ambitionne pas l’hégémonie ou la suprématie dans les affaires mondiales. Elle plaide pour un nouvel ordre politique et économique, lequel doit se mettre en place à travers des réformes en profondeur et la démocratisation des relations internationales ${ }^{37}$.» Selon Beijing, ces accusations de menaces sont le produit de ce qu'il désigne

36. Voir Samuel S. Kim, "China's path to great-power status in the globalization era», Asian Perspective, vol. 27, $\mathrm{n}^{\circ}$ 1, 2003, p. 35-75.

37. Bijian Zheng, «China's "peaceful rise" to great-power status», Foreign Affairs, vol. 84, n' 5, 2005, p. 24. 
par la «China threat theory», participant pour ainsi dire du complot visant à contenir son essor ${ }^{38}$.

Bref, les Chinois, quant à eux, jugent ces réactions exagérées et estiment logique que leur pays, militairement plus faible que les États-Unis et la Russie, tente de combler un retard dans un domaine dont dépend sa propre sécurité en appliquant au militaire les succès obtenus dans les domaines scientifiques et économiques.

Le dernier livre blanc sur la Défense se veut en cela un acte d'adhésion à l'avènement d'une «société harmonieuse», réfractaire à l'hégémonisme et l'expansionnisme militaire. En août 2009, le très discret ministère chinois de la Défense a surpris en lançant un site web dans le but déclaré d'apaiser les craintes générées par un déficit chronique de transparence militaire et de clarifications autour de la modernisation de ses forces armées ${ }^{39}$. Une note de bienvenue sur le site indique qu'il a été conçu afin de promouvoir dans le monde extérieur une meilleure perception de la politique de défense nationale. Quoique appréciable, cet effort d'information du gouvernement chinois risque toutefois de produire un effet boomerang en ce sens que la publication de ce site coïncide avec des investissements faramineux dans le relèvement de ses forces armées afin d'y introduire des armes de haute technologie.

38. Voir par exemple Bill Powell, «Is China's military a threat?», Time, 5 mars 2007.

39. Le site, accessible à l'adresse 〈www.mod.gov.cn〉, a aussi une version anglaise: 〈http://eng.mod.gov.cn〉. 
CHAPITRE 5

\section{Une révolution militaire à la chinoise}

Confrontés aux formes nouvelles prises par les guerres vers la fin $\mathrm{du} \mathrm{xx}^{\mathrm{e}}$ siècle, les dirigeants chinois font le constat de la nette supériorité des puissances rivales, en particulier les États-Unis, en matière d'équipements et de technologies militaires. Ils décident alors de lancer un programme ambitieux afin de relever le niveau de leurs forces armées par la science et la technologie.

Des réformes ambitieuses sont alors engagées qui englobent, entre autres mesures, la mise à jour de la doctrine stratégique de la Chine, la construction d'une nouvelle force armée et la modernisation des systèmes d'armements, dans le dessein avoué de mener à terme une «révolution dans les affaires militaires avec des caractéristiques chinoises».

Mais, conscient de ne pas pouvoir envisager pour le moment un rattrapage avec les principales puissances militaires rivales, Beijing, en guise d'alternative, opte pour une démarche non conventionnelle. Celle-ci consiste en la définition d'une stratégie de défense asymétrique, c'està-dire, procédant d'une prodigieuse combinaison des 
technologies militaires classiques avec celles de l'information dans la conception d'opérations destinées à combattre des ennemis qui lui sont supérieurs. Cette nouvelle tactique est désormais placée au cœur de la stratégie de défense active promue par Beijing: se préparer à gagner des guerres de haute technologie.

Si elle réussissait, une telle approche aurait le potentiel d'inaugurer un nouveau paradigme en matière de philosophie militaire au siècle naissant. Car, au-delà de la rhétorique et de toute exagération, il paraît de plus en plus plausible que l'arme de l'information pourrait doter l'armée chinoise d'une force de frappe insoupçonnable que même celles conventionnelles des États-Unis risquent d'avoir du mal à contenir. L'exploration par la Chine de ces technologies suscite déjà à bien des égards, des appréhensions lui conférant un certain crédit au vu de la gestion novatrice qu'elle s'ingénie à en faire dans sa stratégie de puissance post-guerre froide.

Cette stratégie asymétrique de défense participe des efforts accrus de modernisation militaire de la Chine et fait l'objet de débats sur l'ampleur et la nature du défi qu'elle pose aux États-Unis. Quoiqu'ils soient nombreux à analyser ses intentions et capacités réelles, l'essentiel de ce débat, comme l'a relevé Thomas Christensen, s'est focalisé sur une évaluation de la puissance militaire conventionnelle de la Chine en comparaison avec celle des États-Unis ${ }^{1}$.

Cette fixation sur le «hard military power» (la puissance militaire conventionnelle) risque cependant d'occulter un aspect important du génie militaire chinois,

1. Thomas J. Christensen, «Posing problems without catching up: China's rise and challenges for U.S. security policy», International Security, vol. $25, \mathrm{n}^{\circ} 4,2001$, p. 5-40. 
laissé en jachère. Or, la question relative à la capacité de la puissance militaire chinoise à répondre adéquatement, de quelque manière, aux défis générés par le nouvel environnement sécuritaire international est cruciale. Nous tentons en particulier de voir dans quelle mesure l'information pourrait constituer une arme nouvelle efficace aux mains du régime communiste. Ce dernier pourrait l'utiliser afin de pallier les carences technologiques qui semblent la maintenir aujourd'hui en marge de la «révolution dans les affaires militaires» opérée par les grandes puissances.

\section{Une pensée stratégique en évolution}

L'approche théorique inspirant aujourd'hui l'armée chinoise dans son entreprise de formulation d'une stratégie de modernisation à long terme est celle de «révolution dans les affaires militaires» (RMA, en anglais). Évoqué pour la première fois dans les discussions stratégiques russes, dans des années 1970, les stratèges occidentaux (américains, en particulier) saisiront rapidement l'enjeu de ce concept, développant la notion de revolution in military technological affairs (RMTA) comme s'ils en avaient la paternité ${ }^{2}$.

Quant à la Chine, ce n'est qu'après l'opération «Tempête du désert» (Guerre du Golfe, 1991), et les frappes menées dans le cadre de la guerre du Kossovo (1999) que son lexique militaire choisira d'embrasser la nouvelle doctrine

2. You Ji, «The revolution in military affairs and the evolution of China's strategic thinking», Contemporary Southeast Asia, 1999, <www.fas. org>. 
militaire à la mode dans le monde occidental ${ }^{3}$. Deux événements militaires majeurs qui illustrèrent les nouvelles dimensions que prendraient désormais les guerres sous conditions de haute technologie.

L'adoption du concept de RMA révèle une évolution majeure de la stratégie instaurée par la Chine dans les années 1950. En effet, jusqu'en 1970, sa doctrine militaire se basait sur l'idée de «guerre populaire» qui, dans la version originelle maoïste, table que la population entière pourra être mise à contribution dans l'éventualité d'une invasion ennemie. À cette notion s'est substituée la variante denguiste de «guerre populaire sous des conditions modernes ${ }^{4} »$. La reformulation rend compte implicitement de l'état d'arriération des équipements et technologies, que la Chine se doit de corriger si elle veut s'assurer une certaine compétitivité sur le plan militaire.

Il y a eu, par ailleurs, l'école «high-tech warfare» (guerre de haute technologie), ainsi dénommée en raison du rôle dévolu aux nouvelles technologies militaires au cœur de la stratégie de défense chinoise. Ce courant rejettait l'idée que la Chine envisage d'opérer une RMA, vu que cela impliquerait une politique technologique dont le pays, aux yeux de ses théoriciens, n'a manifestement pas les moyens. Ceux-ci déconseillent par conséquent toute tentative d'informatiser massivement les forces armées et, en revanche, prônent la création de «poches» technologiques dans les secteurs naval et aérien en particulier, afin de pallier les carences de l'armée chinoise.

3. Ibid.

4. A. F. Klimenko «The evolution of China's military policy and military doctrine», Far Eastern Affairs, nº 2, 2004. 
Finalement, sous les nouvelles conditions historiques induites par la fin de la guerre froide, un nouveau paradigme au sein de l'armée s'imposait. Il devait répondre aux défis auxquels l'institution militaire doit faire face, entre autres, la nécessité de se préparer à gagner des guerres de haute technologie à l'avenir. Ainsi, l'expression «révolution dans les affaires militaires avec des caractéristiques chinoises» cristallise-t-elle une période de profonde transformation pour l'Armée Populaire de Libération ${ }^{5}$. Sur presque tous les fronts, celle-ci s'est embarquée dans une myriade de réformes visant à en faire une force plus professionnelle dans un sens à la fois corporatif et institutionnel ${ }^{6}$. Ces changements touchaient à toutes les facettes de l'appareil militaire, des structures au personnel en passant par les équipements.

Dans la Guerre du Golfe, les États-Unis ont expérimenté l'utilisation combinée de systèmes d'armements équipés de technologies de pointe et de technologies d'information. Lors de celles du Kosovo et d'Irak, la haute technologie est apparue comme le facteur dominant des opérations militaires. Attentive à cette évolution qualitative, la Chine a tiré l'enseignement que l'intégration des technologies de l'information constitue la base des opérations militaires modernes et le fondement des nouvelles puissances militaires. Il s'agissait donc de résorber l'avance des principales puissances mondiales en matière de technologie militaire.

5. Taylor Fravel, «China's search for military power», op. cit.

6. David M. Finkelstein (Prologue), dans James Mulvenon et David M. Finkelstein (dir.), China's Revolution in Doctrinal Affairs: Emerging Trends in the Operational Art of the Chinese People's Liberation Army, Alexandria, The CNA Corporation, 2005, p. xi. 


\section{La RMA comme base doctrinale et son évolution}

Composante essentielle de toute grande stratégie, la doctrine militaire réfère aux méthodes et principes de base qui guident l'application par un État de la force militaire. D'un point de vue doctrinal, stratèges et décideurs chinois - à quelques exceptions près - ont unanimement adhéré à la conception très largement répandue dans les cercles militaires occidentaux: s'il devait se produire une autre révolution dans les affaires militaires (RMA) au cours des prochaines décennies, celle-ci serait vraisemblablement basée sur l'exploitation - plutôt que la quantité - des technologies militaires à la disposition d'un État ${ }^{7}$. À ce sujet, Andrew N. D. Yang et Milton Wen-Chung Liao (un colonel retraité) proposent une excellente synthèse de la révolution en cours dans les affaires militaires. Celle-ci comprend quatre caractéristiques essentielles.

D'une part, les guerres modernes sont des guerres de haute technologie, et la technologie ne remplit pas uniquement des missions tactiques et de combats mais peut servir des objectifs stratégiques. D’autre part, les guerres régionales peuvent être des moyens sûrs aux fins de résolution politique et invalider la perspective de guerre de longue portée. Par ailleurs, l'existence de systèmes d'armements de haute technologie éloigne la perspective d'une «résolution rapide» en conduisant des frappes de longue portée, de haute intensité et de précision. Enfin, la présence de systèmes d'armements influence les besoins en termes de combinaison des forces et résultent en de nouveaux types d'opérations combinées.

7. Bates Gill et Lonnie Henley, op. cit. 
En Chine donc - plus qu'ailleurs -, cette période de transition doctrinale a aussi été témoin d'une éclosion d'articles académiques et de livres politiques, contenant pour la plupart les prémisses d'une nouvelle théorisation militaire aux relents de paradigme.

En effet, au lendemain de la guerre froide, observent certains analystes, les guerres régionales de haute technologie sont devenues un phénomène important. Le focus de la stratégie militaire des grandes puissances s'est déplacé sur le déploiement de systèmes de longue portée et unifiés de «forces aériennes, terrestres et navales». Pour réaliser cet objectif, les forces armées doivent orienter leur «mécanisation» vers l'«informatisation».

Les États-Unis, afin d'atteindre cet objectif majeur, ont réduit la taille de leurs troupes et leur budget de la défense. Ils ont mis l'accent sur la haute technologie dans le cadre des guerres régionales. «Utiliser pleinement la technologie expérimentale» est devenu crucial dans le développement des forces américaines ${ }^{8}$.

En particulier, la performance des forces alliées lors des opérations «Tempête du désert» contribuera à cristalliser, dans un premier temps, le nouveau concept militaire en vogue: «Local Wars Under Modern High-tech

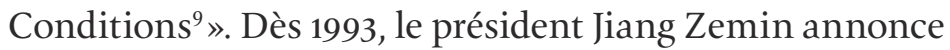
un changement radical dans la stratégie chinoise qui consistait à s'engager prématurément dans une guerre totale ou une guerre nucléaire. Il appelle à viser désormais une guerre locale moderne sous condition de technologies modernes, particulièrement les hautes technologies car

8. Lexington Institute, op. cit.

9. David M. Finkelstein, op. cit. 
«ce changement guidera le développement et l'amélioration de notre orientation stratégique».

Avec la publication en 2004 du troisième livre blanc sur la défense nationale, la nouvelle conceptualisation devient «Local Wars Under Modern Informationalized Conditions ${ }^{10} »$. Pour sa part, le concept «Revolution in Military Affairs» (RMA), employé par le premier ministre Wen Jiabao en 2004, servira de base philosophique aux nouvelles opérations de l'APL ${ }^{11}$. Il déclare ainsi que la Chine doit activement chercher à promouvoir une «révolution dans les affaires militaires avec des caractéristiques chinoises » et faire des efforts en vue d'impulser par des bonds qualitatifs le développement du système de la défense nationale et la modernisation de forces armées $^{12}$.

Le 20 janvier 2009, le Bureau de l'information du Conseil d'État de la RPC a fait paraître un nouveau livre blanc de la Défense. Outil de propagande par excellence de Beijing dans le cadre de ses efforts afin de convaincre le monde de ses intentions pacifistes, ledit document, qui exprime sa vision en matière de sécurité internationale, offre un contraste pour le moins saisissant. Il souligne l'incidence grandissante des variables de sécurité mili-

10. Ibid.

11. Extrait de la déclaration suivante: «[la Chine] doit s'ingénier à promouvoir la revolution dans les affaires militaires avec des caractéristiques chinoises et s'efforcer de réaliser le développement de sa défense nationale et la modernisation de ses forces armées sans délai» (16 mars 2004), cité dans Jason Kelly, "A Chinese revolution in military affairs?», op. cit.

12. Wen Jiabao, «Report on the work of the government», cité dans James Mulvenon, «Your guess is as good as mine: PLA budgets, proposals, and discussions at the second session of the 10th National People's Congress», China Leadership Monitor, n 11, 2004, p. 1. 
taire sur les relations internationales. Guidée par la compétition à tous les niveaux de la puissance nationale et le développement de la science et de la technologie, la compétition militaire internationale devient de plus en plus intense, et la révolution mondiale dans les affaires militaires a atteint un nouveau stade de développement.

Pour la première fois également, l'expression «Military Operations Other Than War» (MOOTW) a été utilisée. À lire entre les lignes, cela signifierait que la Chine se sent suffisamment confiante dans son potentiel militaire croissant et dans la possibilité de mener des opérations [militaires] loin de son territoire ${ }^{13}$. Une telle lecture est en totale cohérence avec le document de référence de la doctrine nucléaire chinoise intitulé Zhanlüexue, publié en deux versions (respectivement en 1999 et 2001). Il précise les ambitions de la Chine en matière d'armes nucléaires décrites comme un atout crucial dans le profil international d'une nation ${ }^{14}$.

Ici, encore une fois, le focus n'est plus uniquement la défense nationale, mais de manière plus ambitieuse, la consolidation du statut de la Chine sur l'échiquier mondial. En effet, la foi de la Chine dans le nucléaire est profondément ancrée chez les stratèges chinois qui ont toujours reconnu aux armes nucléaires une valeur symbolique indispensable à la confirmation et la validation du statut de leur pays comme grande puissance. Ce jugement

13. Kamlesh Kumar Agnihotri, «White paper - “China's national defense 2008": An analysis», op. cit.

14. Michael S. Chase et Evan Medeiros, «China's evolving nuclear calculus: Modernization and doctrinal debate», dans James Mulvenon et David M. Finkelstein (dir.), China's Revolution in Doctrinal Affairs, op. cit., p. 122. 
explique qu'avant toutes choses, Beijing décide de consacrer des ressources importantes au développement des armes nucléaires comme une absolue priorité.

Depuis quelques années maintenant, le régime communiste fait de moins en moins mystère sur ses véritables ambitions. Dès 2006, Beijing exprime en des termes non équivoques son engagement à réaliser pleinement ses objectifs militaires d'ici le milieu du siècle. Dans son livre blanc sur la défense nationale publié cette année-là, il définit un échéancier assorti d'objectifs quantifiables à atteindre dans un horizon temporel.

Dans cette perspective, la Chine poursuit le développement d'une stratégie qu'elle décline en trois étapes majeures au terme desquelles elle se propose de compléter son objectif de modernisation de sa défense nationale et de ses forces armées, ceci en cohérence avec l'agenda global du pays en vue de la réalisation de sa modernisation. La première étape consiste à jeter une base solide vers 2010 pour qu'au cours de la deuxième, vers 2020, elle puisse réaliser des progrès tangibles à la lumière des objectifs fixés à cet effet. Rendue à la troisième étape, vers le milieu du XXI ${ }^{\mathrm{e}}$ siècle, elle devrait avoir atteint son objectif de se doter de forces armées informatisées à même de remporter des guerres de haute technologie.

\section{Du concept à la réalité}

Mais il reste du chemin à parcourir avant d'en arriver là. Beijing se rend bien à cette évidence, mais ne s'arrête pas pour se demander si le jeu en vaut la chandelle. Son approche a consisté à appréhender le concept de RMA d'une manière qui le rende compatible avec sa propre réalité. Or, 
une révolution dans les affaires militaires signifie un changement majeur dans la nature des guerres résultant d'une application novatrice des nouvelles technologies. L'usage de celles-ci, combiné avec des changements drastiques dans la doctrine militaire et les concepts opérationnels, altère fondamentalement le caractère et la conduite des opérations militaires ${ }^{15}$.

S'appuyant sur cette définition, d'aucuns pensent qu'une telle révolution est en train de se produire, et ceux qui en saisissent la portée et en prennent avantage en tireront des profits décisifs sur les champs de bataille à l'avenir. Une «révolution dans les affaires militaires» suppose donc l'application novatrice de technologies militaires dans l'accomplissement de nouvelles compétences militaires non réalisables suivant les méthodes standards à l'usage dans les autres nations. L'idée de «révolution» signifie quant à elle qu'on est le premier à développer et mettre en œuvre un nouveau paradigme dans la poursuite des opérations militaires.

S'en tenant strictement aux standards que nous venons de mentionner, plusieurs analystes objectent radicalement que la Chine puisse pour le moment opérer une révolution dans les affaires militaires. En effet, pour le souligner avec Henley, une telle percée impliquerait pour la Chine un double tour de force: parvenir à rattraper l'avance importante des forces armées américaines et leur emboîter le pas dans la révolution militaire actuellement

15. Jeffrey McKitrick, James Blackwell, et al., «The revolution in military affairs», dans Barry Schneider et Lawrence E. Grinter (dir.)., Battlefield of the Future: 21st Century Warfare Issues, Maxwell Air Force Base, Air University Press, 1995. 
en cours ${ }^{16}$. Il est clair, tant pour les observateurs externes que pour les Chinois eux-mêmes, qu'une telle perspective est encore éloignée.

Comme l'a relevé Christensen, à aucun moment, même les auteurs chinois les plus optimistes, partisans d'une certaine RMA, n'invoquent de scenario suggérant que leur pays puisse, de quelque manière, refermer rapidement l'écart et éventuellement dépasser les États-Unis ou d'autres puissances avancées en systèmes d'information militaires ou même avoir la capacité de les attaquer de manière conventionnelle.

En tout état de cause, et en dépit des avancées obtenues, il ne fait pas de doute parmi les analystes que l'armée chinoise n'est pour le moment pas adéquatement équipée afin de relever le défi d'une guerre de type «révolutionnaire», du moins, prise dans l'acception occidentale du terme. D'ailleurs, le volontarisme des Chinois en cette matière traduit un aveu à peine voilé du fossé technologique qui les éloigne pour le moment du savoir-faire en la matière. L'écart est à ce point immense que, traduit en termes stratégiques, tout progrès significatif demanderait de la Chine, comme le dit Valérie Niquet, qu'elle envisage de sauter les étapes, telles que celle de la mécanisation de l'ensemble des forces chinoises, pour plonger directement dans l'ère des applications des technologies de l'information initiée par les États-Unis ${ }^{17}$.

Toutefois, pour beaucoup de Chinois, le domaine de l'«information warfare» est l'une des rares arènes technologiques où la course à la suprématie entre grandes

16. Bates Gill et Lonnie Henley, op. cit.

17. Valérie Niquet, «La recherche spatiale en Chine: saut technologique et capacités militaires», Asie Visions, 2007, 〈www.ifri.org〉. 
puissances reste indéterminée. Ils sont donc mus par la conviction qu'en exploitant la révolution de l'information, la Chine pourrait surmonter des générations de technologies obsolètes afin de s'élever au niveau du monde développé. Au vu des investissements chinois, une telle hypothèse est fortement prise au sérieux en Occident. Beijing semble convaincu qu'il est possible de bâtir des capacités nouvelles permettant de gagner des guerres asymétriques en exploitant certains créneaux tels que l'utilisation du spectre électro-magnétique, qui permet de rendre inopérationnel l'arsenal de l'adversaire par le biais d'ondes qui détruisent les équipements de transmission sans tuer.

Par définition, une guerre asymétrique est une attaque menée par un adversaire plus faible ou possédant des atouts militaires inferieurs contre un ennemi plus fort en utilisant des moyens inattendus et novateurs, tout en évitant des attaques frontales en s'exposant aux forces de l'adversaire. Dans ce contexte, plutôt que de s'épuiser à vouloir rattraper l'Occident, les efforts de modernisation militaire de Beijing peuvent mieux être décrits comme plaçant le focus sur ce que la littérature spécialisée désigne par le concept d'«asymmetric engagement capabilities». La Chine vise à identifier des tactiques novatrices et l'emploi d'équipements technologiques que son armée aura réussi à appliquer avec succès et qu'elle pourra utiliser raisonnablement au cours des prochaines décennies.

Autrement dit, la stratégie asymétrique que la Chine s'emploie à développer tend à prouver qu'elle a à la fois la volonté et l'intérêt à se préparer dans l'éventualité d'un conflit armé qui pourrait impliquer les États-Unis en particulier. Selon Andrew Mack, «résolution» et «intérêt» 
sont deux variables essentielles qui déterminent l'issue d'un conflit asymétrique ${ }^{18}$. Ivan Arreguin-Toft en arrive à la conclusion que, historiquement, des acteurs forts ont perdu des conflits asymétriques parce qu'ils n'ont pas adopté la bonne stratégie vis-à-vis de leurs adversaires plus faibles ${ }^{19}$.

Pour Beijing, il est indiscutable que la «révolution dans les affaires militaires» continue d'être le concept dominant inspirant le présent et presque certainement le futur des puissances militaires mondiales. Néanmoins, loin de répliquer (à la lettre) à la version occidentale de ce concept, l'idée, explique You Ji dans une analyse détaillée, est plutôt d'en étudier la nature et, dans la mesure du possible, d'en appliquer certains principes compatibles avec la réalité qui est celle de la Chine contemporaine ${ }^{20}$.

Les Chinois partagent en effet la conviction que les grandes puissances pourraient être vulnérables précisément parce qu'elles dépendent davantage des systèmes technologiques avancés que ne le sont des pays émergents comme la Chine ${ }^{21}$. Comme le remarquent deux dirigeants militaires chinois, le lieutenant-général Wang Houqing et le major-général Zhang Xingye, en étant par nécessité plus créative que les États-Unis, la Chine pourrait alors sauter l'étape du développement technologique dans le cadre de la révolution en cours dans les affaires militaires. Elle

18. Andrew Mack, «Why big nations lose small wars: The politics of asymetric conflict», World Politics, vol. 27, n 2, 1975, p. 175-200.

19. Ivan Arreguin-Toft, «How the weak win wars: A theory of asymetric conflict», International Security, vol. 26, n 1, 2001, p. 93-128.

20. You Ji, "The revolution in military affairs and the evolution of China's strategic thinking», op. cit.

21. T. J. Christensen, «Posing problems without catching up, op. cit., p. 28. 
pourrait, pour ainsi dire, rapidement refermer l'écart avec les États-Unis perçus comme excessivement confiants et trop bureaucratiques pour s'intéresser aux réels défis qu'un pays tardivement arrivé sur l'échiquier pourrait leur poser.

Pour Pékin, il faut éviter le piège dans lequel est tombée l'URSS, à savoir s'enliser dans le bourbier que constituerait une course folle aux armements. Il faut plutôt adapter dans la mesure du possible, l'arsenal disponible afin de vaincre un ennemi plus puissant. Selon Christensen, cet impératif, les stratèges chinois le traduisent très simplement: «Nous devons explorer l'art permettant à un faible de défaire un fort en situation de haute technologie».

Dans cette perspective, l'enjeu dans les combats entre des forces rivales est leur capacité à collecter, traiter et analyser des informations. En termes stratégiques, cela signifie que les combats commencent longtemps avant que les premiers coups de feu n'éclatent entre les soldats. Plus crument dit, les centres névralgiques de défense de l'ennemi peuvent être atteints sans l'utilisation d'un chasseur, de bateaux de guerre ou de missiles. Cela peut se faire simplement à travers des virus informatiques, l'utilisation du spectre électro-magnétique et des attaques de logiciels visant à paralyser les systèmes ennemis. La supériorité dans les opérations militaires devient, dans ce contexte, tributaire de la supériorité accumulée dans la conception des opérations militaires ${ }^{22}$.

Cette observation reflète largement un consensus partagé au-delà des cercles stratégiques de Beijing. À Washington, par exemple, la défense spatiale et l'investissement dans des technologies de l'information à des

22. You Ji, op. cit. 
fins militaires apparaissent comme des impératifs stratégiques. En fait foi l'aveu du secrétaire américain à la Défense, Robert Gates, quand il reconnaît qu'«avec des technologies à bon marché et très peu d'investissements, de potentiels adversaires opérant dans le cyberespace peuvent infliger des dommages au vaste réseau du DoD»- le sigle désigne le département américain de la Défense, qui héberge plus de 15 ooo réseaux locaux, régionaux et globaux ${ }^{23}$.

Douglas C. Lovelace, directeur du Strategic Studies Institute du United States Army War College, remarque dans la même veine que «certains pays peuvent en effet tirer profit de la révolution dans les affaires militaires en sautant des générations de technologies [et] en devenant des menaces modernes, sophistiquées, faisant l'économie d'investissements significatifs ${ }^{24}$ ».

China Debates the Future Security Environment, de Michael Pillsbury, contient une compilation d'articles donnant, pour l'essentiel, une bonne mesure de la perspective chinoise quant à la nature des futures guerres au XXI ${ }^{\mathrm{e}}$ siècle et à la réponse appropriée à envisager ${ }^{25}$. Le chapitre 6 , «Forecasting future wars», introduit 55 auteurs militaires chinois, représentatifs des trois principales écoles de pensées militaires, qui proposent une compréhension des différents scenarii à envisager avec, à chaque fois, des recommandations en termes de préparations nécessaires suivant le cas.

23. Robert M. Gates, «Statement to the Senate Armed Services Committee», Washington, 27 janvier 2009, <www.defenselink.mil〉.

24. Toshi Yoshihara, «Chinese information warfare: A phantom menace or emerging threat?», 〈www.au.af.mil $\rangle$.

25. National Defense University Press, 2000, 〈www.fas.org〉. 
La perspective RMA retient l'hypothèse d'attaques de la Chine par une superpuissance. Cette éventualité implique pour la Chine la nécessité d'actualiser sa stratégie et son système de défense en y intégrant les technologies de l'information. Aujourd'hui, un nombre impressionnant de livres et d'articles, publiés en majorité par les Chinois, suggèrent qu'un programme de recherche actif a été mis en place depuis maintenant plusieurs années afin d'examiner comment la Chine devrait développer des capacités militaires la rendant apte à défaire les États-Unis en explorant le concept de RMA plus efficacement et plus rapidement.

\section{David peut vaincre Goliath}

L'histoire regorge d'exemples où l'issue d'un combat asymétrique ne tourne pas en la faveur du plus fort. À entendre les stratèges chinois, on dirait même que c'est une telle conviction qui aiguise le génie chinois au point de transformer tout défi, peu importe son ampleur, en une source prodigieuse d'invention. «Pour réaliser la victoire, conseillait Mao, nous devons, autant que faire se peut, rendre l'ennemi aveugle et sourd en lui crevant les yeux et en bouchant ses oreilles, et induire en erreur ses systèmes de commandement et de contrôle en créant la confusion dans son esprit.» La maxime du Grand Timonier a beaucoup d'à-propos dans le contexte de l'actuelle approche chinoise de la guerre de l'information.

Contrainte de réinventer une stratégie militaire, la Chine mise sur l'«information warfare» qui lui offre l'opportunité de gagner des guerres sans nécessairement en venir au corps-à-corps traditionnel. Si la stratégie de défense active revendiquée par Beijing traduit un changement 
doctrinal majeur par rapport au concept classique de guerre populaire promu par Mao, au demeurant, les tactiques et doctrines chinoises portent sa marque, ainsi que celle de Sun Tzu, le célèbre stratège de l'Art de la guerre ${ }^{26}$.

Le principal défi des stratèges chinois consiste à penser une stratégie asymétrique, basée sur une guerre électronique et de l'information, et destinée à défaire un adversaire plus puissant ${ }^{27}$. L'enjeu devient dès lors de déterminer la meilleure orientation que devrait par conséquent prendre le programme de modernisation de la Chine afin d'en assurer la meilleure efficacité possible. Un premier essai de réponse se trouve dans Unrestricted Warfare ${ }^{28}$, un autre livre publié en Chine en février 1999. Il propose des tactiques, à plusieurs égards révolutionnaires, à l'intention de pays en développement, en particulier la Chine, de nature à les aider à compenser leur infériorité militaire vis-à-vis des États-Unis dans la perspective d'une guerre de haute technologie.

Ainsi, pour les stratèges chinois, le fait marquant de la révolution qui s'opère dans le domaine militaire est l'usage de systèmes d'armements sophistiqués basés sur l'information. Dans cette nouvelle ère, qu'ils décrivent comme transitoire, la meilleure approche consiste à trouver la combinaison appropriée entre les armements plus traditionnels et les nouvelles technologies de l'information. Car, selon eux, même les États-Unis, pays qui détient pour

26. Pour une analyse historique des raisons pour lesquelles des États plus faibles peuvent attaquer de rivaux plus forts, voir: T. V. Paul, Asymetric Conflics: War Initiation by Weaker Powers, New York, Cambridge University Press, 1994.

27. Thomas J. Christensen, op. cit., p. 14.

28. Liang Qiao et Wang Xiangsui, Unrestricted Warfare, Beijing, PLA Literature and Arts Publishing House, 1999. 
le moment le système d'armement le plus sophistiqué, ne possèdent pas encore toutes les clés quant à l'issue d'une guerre dans un environnement technologique.

Plutôt que de se concentrer sur la confrontation militaire directe, ce livre explore de préférence une série d'autres tactiques alternatives qui vont du droit international (Lawfare) à des mesures économiques, en passant par l'intrusion dans des centres névralgiques des adversaires, c'est-à-dire, la pénétration de leurs réseaux informatiques et systèmes de surveillance et de contrôle, l'idée étant de mettre l'adversaire dans une posture telle que ses facultés à mener une action militaire directe seraient entamées.

En Occident, ce document de stratégie militaire est scruté dans les plus hautes sphères politiques. Un tel intérêt est parfaitement compréhensible quand on sait que le livre a été écrit par deux colonels seniors de l'armée chinoise, issus de la plus jeune génération d'officiers militaires et, de surcroît, publié par l'éditeur officiel PLA Literature and Arts. Cela fournit en effet une claire indication que sa publication a été endossée par la hiérarchie de l'armée chinoise. Cette impression est par ailleurs renforcée par une grande interview publique avec un des auteurs suivie d'une revue minutieuse du livre réalisée dans certains milieux médiatiques officiels en Chine.

\section{Contenir l'ennemi en attaquant son tendon d'Achille}

Il s'agissait pour les auteurs de Unrestricted Warfare de contribuer à la définition d'une stratégie de défense nationale qui tienne compte des nouveaux défis auxquels leur pays se trouve confronté, incluant des actions qui seraient susceptibles de rétablir l'équilibre de la puissance face aux 
États-Unis, en particulier en cas d'un conflit éventuel à propos de Taiwan.

Dans un article publié dans le Washington Post en 1999, un journaliste fait le récit du contexte de la parution du livre qui en dit long sur son dessein. L’idée, écrit-il, est née de la crise des missiles de 1996, dans le détroit de Taiwan, qui avait vu le déploiement par les États-Unis de deux porte-avions pour montrer leur détermination à protéger Taiwan en cas d'agression Chinoise. Le message était alors clair pour Beijing: affronter Taipei entraînerait de facto une guerre avec sa puissance tutélaire. Or, il était évident que dans une telle éventualité, la Chine ne ferait pas le poids compte tenu de la prééminence indiscutable des États-Unis en matière de technologie militaire ${ }^{29}$.

Pourtant, certains stratèges chinois croient savoir comment la Chine pourrait se tirer d'affaires dans un pareil cas de figure.

Attaquer l'ennemi à son tendon d'Achille est la recette vendue par les stratèges chinois. Les auteurs de Unrestricted warfare s'appliquent en effet à démontrer la vulnérabilité des États-Unis qu'ils expliquent par une dépendance excessive à l'égard des technologies militaires. Un argument majeur avancé veut que les États-Unis conçoivent la révolution militaire seulement en termes de technologie. En somme, les États-Unis omettraient de placer la révolution dans les affaires militaires dans le contexte plus large de la stratégie militaire, laquelle approche inclurait également des facteurs légaux et économiques.

Une des mesures proposées par le livre est l'idée que la Chine envisage d'infiltrer et d'attaquer les réseaux de ses

29. Thomas J. Christensen, op. cit., p. 8. 
adversaires. Les réseaux, disent ses auteurs, ne sont pas seulement importants pour l'échange de données, mais aussi pour le transport, les institutions financières et la communication. Des attaques destinées à les désactiver peuvent facilement occasionner des dommages incommensurables dans des domaines vitaux qui en dépendent largement ne serait-ce qu'à des fins de coordination.

Un exemple d'une guerre de cette nature consisterait à éteindre un réseau, source de puissance. Dans la mesure où il se produit une faille significative dans la source de puissance causée par l'attaque, il peut en dériver des conséquences contagieuses dans d'autres domaines connexes. Comme l'explique Christensen, «la guerre de l'information et la guerre électronique sont d'importance cruciale, tandis que combattre au sol peut seulement servir à exploiter la victoire. Par conséquent, la Chine est plus convaincue [que jamais] que, en ce qui concerne l'Armée chinoise, une révolution militaire avec la guerre de l'information au centre est en cours où des efforts doivent être consentis afin de rattraper et dépasser des rivaux ${ }^{30}$.»

Dans une excellente étude, Mark A. Stokes révèle comment Beijing tend à faire de l'information son arme militaire fétiche au XXI ${ }^{\mathrm{e}}$ siècle. Larmée chinoise conçoit ainsi de plus en plus l'information comme une arme stratégique. Ce qui porte à croire que la modernisation stratégique de la Chine, si elle aboutissait, permettrait à son armée de conduire des opérations aux effets stratégiques en s'attaquant aux centres névralgiques de l'ennemi.

Ainsi conçues, ces opérations permettraient à Beijing d'atteindre ses objectifs militaires sans nécessairement

30. Thomas J. Christensen, op. cit. 
avoir à affronter les forces militaires de l'adversaire dans le cadre d’opérations étendues. Dans la lignée de Sun Tzu et de Mao, les objectifs de telles attaques stratégiques consisteraient à produire des effets susceptibles de démoraliser le leadership de l'ennemi, les forces militaires et les populations, entamant ainsi la détermination de l'adversaire à poursuivre le conflit ${ }^{31}$. À cette fin, tous les coups seraient permis.

Parmi les récentes discussions sur l'évolution de la doctrine militaire chinoise, aucun thème n'a reçu autant d'attention que celui relatif à l'«information warfare (IW)». La Chine, selon les analystes, est un des trois pays après les États-Unis et la Russie à mettre l'accent sur le développement d'une stratégie basée sur ce concept. L'hypothèse d'une guerre de l'information est aujourd'hui suffisamment credible pour faire l'objet d'un rapport scientifique publié en 2000, dans lequel des chercheurs décrivent la forme qu'elle pourrait prendre. Selon eux, le but d'une telle guerre est surtout, à un moment critique dans la zone d'opérations, d'empêcher l'ennemi d'avoir le contrôle et l'usage de l'information, d'influencer, réduire, et même détruire les possibilités pour l'ennemi d'observer, de diriger, de commander et de contrôler les troupes ${ }^{32}$.

Contrairement à ce que l'on pourrait croire cependant, la Chine n'est pas en train de découvrir le concept d'information warfare, qui est assez ancien dans sa littérature stratégique. Un retour sur l'histoire révèle que ce pays a toujours privilégié la variable information dans sa straté-

31. Mark A. Stokes, China's Strategic Modernization: Implications for the United States, Carlisle, Strategic Studies Institute, 1999, p. 58.

32. Wang Houqing et Zhang Xingye (dir.), Science of Campaigns, Beijing, National Defense University Press, 2000. 
gie de guerre. Une revue de l'Art de la guerre de Sun Tzu (écrit en 500 av. J.-C.) reflète toute l'importance qu'il a traditionnellement accordé à la domination de l'information en temps de guerre. Pendant des siècles, ses dirigeants sont passés maîtres dans l'art de collecter, contrôler et manipuler l'information. C'est donc sur la base de cette compétence traditionnelle cruciale que Beijing absorbe aujourd'hui agressivement des technologies dans le cadre de la révolution en cours dans le domaine de l'information. Si la révolution en information, en soi, n'est pas une révolution dans les affaires militaires; elle constitue dorénavant la nouvelle fondation sur laquelle une nation doit ériger toute puissance militaire fiable ${ }^{33}$.

\section{La guerre de l'information}

Jamais l'idée selon laquelle celui qui détient l'information détient le pouvoir n'a été aussi vraie. Si les armes nucléaires distinguaient une grande puissance dans les années 1950, 1960 et 1970, les technologies de l'information semblent devenir aujourd'hui le critère dominant définissant une grande puissance, pour autant que celle-ci apprenne à bien se servir de ces atouts stratégiques.

Dans cette perspective, l'information attack peut corrompre directement les systèmes d'information de l'adversaire sans pour autant affecter les supports physiques sur lesquels ils reposent. Comme le signalent deux analystes, il s'agit d'un «produit de l'âge de l'information qui dans une

33. Major Norman C. Davis, «An information-based revolution in military affairs», dans James Mulvenon et Richard H. Yang, The People's Liberation Army in the Information Age, Santa Monica, RAND, 1999, p. 94. 
large mesure utilise les technologies de l'information et l'agencement de l'information dans les combats ${ }^{34} »$.

De plus en plus de signes prouvent que l'armée chinoise place la guerre de l'information au centre de sa propre RMA. Elle investit dans le développement d'une doctrine et de systèmes qui visent à lui permettre d'atteindre les centres de gravité stratégiques et opérationnels ennemis et de défendre les siens, ainsi que de poursuivre des objectifs politiques limités avec une économie de force asymétrique.

La guerre de l'information peut revêtir plusieurs formes, parmi lesquelles on retient au premier chef le «computer virus warfare». Les ordinateurs militaires risquent, pour ainsi dire, de se transformer en théâtre principal où sera déterminée l'issue des opérations entre les armées ennemies. À en croire les informations circulant dans les milieux stratégiques, certains pays sont maintenant en train de considérer l'établissement de bataillons d'attaque informatique ${ }^{35}$.

Le département américain de la défense a soupçonné la Chine de développer des stratégies afin de mettre au point des virus en vue de pénétrer les systèmes d'information de ses adversaires potentiels. Plusieurs analyses tendent à confirmer les faits reprochés à Beijing et suggèrent qu'il serait en train de développer de plus en plus et mettre au point des capacités dans le cyberespace. Ces capacités visent non seulement à collecter des informa-

34. John Arquilla et Solomon M. Karmel, «Welcome to the revolution [...] in Chinese military affairs», Defense Analysis, vol. 13, n 3, 1997, p. 259.

35. Wang Baocun et Li Fei, «Information warfare», dans Michael Pillsbury (dir.), Chinese Views of Future Warfare, National Defense University Press, 1997. 
tions sensibles, mais aussi à réaliser des effets militaires capables d'occasionner des dommages économiques, d'affecter des infrastructures cruciales, et d'influencer l'issue des conflits conventionnels armés ${ }^{36}{ }^{»}$.

Dans son Draft Report on China's Strategic Modernization, publié en septembre 2008, l'International Security Advisory Board Task Force du département américain de la Défense, indique: «L'objectif principal est de contrer la présence et les capacités des États-Unis en Asie de l'Est à travers l'acquisition de capacités offensives fonctionnelles dans des secteurs critiques qui exploitent systématiquement les vulnérabilités des États-Unis, incluant des failles dans les systèmes de défense antimissile.»

C'est dans ce contexte qu'une série d'attaques pirates, non revendiquées, contre des ennemis politiques de la RPC, sont souvent imputées au gouvernement chinois, soupçonné dans les milieux occidentaux de les avoir patronnées. Ceci porte à croire que, dans le cadre de sa stratégie de modernisation militaire à long terme, l'APL s'emploie actuellement à développer une capacité afin de cibler et à rendre defaillant le système d'information de ses ennemis potentiels.

Suite à une série d'incidents récents, on ne semble guère douter dans les milieux stratégiques en Occident que la Chine ait et la capacité, et la volonté de mener des attaques informatiques. À ce stade, cependant, les attaques sont conduites uniquement pour harceler des groupes ou organisations à des fins politiques. Les auteurs semblent conscients que des tentatives de nature guerrière contre

36. Brian M. Mazanec, «The art of (cyber) war», The Journal of International Security Affairs, ${ }^{\circ}$ 16, 2009. 
des centres vitaux américains en temps de paix conduiraient à des conséquences plus sérieuses.

Tous ces éléments tendent à prouver que la Chine a fait siennes ces tactiques peu orthodoxes et qu'elle les intègre dans sa stratégie de défense. L'espionnage apparaît comme un des aspects les plus redoutables de ce point de vue. Pour certains, les tentatives d'espionnage répétées de la Chine visent à obtenir des secrets militaires des États-Unis et, comme on peut le supposer, certains centres de renseignements américains figureraient tout naturellement parmi les cibles privilégiées des Chinois. L'affaire se déballe sur la place publique et il n'est pas rare de nos jours de lire dans les journaux en Occident, comme le New York Times, des articles offrant un luxe de détails sur l'intrusion plus que présumée de la Chine dans les principaux réseaux de renseignements gouvernementaux (incluant le département d'État, ceux du commerce et de la défense).

Symptomatiques de cette stratégie, des attaques similaires ont également été dénoncées contre des compagnies en Grande-Bretagne, ou encore n'ont pas épargné des agences gouvernementales en France, en Allemagne, en Corée du Sud et à Taiwan. Dans un rapport présenté en novembre 2008 au Congrès américain, la U.S.-China Economic and Security Review Commission a noté que le gouvernement américain et son économie sont particulièrement vulnérables au cyberspace, au vu en particulier de l'expertise que la Chine est en train de développer dans ce domaine.

Dans le cas de Taiwan, plusieurs incidents ont en effet été enregistrés. En 2003, le Taipei Times a rapporté des attaques incluant la propagation de virus à travers des réseaux d'un certain nombre de compagnies, dont l'objectif 
serait d'infecter un grand nombre de réseaux corporatifs et gouvernementaux. La finalité était vraisemblablement la paralysie de systèmes, l'espionnage ou la préparation de futures offensives de guerre de l'information. D'autres actions du genre se sont produites suite à des événements politiques significatifs, tels que ceux présumés en faveur de l'indépendance de Taiwan. En général, la portée stratégique et politique de ces genres d'attaques suggère l'implication de pirates militaires présumément sponsorisés par le gouvernement ${ }^{37}$.

Les données disponibles, en leur état actuel, ne suffisent pas à établir avec certitude les capacités réelles de la Chine en matière de $I W$. Cependant, comme l'affirment de plus en plus d'analystes, «au-delà de toute rhétorique et exagération, l'IW, si maîtrisée, fournit à la Chine une arme asymétrique potentiellement efficace. Pensée soigneusement, elle pourvoit l'armée chinoise de capacités de projection de longue portée contre les forces des ÉtatsUnis que les forces conventionnelles chinoises ne peuvent actuellement espérer contenir ${ }^{38}$.»

Dans une allusion à peine voilée à la Chine, un rapport officiel américain prévenait déjà en mai 1997 que, à l'avenir, des adversaires potentiels pourraient «employer des méthodes asymétriques afin de retarder ou refuser l'accès à des sites critiques; de perturber nos réseaux de commandement, de contrôle, de communications et de renseignement; ou d'infliger plus de dommages qu'escompté dans le dessein d'entamer notre détermination nationale».

37. Daniel Asen, «From the battlefield to the web: The dangers of PRCsponsored hacking», 〈www.istar.upenn.edu>.

38. James C. Mulvenon, «The PLA and information warfare», op. cit., p. $175-176$. 
Une telle lecture a reçu un écho favorable au-delà des milieux gouvernementaux américains. Le National Defense Panel, un groupe d'analystes considérés comme indépendants, a émis l'hypothèse que de potentiels adversaires puissent envisager de paralyser les structures permettant le lancement des opérations militaires des États-Unis. Ainsi, les bases militaires déployées à l'étranger pourraient vraisemblablement être l'objet de ces genres d'attaques. Des réseaux cruciaux qui permettent les communications, les transports, le déploiement, entre autres moyens de projection de la puissance, seraient ainsi rendus vulnérables ${ }^{39}$.

L'information warfare est particulièrement attractive dans le cadre d'une stratégie asymétrique visant à dissuader les États-Unis d'intervenir dans un conflit éventuel avec Taiwan. Au cours de deux exercices de cyber-attaque en 1997 et 1999, les militaires américains ont trouvé qu'un groupe de pirates, utilisant des ressources publiques disponibles, pouvait empêcher les États-Unis de mener une guerre efficacement. Le Pentagone a utilisé comme prémisse une crise militaire sur la péninsule coréenne. Le résultat de l'exercice était préoccupant car la série d'attaques contre les réseaux civils et militaires a exercé un effet paralysant sur les systèmes de commandement et de contrôle américains aux niveaux les plus élevés de l'opération.

Il est par conséquent imaginable que l'«information warfare» pourrait fournir à la Chine la capacité de gêner des opérations militaires américaines dans l'Asie Pacifique, une région d'importance centrale pour les inté-

39. National Defense Panel, «Transforming defense: National security in the 21st century», Joint Force Quarterly, 1997, p. 10-11. 
rêts de sécurité nationale des États-Unis. La stratégie de l'IW est donc centrale dans la nouvelle stratégie militaire de ce pays et représente un sujet de préoccupation pour ses rivaux, au premier rang desquels se trouvent les ÉtatsUnis ${ }^{40}$.

40. Jayshree Bajoria, «China's military power», New York Times, 5 février 2009, p. 2. 



\section{La dimension politique de la stratégie chinoise}

Un objectif central de la stratégie de puissance de la Chine consiste à promouvoir un environnement international stable pendant qu'elle cherche à modifier l'équilibre mondial de la puissance. Les précédents chapitres ont tenté d'expliciter la logique qui sous-tend le train de réformes économiques et militaires dans lequel la Chine s'est embarquée au cours des dernières années. Il s'agissait de démontrer que ces efforts multidimensionnels s'inscrivent dans le cadre d'une grande stratégie visant à maximiser la puissance relative de la Chine et, ultimement, à en faire une grande puissance.

Il convient à présent de se demander dans quelle mesure cette stratégie s'accompagne d'une offensive politique sur la scène internationale. Autrement dit, y a-t-il lieu d'affirmer que, forte de ses atouts économiques et militaires, la Chine pense et agit actuellement comme une «puissance révisionniste» dans l'arène politique et diplomatique?

Afin de répondre à cette question, ce chapitre examine d'abord les contours de la politique extérieure chinoise. 
Il montre ensuite comment la Chine a entrepris d'instrumentaliser le multilatéralisme comme rempart contre l'hégémonie américaine et pour la défense de ses intérêts nationaux. Ce multilatéralisme est combiné avec le bilatéralisme, les deux mis au service d'une diplomatie de grande puissance. Enfin, la politique de Beijing vis-à-vis de certaines puissances moyennes et d'États plus faibles est brièvement évoquée, en guise d'illustration du réalisme guidant sa politique étrangère dans sa stratégie de conquête du tiers-monde.

\section{L'expansionnisme chinois}

Pour plusieurs analystes, la Chine remettra forcément en question la suprématie américaine, de sorte que la question est maintenant de savoir «quand» et non «si» les relations États-Unis-Chine deviendront hostiles, voire conflictuelles. En plus des conséquences économiques et militaires analysées précédemment, l'émergence de la Chine s'accompagne aussi d'une influence politique bien remarquée. La Chine est en train de bousculer sérieusement l'ordre mondial centré autour de la superpuissance américaine. Il est vrai que les relations diplomatiques de Beijing tendent à devenir extrêmement ambitieuses et globales par leur ampleur. Ce phénomène sans précédent dans l'histoire du pays n'échappe pas à vigilance de certains experts à Washington ${ }^{1}$ et constitue maintenant l'un des phénomènes les plus étudiés en relations internationales.

1. Andrew Scobell, «Chinese diplomacy goes global: Motives, methods, and mechanisms». Témoignage devant l'U.S.-China Economic and Security Review Commission, p. 6, 〈www.uscc.gov>. 
Renseignés par l'histoire, de nombreux analystes réalistes proposent d'une manière générale une lecture plutôt pessimiste de l'avenir des relations sino-américaines. Il est en effet avéré que les puissances émergentes ont eu tendance à jouer les trouble-fête aux dépens de leurs rivales mieux nanties dans le système international, soucieuses qu'elles sont d'une meilleure répartition de la puissance mondiale. Cela a toujours été le cas, du point de vue réaliste, indépendamment du type de régime en place. C'est d'ailleurs ce constat qui inspire à John Mearsheimer le livre The Tragedy of Great Power Politics (2001). Ce fut aussi vrai dans le cas des États-Unis d'Amérique démocratique émergents que dans celui de l'Allemagne autocratique, constate-t-il.

Dans le même ordre d'idées, Samuel Huntington écrit: «L'expansionnisme de la Grande-Bretagne, de la France, de l'Allemagne, du Japon, de l'Union soviétique et des États-Unis coïncidait avec des phases d'intense industrialisation et de développement économique ${ }^{2}$ ». Robert Gilpin, dans son ouvrage fondamental, War and Change in International Politics (1981), mentionne les principales raisons à cela. Selon lui, un État plus riche et plus puissant s'assignera un plus large éventail d'objectifs de sécurité et de bien-être que des États plus démunis et moins puissants.

C'est que, théorisent les réalistes, les puissances émergentes ne se contentent pas uniquement de sécuriser leurs frontières mais aussi cherchent à se projeter au-delà, prenant des mesures en vue de créer des accès aux marchés, aux ressources matérielles et aux voies de transport; afin

2. Cité dans Aaron L. Friedberg, op. cit., p. 19. 
de protéger leurs expatriés, défendre leurs amis et alliés étrangers et véhiculer leurs valeurs et, en général, pour avoir ce qu'elles considèrent comme étant leur légitime mot à dire dans les affaires régionales et plus largement mondiales.

C'est donc le fait de vouloir réclamer leur «place au soleil» qui conduira les puissances émergentes à croiser le chemin des puissances hégémoniques, architectes et principaux bénéficiaires de l'ordre mondial existant. Ainsi, analysant son économie en nette expansion et sa puissance militaire en transformation, la plupart des auteurs réalistes ne trouvent aucune raison de croire que la Chine innoverait et, donc, romprait avec cette tradition bien établie dans le monde de la realpolitik. Au contraire, juxtaposant sa croissance interne rapide et son expansion consécutive fulgurante, Huntington prédit que la Chine aussi «inévitablement prendra cette orientation dans les prochaines décennies ${ }^{3} »$.

Ces considérations tendent à invalider la thèse, âprement promue par Beijing, d'un développement pacifique de la Chine. Selon cette persective, la Chine, comme toutes les autres puissances hégémoniques potentielles avant elles, ne se privera pas, le moment venu, de jouir de ses prérogatives. Il serait en effet difficile d'imaginer que, parvenue au faîte de la puissance, même si elle n'avait aucune raison de se battre, la Chine renoncerait à l'opportunité de dominer le système international.

Ils sont en effet bien rares, soutiennent les réalistes, les dirigeants politiques à se déclarer satisfaits de leur part de la puissance mondiale alors qu'ils auraient la capacité d'en 
obtenir davantage. À l'opposé, l'histoire regorge d'exemples tendant à montrer que les grandes puissances n'attendent que le moment favorable afin d'incliner la balance de la puissance en leur faveur. C'est aussi en cela que le comportement de la Chine, en apparence défensif, peut être trompeur pour les adeptes de la théorie de l'équilibre entre l'offensive et la défensive, pilier fondamental du réalisme défensif de Kenneth Waltz que nous avons déjà souligné plus haut.

Cette attitude de repli de la Chine ne serait, pour ainsi dire, qu'une stratégie qui reflète davantage le rapport de force en présence pour le moment, que ses visées politiques à long terme, comme cela a souvent été le cas dans l'histoire de l'empire. Sans être nécessairement agressive, la Chine a suffisamment montré au cours de ces dernières années que la recherche de la maximisation de sa puissance était le fil directeur de sa politique intérieure comme de sa politique étrangère.

La Chine est souvent considérée comme étant déjà régionalement hégémonique. Elle est en train de se faire une place confortable à la table mondiale de la puissance, à telle enseigne que la question est maintenant de savoir si elle poursuit une domination mondiale ou préfère jouer au bon enfant, commentent, ironiques, certains observateurs.

Bon élève, la Chine l'a été jusqu' ici avec toutes les mentions d'excellence possibles à l'école de la realpolitik. Mais certainement pas bon enfant. Depuis la fin de la guerre froide, plusieurs éléments de sa politique étrangère indiqueraient qu'elle est loin d'être satisfaite de certains aspects de l'ordre mondial, en particulier l'unilatéralisme qui résulte de la suprématie américaine. Elle n'a d'ailleurs de cesse d'appeler à l'avènement d'un ordre multipolaire, 
percevant la politique étrangère américaine comme arbitraire, sans borne et contraignante. Une des principales appréhensions de ses stratèges est la volonté prêtée à Washington de déployer dans leur périphérie, les instruments de puissance dans le cadre de sa politique dite d'endiguement.

En réponse, Beijing a adopté des mesures dont le but est d'accroître le rayonnement international du pays sans provoquer une réaction hostile à son ascension fulgurante. Sur le plan externe, la grande stratégie de la Chine renvoie à une politique extérieure dynamique et efficace, articulée autour de deux composantes essentielles qui feront l'objet des deux prochaines sections: l'adhésion tous azimuts de la Chine aux institutions multilatérales et l'établissement de divers partenariats bilatéraux stratégiques.

\section{Le multilatéralisme comme rempart contre l'hégémonie américaine}

Pour comprendre l'intérêt de la Chine pour le multilatéralisme, il faut retourner aux auteurs réalistes qui soutiennent que les institutions sont essentiellement le reflet de la configuration de la puissance dans le monde. Elles résultent des calculs intéressés des grandes puissances et n'ont aucun effet indépendant sur le comportement d'un État ${ }^{4}$. Il n'est donc pas surprenant que la Chine ait abandonné subitement son mépris historique à l'égard des institutions multilatérales pour en faire l'un des piliers de

4. John J. Mearsheimer, «The false promise of international institutions», International Security, vol. 19, n 3, 1994-1995, p. 7. 
sa stratégie d'affirmation de puissance dans l'ère postguerre froide.

Pour les réalistes en théorie des relations internationales, les organisations internationales (OI) ne demeurentelles pas une arène privilégiée où se pratique le jeu des puissances? Celles-ci ne sont-elles pas toujours prêtes à sauter sur la moindre opportunité afin d'en tirer profit aux dépens des autres, la méfiance étant toujours de rigueur entre elles? Les OI, ne reflètent-elles pas les intérêts des puissances dominantes de l'ordre mondial que cellesci ont contribué à mettre en place? Quand les États agissent à travers les OI, ne tendent-ils pas à toujours s'en servir dans le dessein bien compris de les instrumentaliser au service de leurs intérêts nationaux? Les institutions internationales, comme l'écrivait jadis le maître à penser du néoréalisme, Kenneth Waltz, servent plus les intérêts nationaux que les intérêts internationaux ${ }^{5}$.

Loin de l'invalider, les actions de la Chine semblent conforter la thèse des «fausses promesses des institutions internationales ${ }^{6} »$ de John Mearsheimer, qui veut que les États les plus puissants dans le système créent et influencent les institutions pour qu'ils puissent préserver leur part de la puissance mondiale, ou mieux l'accroître. On admet en effet de plus en plus aujourd'hui que le revirement spectaculaire de la Chine, s'agissant de sa participation active dans les OI, tient davantage au pragmatisme de la puissance mondiale qu'elle est en train de devenir qu'à toute autre chose.

5. Kenneth Waltz, «Structural realism after the Cold War», International Security, vol. 25, $\mathrm{n}^{\circ} 1$, p. 21.

6. John J. Mearsheimer, «The false promise of international institutions,p. 5-49. 
Tardivement arrivée dans un système international dont elle n'a pas véritablement été au centre de la confection, la Chine émergente a néanmoins compris la nécessité de prendre le train en marche. Elle hâte même son adhésion à ce nouvel espace de puissance que symbolisent les OI. Pendant longtemps, Beijing jetait un regard assez suspicieux sur ces institutions multilatérales, accusées de faire partie du grand complot impérialiste afin d'asseoir l'hégémonie occidentale. En guise d'alternative, la Chine privilégiait les relations bilatérales qui lui servaient plus facilement de levier diplomatique. Il faudra attendre la décennie 1990 pour voir la Chine amorcer un virage crucial$^{7}$, quoique, ce que Medeiros et Fravel désignent par China's New Diplomacy ne date pas de la fin de la guerre froide.

On met généralement à l'actif de Deng Xiaoping, l'architecte des politiques de réforme, la première grande transformation diplomatique initiée au tournant de la décennie 1970. En effet, l'ouverture dont a fait montre Deng tranchait avec le repli de Mao qui, arc-bouté sur sa doctrine marxiste-léniniste, enveloppait la Chine dans un isolationnisme idéologique. Son successeur lui, a conduit le pays dans une direction diamétralement opposée. Sous son règne, la Chine entre progressivement dans les rouages des institutions intergouvernementales et non gouvernementales, en particulier les institutions financières, améliorant ainsi son profil international. Cette évolution, certes significative, demeurait toutefois partielle.

En revanche, vers le milieu de la décennie 1990, Beijing, convaincu des avantages de la diplomatie multilatérale

7. Andrew Scobell, op. cit., p. 5. 
pour son ascension, fera preuve d'un réalisme exemplaire. Les dirigeants mettent entre parenthèses la vision conservatrice de leurs prédécesseurs pour embrasser une approche plus pragmatique de la politique étrangère. «Il sera impossible pour la Chine de mettre en œuvre sa stratégie d'émergence pacifique au $\mathrm{XXI}^{\mathrm{e}}$ siècle sans une ouverture culturelle et politique sur le reste du monde. La Chine a besoin d'un environnement pacifique sur le double plan interne et externe ${ }^{8}$.»

Le multilatéralisme occupera dorénavant, une place prépondérante dans la stratégie chinoise d'affirmation de puissance. C'est ainsi que «le pays le plus peuplé au monde œuvre maintenant dans le cadre du système international. Il a embrassé la plupart de la constellation d'institutions, règles et normes internationales en guise de moyens de promouvoir ses intérêts nationaux ${ }^{9} »$. Assez significative, à cet égard, est la déclaration de Jiang Zemin dans un rapport devant le $15^{\mathrm{e}}$ Congrès du Parti Communiste: «Nous devons participer activement aux activités diplomatiques multilatérales ${ }^{10}$.»

Beijing réalise que l'adhésion aux organisations internationales lui offrirait l'opportunité d'influencer leurs règles afin de mieux asseoir ses intérêts nationaux. Voilà donc comment il convient de comprendre l'enthousiasme avec lequel Beijing s'est depuis jeté dans les bras du multilatéralisme. Dans Same Bed, Different Dreams: Managing U.S.-China Relations, Lampton revient sur cette espèce de

8. Lanxin Xiang, «China's Eurasian experiment», Survival, vol. 46, n 2 , 2004, p. 116.

9. Evan S. Medeiros et M. Taylor Fravel, «China's new diplomacy», Foreing Affairs, vol. 82, nº 6, 2003, p. 22.

10. 〈http://english.peopledaily.com.cn〉. 
romantisme cultivé par Beijing vis-à-vis du multilatéralisme:

$\mathrm{Au}$ cours de la dernière décennie, la Chine... a courtisé plusieurs institutions internationales importantes, incluant l'OMC (qu'elle a intégrée en 2001) et le régime de non prolifération nucléaire (qu'elle a joint en 1996). En outre, elle a commencé à jouer un rôle plus actif et prédominant aux Nations unies. En fait, l'adhésion de la RPC aux organisations formelles gouvernementales internationales a plus que doublé entre 1977 et 1997 (passant de 21 à 52), tandis que sa participation dans les organisations internationales non gouvernementales a explosé au cours de la même période, passant de 71 à $1163^{11}$.

Il en résulte que, comme en témoigne le document politique China's 2006 Defense White Paper, «jamais avant la Chine n'a été si étroitement liée au reste du monde comme elle l'est aujourd'hui ${ }^{12}{ }^{2}$. La Chine se retrouve même à exercer un leadership exceptionnel - ce que déconseillait Deng- très apprécié dans l'émergence du multilatéralisme régional en Asie.

En effet, c'est en Asie centrale que se sont d'abord manifestés les intentions de la Chine d'utiliser les OI afin de poursuivre ses intérêts nationaux dans ses périphéries après la guerre froide ${ }^{13}$. En témoigne l'initiative qu'elle a prise en 1996 de formuler l'Accord de Shanghai, lequel a réussi à rallier la Russie et les pays de l'Asie Centrale comme le Kazakhstan, le Kyrgyzstan et le Tajikistan afin d'explorer des pistes de coopération économique et en matière de sécurité.

11. David L. Lampton, Same Bed, Different Dreams: Managing U.S.-China Relations, 1989-2000, Berkeley, University of California Press, 2001, p. 163.

12. Andrew Scobell, «Chinese diplomacy goes global», p. 1.

13. Robert G. Sutter, Chinese Foreign Relations: Power and Policy Since the Cold War, Lanham, Rowman and Littlefield, 2008, p. 313. 
Comme le note un analyste à cet égard, cette démarche relève d'une volonté non déclarée mais manifeste de créer une organisation pour contrer l'influence grandissante des États-Unis et de l'OTAN dans des domaines précédemment contrôlés par l'Union soviétique ${ }^{14}$. Ce regroupement a été formalisé sous l'appellation d'Organisation de Coopération de Shanghai (OCS) avec la participation supplémentaire de l'Uzbekistan en octobre 2001. Lors du sommet de 2005, l'Inde, le Pakistan et l'Iran ont rejoint l'OCS comme membres observateurs ${ }^{15}$.

Selon les réalistes, l'irruption de Beijing au sein des OI ne constitue nullement, comme on tendrait à le croire, une socialisation aux normes et règles supranationales ${ }^{16}$. Tout d'abord, sa présence au sein des principaux organismes internationaux lui procure un nouvel argument en faveur du "peaceful development», en vertu duquel la Chine entend jouer un rôle constructif dans la préservation de la stabilité et de la paix dans ses régions périphériques $^{17}$. Par ailleurs, comme le signale Goldstein, le multilatéralisme:

[...] est devenu pour Beijing l'un des outils permettant de faire face aux perceptions et suspicions hostiles [planant sur] la Chine qui ont caractérisé l'environnement stratégique dans la région. Par sa participation, la Chine entend prévenir la transformation des institutions multilatérales au profit des États-Unis et de leurs alliés en Asie Pacifique, et de préférence saisir les opportunités qu'elles offrent afin de contenir la

14. Vidya Nadkarni, «Strategic partnerships in Eurasia and Asia», présentation à l'Annual Convention of the International Studies Association, San Diego, 22-27 mars 2006, <www.allacademic.com>.

15. Vidya Nadkarni, Strategic Partnerships in Eurasia and Asia: Balancing Without Alliances, New York, Routledge, 2009.

16. Yuan-Kang Wang, «China's grand strategy and U.S. primacy», p. 23.

17. Avery Goldstein, Rising to the Challenge, p. 121. 
menace qu'elle perçoit dans la primauté américaine en vue d'accélérer, à terme, la fin de l'ère unipolaire. À cette fin, la Chine a commencé à soutenir que l'éclosion de la diplomatie multilatérale a réduit le besoin pour d'autres de déployer des systèmes d'armements dans la région, (particulièrement les missiles balistiques de défense) et de s'appuyer sur des alliances militaires (spécialement avec les États-Unis) ${ }^{18}$.

Il ne s'agit pas ici d'occulter l'attitude coopérative de Beijing dans les institutions internationales. Son influence grandissante a facilité l'avancement de dossiers cruciaux liés à la sécurité internationale. Son implication dans la gestion de la crise nord-coréenne relative au nucléaire est un cas de bonne pratique abondamment cité ${ }^{19}$. L'idée est plutôt de souligner que son activisme spontané relève de la realpolitik. Selon Avery Goldstein, Beijing a entrepris de s'ajuster afin de symboliser son nouveau statut comme acteur à part entière dans les organes de délibération d'importance régionale et globale ${ }^{20}$. Mais s'il y a lieu de saluer, d'un côté, des tendances encourageantes en matière de coopération, il faut, de l'autre, y voir des défis importants. Comme l'écrivait une analyste dont la réflexion vaut la peine d'être reprise ici intégralement:

Les Américains doivent toujours se rappeler... qu'alors même que la Chine devient de plus en plus engagée, elle [utilise] sa politique et relations étrangères au service de ses intérêts. La Chine d'aujourd'hui est certainement plus intelligente et sophistiquée - mais pas nécessairement plus tendre et gentille. Ses nouvelles qualifications tendent parfois à gêner les objectifs de Washington, à mesure qu'elle se positionne mieux

18. Ibid., p. 127.

19. Evan S. Medeiros et M. Taylor Fravel, «China's new diplomacy», op. cit., p. 34.

2O. Avery Goldstein, op. cit., p. 119. 
afin de mettre à mal, et remettre en question politiquement, les stratégies des États-Unis et de leurs alliés. Ainsi sa dextérité à neutraliser les États-Unis à la Commission des Droits Humains des Nations unies a eu la valeur d'une sonnette d'alarme. Les décideurs et diplomates américains devraient se préparer à traiter avec une Chine plus efficace au sein des institutions internationales... Tandis qu'elle semble préparée à opérer dans le cadre des règles et normes internationales afin de défendre ses intérêts, elle se montre insatisfaite de certains aspects de ce système, tels la prédominance des ÉtatsUnis et particulièrement le statut de Taiwan. Washington ne doit pas perdre de vue ses frustrations et doit tisser des liens avec Beijing et ses voisins d'une façon qui tienne compte de la réalité de son rôle régional étendu ${ }^{21}$.

Dans ce contexte, il n'est pas étonnant que les chercheurs chinois conçoivent le multilatéralisme davantage comme un moyen au service de leur pays ${ }^{22}$. Son adhésion au multilatéralisme participe par conséquent purement et simplement de tactiques afin d'arriver à un objectif stratégique de long-terme: parvenir à l'hégémonie régionale ${ }^{23}$. D'autres analystes se réfèrent à l'histoire chinoise, brièvement évoquée au chapitre 2 , pour en relever les traits distinctifs qui, à leurs yeux, s'accomoderaient mal de la civilisation occidentale et des institutions qui lui servent de véhicule. Martin Jacques rappelle par exemple que la Chine n'est pas un État-nation, mais plutôt un Étatcivilisation. Ceci pour dire qu'elle tâchera de rester conséquente avec son passé alors qu'elle (ré-)émergera au rang op. cit.

21. Evan S. Medeiros et M. Taylor Fravel, «China's new diplomacy»,

22. Zhang Xiaoming, "The rise of China and community building in east Asia», Asian Perspective, vol. 30, n 3, 2006, p. 146.

23. Hugh De Santis, «The dragon and the tigers: China and Asian regionalism», World Policy Journal, vol. 22, n 2, 2005, p. 23-36. 
de la puissance et que, ce faisant, et elle ne se soumettra pas aux diktats des institutions multilatérales ${ }^{24}$.

\section{Le bilatéralisme au service d'une diplomatie de grande puissance}

Cultiver des partenariats fait aussi partie de la stratégie de la Chine afin de faire face aux défis posés par la puissance américaine dans l'ère post-guerre froide et en vue de hâter l'avènement d'un système international dans lequel les États-Unis ne seraient plus dominants ${ }^{25}$. Avec le multilatéralisme, le bilatéralisme constitue l'autre bras diplomatique qui équilibre sa politique extérieure.

La Chine a concentré ses efforts à forger des relations bilatérales tout en embrassant le multilatéralisme ${ }^{26}$. Malgré son nouvel attrait marqué pour le multilatéralisme, elle ne s'est pas privée de cultiver des actions diplomatiques tous azimuts sous la forme de partenariats

Depuis 1996, elle a établi des partenariats variés avec chacune des puissances mondiales. L'expression «strategic partnership» est de ce point de vue dédiée aux relations bilatérales avec les grandes puissances du système ayant une valeur particulièrement stratégique. Ces partenariats lui permettent de résoudre certains problèmes liés à l'hégémonie américaine sans qu'il soit nécessaire d'engager des conflits directs ${ }^{27}$. Depuis 1993, ces pays incluent le

24. Voir le livre récent de Martin Jacques, When China Rules the World. The End of the Western World and the Birth of a New Global Order, Londres, Allen Lane, 2009.

25. Avery Goldstein, «The diplomatic face of China's grand strategy», p. 846 .

26. Andrew Scobell, «Chinese diplomacy goes global, op. cit., p. 5.

27. Avery Goldstein, Rising to the Challenge, p. 133-134. 
Brésil, la Russie, les États-Unis, l'Afrique du Sud, le Mexique, l'Égypte et l'Union Européenne (ainsi que les membres influents de cette dernière individuellement).

Chine-Russie: un "partenariat stratégique » anti-hégémonique

Rien a priori dans l'histoire récente de leurs relations tumultueuses ne prédisposait ces deux pays à être des partenaires stratégiques. Mais les impératifs de la Realpolitk en ont décidé ainsi. Ancien et nouveau challenger des États-Unis dans la course à l'hégémonie, l'un comme l'autre est inconfortable avec l'interventionnisme américain dans ce qu' ils considèrent comme les «affaires internes de pays souverains».

L'illustration fournie par les cas du Kosovo et de l'Irak n'a été en rien pour les rassurer. Cette préoccupation partagée leur sert donc de trait d'union. À la lumière de l'expansion de l'OTAN - à leurs yeux, instrument de l'hégémonisme américain -, et du renforcement des alliances des États-Unis en Eurasie, Moscou et Beijing ont tissé des liens bilatéraux exemplaires.

Ceux-ci se sont soldés en 1996 par la conclusion d'un "partenariat de coopération stratégique», baptisé par Beijing «nouvelles relations d'État-à-État» et qualifié de «premier en son genre ${ }^{28}$ ». Le partenariat stratégique de Beijing avec Moscou revêt, pour des raisons géostratégiques indiscutables, un caractère particulier - Moscou étant préoccupé au premier chef par l'expansionnisme américain en Eurasie. Il n'est donc pas surprenant qu'il 
mette l'accent sur la coopération comme levier permettant de «balancer» la puissance américaine.

Ce partenariat se concrétise essentiellement par une vente conséquente d'armements de fabrication russe et le transfert de technologies russes. Cette relation revêt un caractère régional stratégique en matière de sécurité, comme en témoigne l'opération conjointe dénommée «Mission de Paix» d'août 2005 ${ }^{29}$. Les activités qui ont eu lieu dans ce cadre de même que les technologies militaires exhibées, à grand renfort de publicité, revêtaient à l'évidence, en ce qui concerne la Chine, une valeur dissuasive visant à convaincre les Américains des coûts élevés qu’impliquerait leur intervention dans tout conflit éventuel avec Taiwan. En contrepartie, les demandes massives chinoises en armements sophistiqués apportent une bouffée d'oxygène à une économie russe qui était au bord de l'asphyxie.

Un auteur résume parfaitement le caractère donnantdonnant de la coopération sino-russe: «la Russie exporte ce dont la Chine a cruellement besoin - des équipements militaires et ressources énergétiques - tandis que la Chine fournit des investissements et produits manufacturiers à des prix compétitifs ${ }^{30}$ ». Une coopération mutuellement bénéfique mais qui, dans le cas de la Chine, lui a permis également d'atténuer considérablement les effets de l'embargo américain imposé sur son armement suite au massacre de Tienanmen. La Russie compte pour $85 \%$ des importations totales d'armes de la Chine depuis le début

29. Phillip C. Saunders, «China’s global activism: Strategy, drivers, and tools», Washington, National Defense University Press, 2006.

30. Lanxin Xiang, "China's Eurasian experiment», Survival, vol. 46, $\mathrm{n}^{\mathrm{o}} 2$, 2004, p. 112. 
des années 1990 et constitue le principal catalyseur de sa modernisation militaire ${ }^{31}$.

\section{Chine-États-Unis : des relations de puissance}

Aujourd'hui, malgré des frictions diplomatiques persistantes, on est bien loin de l'ambiance diplomatique enflammée ayant suivi la crise de l'avion-espion américain abattu au-dessus du territoire chinois et les ventes d'armes à Taiwan qui ont provoqué l'ire de la Chine quelques mois après l'arrivée de Georges W. Bush à la Maison Blanche en 200o. Beijing et Washington ont rapidement trouvé les moyens de calmer ces hostilités et ainsi refermer ce nouvel épisode d'intenses tensions et de crises diplomatiques.

Les relations entre les deux pays ont connu depuis un réchauffement spectaculaire, à telle enseigne qu'une analyste observait que «la Chine et les États-Unis sont peut-être au mieux de leurs relations depuis $1989^{32}$ ». Bref, la Chine n'est plus revêtue du manteau d'infamie que lui avaient taillé les États-Unis en signe de leurs divergences idéologiques. À quoi ce changement est-il dû?

Le réalisme offensif propose une explication plausible à ce phénomène. Diplomatiquement, un État peut choisir d'entretenir de bonnes relations avec un rival potentiel, dans l'espoir que cela détournerait l'attention belligérante de ce dernier vers un autre rival ${ }^{33}$.

Cette situation traduit, de ce point de vue, une gestion stratégique des relations avec Washington. Pour cause, les

31. Yuan-Kang Wang, op. cit., p. 25.

32. Elizabeth Economy, "Changing course on China», Current History, vol. $102, \mathrm{n}^{\circ} 665,2003$, p. 243.

33. Glenn H. Snyder, «Mearsheimer's world - offensive realism and the struggle for security», International Security, vol. 27, n 1, 20O2, p. 1649. 
États-Unis sont le seul pays ayant la capacité et l'ambition d'exercer une primauté mondiale aujourd'hui et dans un futur lointain. Ce pays contrôle une plus grande part de puissance que ni la France napoléonienne, ni l'Allemagne nazie n'ont pu mobiliser en leur temps ${ }^{34}$. En outre, ils sont un partenaire commercial majeur pour la Chine et y exercent, tout comme dans sa périphérie, une influence importante.

Cela signifie que les États-Unis (avec aussi la Russie) sont le pays qui exerce le plus de pression sur la Chine d'un point de vue stratégique. D'aucuns parlent d'un triangle stratégique, en référence aux relations entre la Chine, la Russie et les États-Unis ${ }^{35}$. C'est pourquoi quoique Taiwan demeure une pomme de discorde entre les deux pays, plusieurs considérations ont porté Beijing à pratiquer un double jeu alternant des aspects positifs et négatifs.

Il y a d'abord la nécessité d'entretenir un environnement international favorable au développement économique essentiel à son émergence. Ensuite - et ce n'est qu'un corollaire de ce qui précède -, le marché américain, première économie mondiale, est également la première source de capitaux et de technologies nécessaires à l'approvisionnement de l'économie chinoise. De là, cet aveu éloquent de $\mathrm{Hu}$ Jintao: «l'importance des États-Unis pour le développement économique de la Chine requiert une posture flexible et conciliante qui maintienne les rela-

34. Jeremy Pressman, «Strategies of resistance and the road to balancing», présentation à la convention annuelle de l'American Political Science Association, Chicago, 2-5 septembre 2004.

35. Yoram Evron, «Sino-American relations and the new administration», Strategic Assessment, vol. 11, n 3, 2009, p. 36. 
tions sino-américaines au beau fixe ${ }^{36}$ ». Dans le même esprit, Avery Goldstein écrit qu'«une grande stratégie raisonnable devait munir la Chine d'une approche satisfaisante afin d'entretenir des relations avec la superpuissance du monde, des relations qui avaient été perturbées de façon récurrente depuis la fin de $198 \mathrm{O}^{37}$ ».

Le maintien de bonnes relations avec la seule superpuissance est donc perçu comme crucial pour la pérennité du régime communiste, sa prospérité économique et, par conséquent, devient un impératif de sécurité nationale ${ }^{38}$. Ceci explique les efforts de Beijing en vue de conclure un second partenariat stratégique avec Washington ${ }^{39}$. Comme le rappelle un analyste, «un partenariat coopératif avec Washington est de première importance pour Beijing, où la prospérité économique et la stabilité sociale sont des préoccupations majeures ${ }^{40}$.» À cet égard, que Washington soit le siège de la plus importante mission diplomatique chinoise à l'étranger n'a rien d'étonnant. De même, le fait qu'au terme de son séjour diplomatique aux États-Unis, un ambassadeur chinois soit promu ministre des affaires étrangères de son pays ${ }^{41}$.

Cela participe d'une série d'ajustements politiques faits afin de stabiliser les relations bilatérales avec les États-Unis ${ }^{42}$. Il en résulte des gains non moins importants

36. Elizabeth Economy, «Changing course on China», p. 243.

37. Avery Goldstein, Rising to the Challenge, p. 143.

38. Andrew Scobell, «Chinese diplomacy goes global: Motives, methods, and mechanisms», p. 2.

39. Avery Goldstein, op cit.

40. Jisi Wang, «China's search for stability with america», Foreign Affairs, septembre-octobre 2005.

41. Andrew Scobell, op. cit.

42. Phillip C. Saunders, «China's global activism: Strategy, drivers, and tools», op. cit., p. 6. 
comme le soutien indispensable de Washington pour l'entrée à l'Organisation Mondiale du Commerce (OMC) en 2001. En un mot, sa relation avec Washington est loin d'être un jeu à somme nulle pour Beijing qui continue de percevoir sa rivale à la fois en termes de menaces et d'opportunités. Par exemple, si la Chine a paru tolérer la coopération croissante des États-Unis avec Taiwan en matière de sécurité, remarque Saunders, ce fut notamment en raison de l'engagement sans équivoque de l'Administration Bush à œuvrer contre la déclaration d'indépendance de l'île.

Cela ne signifie pas que les différences entre les deux pays aient disparu ou que ce partenariat continuera indéfiniment à garantir ce niveau d'accommodement mutuel. Ainsi, il existe une conviction largement répandue en Chine selon laquelle les États-Unis constituent un obstacle au statut de puissance régionale ou mondiale ${ }^{43}$. Ainsi, des dossiers aussi divers que la sécurité, l'économie et la politique, entre autres, continuent-ils de rendre la relation bilatérale compliquée et difficile à gérer pour les deux pays $^{44}$. L'ironie, comme l'observe un analyste, est qu'en dépit de désaccords de nature idéologique et diplomatique, la puissance grandissante de la Chine et son activisme sur la scène internationale en font un partenaire potentiel pour la conduite des relations internationales du point de vue des Américains ${ }^{45}$.

43. Elizabeth Economy, op. cit., p. 248.

44. Robert G. Sutter, Chinese Foreign Relations: Power and Policy since the Cold War, p. 155.

45. Yoram Evron, «Sino-American relations and the new administration», p. 35. 
Chine-Europe: «entente stratégique» pour un nouvel ordre mondial

Le rapprochement entre la Chine et l'Europe a été qualifié de phénoménal dans les relations internationales au cours de ces dernières années. Parallèlement, la Chine noue des relations bilatérales privilégiées avec la plupart des grandes puissances européennes (telles l'Allemagne, la France et la Grande-Bretagne), dans le cadre d'une approche que celles-ci baptisent $\mathrm{d}^{\text {« }}$ engagement constructif ${ }^{46}$ ».

Depuis 1997, un sommet annuel Chine-UE se tient alternativement à Beijing et à Bruxelles ou dans la capitale de la présidence de l'Union. David Shambaugh analyse ainsi cette évolution: «l'ampleur et la profondeur des relations Chine-Europe sont impressionnantes, et l'importance globale de cette relation s'impose comme un axe émergeant dans les affaires mondiales ${ }^{47}$ ». Pour sa part, faisant référence à l'ampleur des contacts économiques et politiques entre la Chine et l'Europe, et en allusion à Shambaugh, Robert Sutter parle de l'UE en termes de «pièce maîtresse dans la politique extérieure chinoise ${ }^{48} »$.

Plus nuancé, Jean-Pierre Cabestan, préfère mettre l'accent sur les faiblesses et le manque de cohérence des approches européennes, notamment en matière de droits de l'homme. Néanmoins, son bémol ne minimise en rien

46. À ce sujet, voir Kay Möller, «China and Europe since 1978: A European perspective», The China Quarterly, n 169 , 2002, p. 10-32. Pour une analyse plus factuelle et exhaustive des relations bilatérales sinoeuropéennes, voir Markus Taube, «Economic relations between the PRC and the states of Europe», The China Quarterly, n' 169 , 2002, p. 78-107.

47. David Shambaugh, "China and Europe: The emerging axis», Current History, vol. 103, $\mathrm{n}^{\circ}$ 674, 2004, p. 243-248.

48. Robert G. Sutter, Chinese Foreign Relations: Power and Policy since the Cold War, p. 340. 
l'importance grandissante des liens entre la Chine et l'Europe depuis la fin de la guerre froide ${ }^{49}$.

Afin de saisir les tenants du couple Chine-Europe, et d'ainsi comprendre la realpolitik guidant cette coopération, il convient d'en interroger la pertinence de la stratégie chinoise pour la promotion d'un «développement pacifique». Traduite en matière de politique extérieure, cette stratégie repose sur la théorie de la démocratisation des relations internationales comme principe ${ }^{50}$.

Comme le souligne Sutter, au lendemain de la guerre froide, les relations entre les deux parties n'étaient pas de première importance. Celles, par contre, avec les ÉtatsUnis et le Japon, entre autres puissances périphériques à la Chine, continuaient de recevoir une attention soutenue de sa part ${ }^{51}$.

En plus des motifs économiques, l'aspiration commune à un monde multipolaire et la collaboration au sein d'organisations multilatérales a favorisé un rapide rapprochement entre Chinois et Européens. Lanxin Xiang résume cette stratégie en des termes simples: «La Chine se tourne vers le multilatéral dans ses relations, les États-Unis embrassent l'unilatéral... Dans ces conditions, la Chine se tourne vers l'Union Européenne ${ }^{52}$.»

Dès lors, on comprend que cette perche tendue par la première puissance émergente asiatique rencontre l'adhésion empressée de ses pairs européens qui, depuis la fin

49. Jean-Pierre Cabestan, «European Union-China relations and the United States», Asian Perspective, vol. 30, n 4, 2006, p. 12.

50. Lanxin Xiang, "China's Eurasian experiment», p. 116.

51. Robert G. Sutter, Chinese Foreign Relations: Power and Policy since the Cold War, op. cit.

52. Lanxin Xiang, «China and the emerging Euro-Asian strategic landscape», 〈www.saias.ecnu.edu.cn〉. 
de la guerre froide, se plaignent de l'arrogance, parfois humiliante, avec laquelle les États-Unis d'Amérique affichent leur supériorité sur la scène mondiale. Depuis la fin de la guerre froide, la France a milité en faveur de la création d'un système multipolaire dans lequel l'Europe serait un pôle important afin de balancer les États-Unis. Ainsi, les récentes démonstrations de l'hégémonie américaine, dont la doctrine dite «preventive and preemptive» de George Bush a marqué le paroxysme, n'ont fait qu'apporter de l'eau au moulin des relations Chine-Europe.

L'invasion unilatérale de l'Irak par les États-Unis en 2002 a fourni un exemple de l'effort du soft balancing chinois contre l'hégémonisme américain, avec un fort appui européen. Comme le souligne T. V. Paul,

les États opposés sont engagés dans un «balancing» diplomatique intense à l'ONU, menaçant d'utiliser le veto contre toute résolution qui aurait autorisé l'usage de la force. Au bout du compte, les États-Unis ont lancé l'assaut sans la couverture d'une résolution de l'ONU et ainsi sans la légitimité internationale qu'ils cherchaient préalablement... la France, l'Allemagne et la Russie, auxquels s'est jointe la Chine, exigeaient plus de temps afin de permettre aux inspecteurs en armement de compléter leur travail ${ }^{53}$.

En un mot, l'UE est une direction vers laquelle se tourner quand il est difficile de traiter avec les États-Unis et, dans une certaine mesure, le Japon aussi ${ }^{54}$. Dans une excellente analyse, Kay Moller retrace l'histoire des rapports entre l'Europe et la Chine. Jadis un rempart contre l'hégémonisme américain ou soviétique, la Chine perçoit

53. T. V. Paul, «Soft balancing in the age of U.S. primacy», International Security, vol, 30, $\mathrm{n}^{\circ}$ 1, 2005, p. 66-70.

54. Richard Louis Edmonds, «China and Europe since 1978: A European perspective», The China Quarterly, nº 169, 2002, p. 1-9. 
désormais l'UE comme un élément majeur dans l'avènement d'un monde multipolaire. Elle a, par conséquent, une préférence marquée pour ses relations avec l'Union, plutôt qu'avec l'OTAN, par exemple.

La nature de ses relations avec l'Europe a poussé la Chine à élaborer en 2003 un paper policy, le premier en son genre $^{55}$. L'UE y est reconnue comme «une force majeure du monde», mais ce document impose aussi une longue liste de conditions nécessaires si, comme dans le cas de la Russie, son alliance avec l'Union doit jouir du statut de strategic partnership. À certains égards, la démarche de Beijing ressemble même à une tentative d'amadouer l'UE, qui représente à ses yeux un pôle militaire, politique et économique mondial important. Comme le montre Cabestan:

Le document souligne les vues convergentes entre la Chine et l'UE, l'absence de conflits d'intérêts, ainsi qu'une volonté supposément partagée de lutter en faveur d'un monde plus démocratique et multipolaire - une démocratisation qui, cependant, doit s'estomper aux frontières de la Chine. Ici encore, la Chine semble croire que l'ensemble de l'UE épouse l'approche française - et pour être plus précis, au sein de la France, le point de vue néogaulliste promu par Jacques Chirac - dans les relations internationales avec les États-Unis ${ }^{56}$.

Ce document trahit les véritables attentes de la Chine qui vont des questions liées à Taiwan et au Tibet à celles concernant les droits de l'homme, et la levée de l'embargo américain sur l'armement. Comme le prédit Shambaugh: «Le partenariat Chine-Europe continuera de croître et de

55. 〈www.fmprc.gov.cn〉.

56. Jean-Pierre Cabestan, «European Union-China relations and the United States», p. 17. 
se développer à un rythme accéléré. À terme, il deviendra un axe dans les affaires du monde et servira comme une source de stabilité dans un monde volatil ${ }^{57}$.»

\section{À l'assaut du tiers-monde: le «Dragon » contre l'« Aigle »}

Il ressort de l'analyse qui précède que la Chine continue de mettre ses relations avec les grandes puissances et les pays de sa périphérie au centre de sa politique étrangère. Parallèlement, depuis la fin de la guerre froide, son irruption sur la scène mondiale, à travers des liens diplomatiques et économiques grandissants sur tous les continents, la situe dans la trajectoire de l'«Aigle» américain, en particulier dans le tiers-monde.

Ce que nous appellerons ici l'«offensive tiers-mondiste chinoise» fournit un exemple probant de sa stratégie pragmatique qui combine ses influences économiques et diplomatiques afin de faire échec à l'hégémonie occidentale. Dans ce cadre, note Cabestan, le leadership du PCC a promu depuis 2003 un discours international dans lequel il tend la perche à ses voisions et au reste du monde pour montrer que la Chine n'a aujourd'hui plus d'ennemis ${ }^{58}$. Au gré des circonstances, les expressions «d'émergence pacifique», de «développement pacifique»et, dernière en date, d'«harmonie interne et internationale» deviennent les concepts clés de la politique stratégique chinoise.

Cependant, ce qui distingue véritablement le géant asiatique, c'est son approche dépourvue d'exigence en

57. David Shambaugh, "China's new diplomacy in Asia», op. cit.

58. Jean-Pierre Cabestan, «Chine, des armes pour quoi faire?», Politique internationale, $\mathrm{n}^{\circ} 110,2006, \mathrm{p} .7$. 
matière de droits humains, au grand dam des puissances occidentales: «Business now, politics later», est son principal crédo ${ }^{59}$. Comme l'observe Michal Meidan, il est clair que Beijing veut exporter son modèle socioéconomique et politique à d'autres pays en développement, juste comme les États-Unis se sont engagés historiquement - du moins dans la rhétorique - à propager la démocratie. Autrement dit, en termes d'idéologie, même si la Chine est en train de limiter la mesure de son modèle, elle affiche un désir constant de questionner le modèle occidental existant.

Les relations économiques étroites que Beijing a entrepris de développer avec les pays autres que les grandes puissances doivent être replacées dans le cadre de sa stratégie globale afin de contrer l'hégémonie américaine en Afrique, en Asie et en Amérique Latine. En termes d'importance, ses relations avec le tiers-monde viennent immédiatement derrière celles avec les grandes puissances $^{60}$. Cette campagne de Beijing a été couronnée de succès, si l'on en croit plusieurs analyses. Selon Joseph Tse-Hei Lee:

Quoique la Chine ne possède pas encore la puissance et les infrastructures pour être un État du premier-monde, elle possède néanmoins la capacité, les ressources et la volonté politique pour devenir un leader du tiers-monde... À l'instar de ses prédécesseurs, le président $\mathrm{Hu}$ Jintao conçoit le tiersmonde tant en termes idéologique que géopolitique. Il poursuit une plus grande stratégie qui vise la mise en place d'un ordre mondial multipolaire et anti-hégémonique, mais il est déterminé à combiner cette cause avec l'objectif de la

59. Michal Meidan, "China's policy: Business now, politics later», Asian Perspective, vol. 30, $\mathrm{n}^{\circ}$ 4, 2006, p. 69-93.

60. «China: Relations with the Third World», <www.country-data. com>. 
Chine de rivaliser avec les États-Unis dans différentes régions du monde ${ }^{61}$.

Certes, les réalités du nouvel ordre mondial vont pousser la Chine à faire preuve de pragmatisme dans sa quête de marchés, d'énergie et de matières premières, mais aussi d'influence politique comme puissance émergente. Mais au-delà des intérêts économiques qui les unissent, autant les leaders chinois ont toujours paru considérer les nations en développement des trois A (Asie, Afrique et Amérique Latine) comme une force majeure dans les affaires mondiales, autant celles-ci ont vu Beijing comme faisant partie intégrante du tiers-monde.

\section{La Chine en Afrique: une stratégie \\ de contournement de l'Occident}

«Il nous faut nous tourner vers l'Est, là où se lève le soleil.» C'est en ces termes que le président Robert Mugabe a célébré, à l'occasion du $25^{\mathrm{e}}$ anniversaire de l'indépendance du Zimbabwe, les retrouvailles entre l'Afrique et la Chine. C'est que, après ce qui est considéré comme une «période de repli relatif ${ }^{62} »$, depuis quelques années, Beijing manifeste un intérêt plus marqué pour l'Afrique. Pourtant, ses nouvelles motivations ne sont plus idéologiques comme ce fut le cas dans les années 1960 et 1970 quand elle se présentait comme une alternative aux États-Unis et à

61. Joseph Tse-Hei Lee, «The dragon and the eagle: China's encounters with the United States in the third world», Asia Journal of Global Studies, vol. $2, \mathrm{n}^{\circ} 1$, p. 2.

62. Valérie Niquet, «La stratégie africaine de l'Afrique», <www.diplomatie.gouv.fr $>$. Niquet situe ce repli entre le début des années 1980 et le milieu des années 1990. Selon elle, ce retrait est dû essentiellement à une thématique bilatérale - la question de Taiwan. 
l'Union soviétique et fournissait un appui salutaire aux mouvements de libération africains.

Sa nouvelle politique africaine recèle une dimension qui dépasse par ailleurs les ambitions strictement économiques qui caractérisaient ses relations avec les pays africains danscles années 1980. Autrement dit, ce que Philippe Richer nomme «l'offensive chinoise en Afrique» sur un continent considéré jadis comme une chasse-gardée de l'Occident, puise ses raisons dans la nouvelle «mutation de la puissance chinoise ${ }^{63}$ ».

Peuvent en témoigner la série de visites en grande pompe de $\mathrm{Hu}$ Jintao dans une vingtaine de pays depuis $2004^{64}$ et le fait que chaque année, en janvier, la Chine réserve ses premières sorties diplomatiques à l'Afrique. En retour, les dirigeants africains se succèdent à Beijing où ils sont accueillis avec un faste difficilement égalable. Pourtant, pris objectivement, peu de raisons plaideraient a priori en faveur de relations si intenses entre deux continents éloignés tant par leur géographie que leur langue et leur culture. Qu'en est-il donc exactement?

En premier lieu, il est largement reconnu que la présence de la Chine en Afrique est motivée par un enjeu pétrolier, entre autres ressources nécessaires à son développement économique. Deuxième pays consommateur de pétrole du monde après les États-Unis, la Chine se doit impérativement de trouver de nouvelles zones productrices pour sécuriser ses approvisionnements ${ }^{65}$. Aujourd'hui,

63. Philippe Richer, L'offensive chinoise en Afrique, préface par Jean-Luc Domenach, Paris, Karthala, 2008.

64. François Lafargue, «La Chine, une puissance africaine», Perspectives chinoises, juillet-août 2005, <http://perspectiveschinoises.revues.org〉.

65. Voir «Relations sino-africaines», CEREMS, septembre 2005, <www. cerems-travail.fr>. 
comme le note François Lafargue, si les flux commerciaux entre la Chine et l'Afrique restent limités, leur croissance est significative.

La Chine figure parmi les premiers partenaires commerciaux de nombreux pays africains: deuxième client du Gabon après les États-Unis, deuxième fournisseur du Bénin, cinquième fournisseur de l'Afrique du Sud, sixième fournisseur de l'Algérie ${ }^{66}$. À cet égard, relève Jean-Raphaël Chaponnière, «entre 2000 et 2007, la multiplication par sept du commerce sino-africain - de 10 à 70 milliards de dollars - classe la Chine au premier rang des fournisseurs du continent et au second rang de ses partenaires commerciaux derrière les États-Unis. Cette progression spectaculaire a arrêté le processus de marginalisation de l'Afrique dans le commerce mondial qui avait débuté en $1980^{67}$.»

En second lieu, il y a la question de Taiwan qui, toutefois, ne constitue plus l'élément principal de la politique africaine de la Chine ${ }^{68}$ puisqu'en dépit d'une politique de marginalisation diplomatique de Taipei, elle n'a pas réussi à le mettre totalement en quarantaine sur le continent africain. Parmi les États qui reconnaissent Taiwan, quatre sont des pays africains ${ }^{69}$.

En troisième lieu, vient aussi la dimension onusienne. Les pays africains représentent à eux seuls environ le tiers des effectifs de l'Organisation des Nations Unis (ONU). Ils

66. François Lafargue, op. cit.

67. J.-R. Chaponnière, «L'aide chinoise à l'Afrique: origines, modalités et enjeux», L'Économie Politique, vol. 2, nº 38, p. 8.

68. Voir Valérie Niquet, «La stratégie africaine de la Chine», op. cit.; Jiang Chung-lian, «Pékin et Taïpeh: les enjeux africains», Géopolitique africaine, $\mathrm{n}^{\circ}$ 10, 2003, p. 239-254.

69. Voir François Lafargue, op. cit., p. 2-10. 
s'imposent dès lors en alliés incontournables si Beijing veut damer le pion aux puissances occidentales dans la gestion de certains dossiers internationaux. Dans le même temps, «la dimension des Nations unies demeure centrale dans la mesure où Beijing peut offrir à ses partenaires africains un "paquet diplomatique" grâce à son double statut de pays en développement et de grande puissance à même de peser de tout son poids sur l'arène de la politique mondiale ${ }^{70} »$.

Cependant, à elles seules, ces dimensions ne suffisent pas à expliquer la dynamique des relations sino-africaines $\mathrm{au} \mathrm{XXI}^{\mathrm{e}}$ siècle. Les enjeux de la nouvelle politique africaine de la Chine dépassent de très loin ce continent, souligne Niquet. Selon elle, la politique africaine de la Chine s'inscrit également dans le cadre plus large d'une stratégie de contournement ou d'affaiblissement des puissances occidentales ou assimilées. Elle vise principalement les ÉtatsUnis, dans une situation internationale décrite par Pékin comme «complexe», c'est-à-dire, pour décoder la terminologie officielle, peu favorable à ses intérêts ${ }^{71}$.

Beijing mène en effet une stratégie de conquête politique sans précédent en Afrique. Dans ce contexte, la «nouvelle» politique africaine de la Chine, élaborée en 2006, pose les bases d'une coopération «mutuellement bénéfique», fondée sur la «non-ingérence $»^{72}$. Au cours des

70. Kwesi Aning et Delphine Lecoutre, «China's ventures in Africa», African Security Review, vol. 17, $\mathrm{n}^{\circ}$ 1, 2008.

71. Valérie Niquet, op. cit. Pour approfondir le sujet, voir également: Jacques de Lisle, «Into Africa: China's quest for resources and influence», février 2007, 〈www.fpri.org〉.

72. Cette coopération s'inspire essentiellement des mêmes principes relevés dans le discours prononcé à Accra en 1964 par Zhou Enlai. Il énonça alors «huit principes» qui, à plusieurs égards, régissent encore aujourd'hui l'aide chinoise, même si leur interprétation a changé au cours du temps: 
dernières années, la diplomatie publique occidentale a fait des «États voyous» et autres «axes du mal» son point focal; Beijing, en contraste, promeut une perspective bien différente. Par exemple, ses relations avec l'Angola, le Soudan et le Zimbabwe ont permis à ces pays d'ignorer royalement les pressions internationales et ont nui constamment à tout effort en vue de contraindre leurs dirigeants à réformer leur gouvernance interne ${ }^{73}$.

L'Angola, décrit comme passant de l'«afro-stalinisme» au «pétro-diamant-dollar», est l'archétype des pays africains ayant la démocratie en horreur ${ }^{74}$. En déficit de crédibilité auprès des institutions internationales en raison de sa mauvaise gouvernance, Luanda s'est alors tourné vers l'Est. Beijing ne s'est pas fait prier pour délier les cordons de la bourse ${ }^{75}$.

Avec le Soudan, selon certains, la Chine a scellé un partenariat à base «pétrole contre dictature». «À certains égards, le cas du Soudan est unique: il est le prototype de la volonté de la Chine d'offrir un partenariat large - argent, technologies, infrastructures et protection politique contre les pressions internationales (Occident) sur les questions de droits humains ${ }^{76}$.»

l'égalité entre les partenaires, les bénéfices mutuels, le respect de la souveraineté, l'utilisation de dons ou de prêts sans intérêt et l'allégement des charges, le renforcement du bénéficiaire, le respect des obligations, l'égalité de traitement entre experts chinois et locaux. Voir J.-R. Chaponnière, «L'aide chinoise à l'Afrique», op. cit. p. 37.

73. Philippe D. Rogers, «Dragon with a heart of darkness? Countering Chinese influence in Africa», Joint Force Quaterly, 2007.

74. Philippe Richer, L'offensive chinoise en Afrique, p. 159.

75. Voir Ian Taylor, «Unpacking China's resource diplomacy in Africa», $\langle$ www.cctr.ust.hk>.

76. Ndumbe Anyu et J.-P. Afam Ifedi, «China's ventures in Africa: Patterns, prospects, and implications for Africa's development», Mediterranean Quarterly, vol. 19, n 4, 2008, p. 99. 
Au Nigeria, pays qui a toutes les apparences d'une démocratie (président élu, élections régulières, etc.), mais réputé pour ses violations répétées de droits de l'homme, la Chine a augmenté ses chances de profiter de concessions de contrats juteux en troquant la «diplomatie contre le pétrole'77.

Le Zimbabwe est un autre cas typique. Tandis que les Américains et les Européens se sont retirés, en raison d'une réforme agraire destructive et des violations des droits de l'homme, la Chine entretient d'excellentes relations avec cette nation africaine figurant sur la liste noire occidentale d'«États voyous ${ }^{78}$ ».

L'offensive que la Chine conduit depuis quelques années en Afrique - continent considéré jadis, nous l'avons dit, comme la chasse-gardée de l'Occident - est sans doute le signe le plus tangible que son statut mondial s'est transformé $^{79}$. Tandis que les États-Unis sont empêtrés dans un bourbier avec la gestion de plusieurs défis globaux liés à leur sécurité depuis 2001, la Chine a utilisé ce qu'elle appelle une politique étrangère indépendante (en fait, un concept employé pour dénoter son indépendance de la puissance américaine) pour promouvoir une influence diplomatique, militaire et économique dans les nations africaines, en échange d'aide inconditionnelle, peu attentive à la situation des droits humains ${ }^{80}$.

Face à cette montée spectaculaire de la Chine, le président Nicolas Sarkozy ne cache pas sa préoccupation: «La

77. ISN Security Watch, «Influence anxiety: China's role in Africa», <www.cfr.org .

78. Paul Money, «China’s African safari», 〈http://yaleglobal.yale.edu〉.

79. Extrait de la préface de Jean-Luc Domenach, dans Philippe Richer, op. cit., p. 5.

80. Philippe D. Rogers, op. cit. 
Chine est en train de transformer sa quête insatiable de ressources matérielles en une stratégie de contrôle, spécialement en Afrique ${ }^{81}$.» En février 2007, quand le président Hu Jintao a annoncé que le commerce entre la Chine et l'Afrique atteindrait 100 milliards de dollars en 2010 (une croissance effectivement réalisée de $50 \%$ en quatre ans, après $40 \%$ par an entre 2000 et 2007), il a du coup fait de la Chine le premier partenaire commercial de l'Afrique.

Selon l'African Labour Research Network, «Après la fin de la guerre froide, la Chine a accordé une importance tant aux bénéfices politiques qu'économiques et s'est projetée comme un partenaire économique attrayant et un ami politique. Pour les gouvernements africains, cela a offert une alternative au "Consensus de Washington", sous la forme du "Consensus de Beijing", c'est-à-dire le soutien sans interférence dans les affaires internes.» De la sorte, l'Afrique est devenue de toutes les régions du monde, la plus récente frontière à l'expansionnisme chinois ${ }^{82}$.

\section{L’Amérique latine: défier Washington dans son arrière-cour}

Depuis la visite officielle de Hu Jintao en Amérique latine ${ }^{83}$ en $2004^{84}$, la «fièvre chinoise» se propage très fortement à travers le sous-continent. Freiner sa contagion risque

81. «French President Nicolas Sarkozy's Speech at the Opening of the Fifteenth Ambassadors' Conference», 27 août 2007, <www.ambafrance-uk. org>.

82. Joseph Tse-Hei Lee, «The dragon and the eagle: China's encounters with the United States in the third world», p. 10.

83. Dans ce texte, Amérique latine désigne l'Amérique du Sud, l'Amérique centrale, le Mexique et les Caraïbes.

84. Celle-ci a fait suite à une première tournée en 2001. En novembre 2008, le président Hu Jintao a effectué un voyage au Costa Rica, à Cuba et au Pérou. 
même de constituer, au début du Xxi ${ }^{\mathrm{e}}$ siècle, le principal défi à la doctrine Monroe qui proclamait: l'Amérique aux Américains.

En effet, depuis l'alliance stratégique de l'Union soviétique avec Cuba dans les années 1960, aucune autre puissance ne semble avoir autant convoité l'arrière-cour de la seule superpuissance au monde. Or, «discrètement mais résolument, dans des douzaines de régions du Chili à Cuba, la Chine est en train de gonfler ses muscles dans les étapes embryonnaires de ce qu'analystes militaires et des services de renseignement perçoivent comme étant un plan visant à défier les États-Unis politiquement et stratégiquement dans sa propre arrière-cour ${ }^{85}$ ».

En Amérique latine, la Chine évolue certes dans un environnement moins familier qu'en Afrique ${ }^{86}$, mais elle ne s'y retrouve pas non plus en territoire inconnu. Au cours de la décennie 1960, la Chine de Mao découvre, dans le contexte de la guerre froide, la révolution cubaine qui, emmenée par Fidel Castro, constituait une «entorse à la doctrine Monroe» telle que pratiquée depuis plus d'un siècle par les États-Unis. Mais absorbée par sa propre révolution culturelle, l'influence de la Chine ne consistera qu'en un soutien limité à des mouvements révolutionnaires latino-américains.

Depuis les années 1970, les relations diplomatiques et économiques sino-latino-américaines n’ont cessé de croître à un rythme significatif, en particulier dans les

85. Jane Bussey et Glenn Garvin, «China exerting regional influence, analysts warn of political, strategic challenges to U.S. in Latin America», The Miami Herald, 15 avril 2001, p. A1, 〈www.latinamericanstudies.org〉.

86. Depuis 1950, la Chine a activement participé au combat pour l'émancipation de certains peuples sur le continent noir. 
domaines du commerce, de l'investissement et de la coopération scientifique et technologique ${ }^{87}$. Au sortir de la guerre froide, tant l'Union soviétique que les États-Unis ont tourné le dos à l'Amérique latine dont la portée stratégique de «région-satellite» s'est considérablement dévaluée. En particulier, la désintégration de l'URSS induira un vacuum que cherchera dès lors à combler la principale puissance émergente. "La Chine a certainement mis à profit ce changement dans la configuration internationale de la puissance afin d'étendre son influence dans une région où elle a d'importants intérêts ${ }^{88}$.»

Le sous-continent est ainsi devenu pour elle, une source vitale d'énergie, de matières premières et de produits alimentaires. "Elle est devenue un acteur "discret" mais de plus en plus important en Amérique latine ${ }^{89}$.» Aujourd'hui, le géant asiatique est le deuxième plus grand partenaire de la région, derrière seulement les ÉtatsUnis $^{90}$. Le commerce avec l'Amérique latine a fortement augmenté depuis dix ans, atteignant 102 milliards de dollars en $2007^{91}$. De quoi inquiéter Washington, peu enthousiaste de voir Beijing s'immiscer dans une région dont le contrôle tendait déjà à lui échapper. En effet:

En quelques années, après Hugo Chavez au Venezuela (1998) et Lula Da Silva au Brésil (2002), la plupart des pays d'Amérique

87. Voir Frank O. Mora, «Sino-Latin American relations: Sources and consequences, 1977-1997», Journal of Interamerican Studies and World Affairs, vol. 41, n 2, 1999, p. vi-116.

88. He Li, «China's growing interest in Latin America and its implications», The Journal of Strategic Studies, vol. 30, $n^{\text {os }} 4-5$, 2007, p. 833.

89. Ibid.

90. Informations extraites de Luis Arce, «China challenges US dominance in Latin America», 〈www.wsws.org >.

91. Jean-Michel Caroit, «Pékin resserre ses liens avec les économies latino-américaines», Le Monde, 18 novembre 2008, 〈www.bilaterals.org〉. 
latine ont élu un gouvernement de gauche populiste, aux positions souvent hostiles à la politique américaine, comme Nestor Kirchner en Argentine (2003), Tabaré Vazquez en Uruguay (2004), puis [...] Evo Morales en Bolivie et Michelle Bachelet au Chili. Surtout, la victoire de Daniel Ortega au Nicaragua en novembre 2006 inquiète les États-Unis qui redoutent de voir se réduire leur emprise sur le continent latino-américain ${ }^{92}$.

Si donc pendant un demi-siècle, elle n'a manifesté qu'un intérêt mitigé pour l’Amérique latine, cette époque d'indifférence est maintenant révolue. La Chine, écrit François Lafargue, multiplie les investissements du Rio Grande à la Terre de feu et figure parmi les premiers partenaires commerciaux du Brésil, de l’Argentine et du Chili. Elle achète du soja et du fer au Brésil, du cuivre au Chili, de l'étain à la Bolivie, du nickel à Cuba et du pétrole au Venezuela.

Dans un contexte mondial de récession économique, où les fonds tendent à se raréfier pour les économies émergentes, comme en Afrique, elle n'hésite pas à jouer la carte de la diplomatie du carnet de chèque. «Les dirigeants chinois semblent vouloir profiter de la crise mondiale et des difficultés des pays occidentaux pour gagner du terrain dans les pays en développement, en se servant de leurs confortables finances», commente un article du Figaro $^{93}$. Pékin vient ainsi de doubler la mise pour un fonds de développement au Venezuela à hauteur de 12 milliards de dollars; a prêté 10 milliards de dollars à la compagnie nationale pétrolière du Brésil et a signé avec

92. François Lafargue, «La Chine en Amérique latine: stratégies, objectifs et limites d'une présence», Perspectives Chinoises, $\mathrm{n}^{\circ}$ 97, 2006, p. 8.

93. Arnaud de La Grange, «L'intérêt croissant de Pékin pour l’Amérique latine», Le Figaro, 20 avril 2009, 〈www.lefigaro.fr〉. 
l'Argentine un accord d'échange de devises (swap) pour un montant de 10 milliards de dollars.

Par ailleurs, «en 2003, les investissements de la Chine à l'étranger ont plus que doublé en une année (quoiqu'ils demeurent à un bas niveau) et l'Amérique latine a reçu un tiers des IDE chinois. L'année suivante, environ $50 \%$ des IDE chinois ont été en Amérique latine (16\% en 2005, d'un montant total de 7 milliards investis à l'étranger) ${ }^{94}$.» Constatant le poids de la Chine dans les négociations entre l'OMC et l'Amérique latine, Pascal Lamy s'étonne que l'attraction de la Chine puisse à ce point avoir ébranlé des «équilibres politiques» que l'on croyait acquis ${ }^{95}$.

Cet activisme est loin d'être de la philanthropie cependant. «Avec les États-Unis au fond de sa pire crise financière depuis sept décennies, l'irruption de la Chine dans la région va bien au-delà de ses besoins immédiats de ressources matérielles afin d'alimenter sa croissance industrielle ${ }^{96}$.»

David Rothkopf, spécialiste américain des questions stratégiques, s'interroge sur ses réelles intentions: «C'est ainsi que s'incline progressivement la balance de la puissance en temps de crise», déclare-t-il au New York Times. Les analystes se réfèrent généralement aux généreux prêts chinois en guise d'indication de sa puissance dans un monde changeant de direction, avec les Chinois devenant de plus en plus actifs. Il paraît évident que, sur le plan politique, la présence de la Chine en Amérique latine

94. Javier Santiso, «China: A helping hand for Latin America?» Introduction to The Visible Hand of China in Latin America, 〈www.oecd.org $>$.

95. <www.latinreporters.com>.

96. Luis Arce, "China challenges US dominance in Latin America», op. cit. 
conduira à termes à l'érosion de l'influence de Washington dont l'isolement est déjà patent. Une telle thèse est d'autant plus crédible qu'au niveau du sous-continent, seuls le Nicaragua, le Honduras, la République dominicaine et le Salvador avaient répondu à l'appel afin de participer à la coalition formée par les États-Unis pour déloger Sadam Hussein.

Témoignant devant le Congrès américain, Albert Santoli tire la sonnette d'alarme quant aux «velléités expansionnistes» de la Chine en Amérique latine ${ }^{97}$. Significative en cela est cette déclaration du fils spirituel de Fidel Castro, Hugo Chavez, en visite officielle dans la région asiatique. À la veille du sommet du G2O à Londres en avril 2009, le nouvel homme fort du sous-continent, bête noire des États-Unis, a tenu à faire le voyage en Chine pour, comme l'écrit Le Figaro, définitivement y «enterrer l'hégémonisme américain». Celui qui dirige le premier pays producteur de pétrole en Amérique latine, a ainsi déclaré que le «centre de gravité du monde s'est désormais déplacé à Pékin ${ }^{98}$ ». Hugo Chavez, dont on connaît bien l'impétuosité, a peutêtre proclamé haut et fort ce qu'on est de plus en plus nombreux à penser tout bas dans la région et ailleurs.

On le voit, à mesure que sa puissance économique et militaire s'accroît, Beijing revendique aussi une influence politique grandissante dans les affaires internationales. Ce désir se manifeste à travers des relations multilatérales et bilatérales traduites en liens stratégiques avec des puissances majeures du système et une offensive tous azimuts

97. Albert Santoli, "China's strategic reach into Latin America», $\langle$ www.uscc.gov $\rangle$.

98. Arnaud de La Grange, «L'intérêt croissant de Pékin pour l'Amérique latine», Le Figaro, 20 avril 2009. 
en direction des pays du tiers-monde. Partout, mais dans ces derniers en particulier, Beijing fait preuve d'originalité. Elle joue tour à tour les cartes de la diplomatie, du charme, de la communauté de destin et du carnet de chèque, tous des instruments alternatifs ou complémentaires au service de son ascension au sommet de la puissance. 



\section{CONCLUSION}

La réponse chinoise à l'hégémonie américaine s'apparente à une énigme dont aucune des théories en relations internationales ne semble avoir la clé. En particulier, elle s'inscrit à l'antipode des prévisions de l'influente théorie de l'équilibre des puissances, promue par le réalisme défensif de Waltz, qui eût voulu que la Chine prît la tête d'une coalition anti-hégémonique (hard coalition) contre la superpuissance américaine.

Cette prédiction ne s'étant pas vérifiée, certains auteurs ont ajusté leur analyse, avançant qu'il serait téméraire pour une puissance émergente, nonobstant son potentiel, de se lancer dans une aventure qui l'expose aux représailles de la seule superpuissance du globe.

Pourtant, on l'a vu, la Chine a bel et bien entrepris un mouvement d'équilibrage (balancing), mais qui jure avec les formes traditionnelles de cette stratégie. Confrontée à une nette supériorité des États-Unis dans les domaines économique, militaire et technologique, la Chine a entrepris de «balancer» la superpuissance américaine avec un pragmatisme qui n'est pas sans rappeler certaines pratiques de son histoire lointaine. 
Dans ce contexte, son principal défi a consisté à inventer une recette lui permettant d'émerger sans avoir à affronter prématurément son adversaire. Elle a conçu une stratégie qui combine trois dimensions complémentaires: sur le plan interne, des réformes économiques et militaires, et à l'externe, une diplomatie efficace en adéquation avec ses ambitions de puissance. La démarche a ceci de novateur qu'elle vise à relever le statut national et international du pays essentiellement par le jeu de la puissance économique, plutôt que militaire. La stratégie chinoise introduit de ce fait une dérogation majeure aux conventions en vigueur dans l'analyse des rapports entre puissances établies et en devenir. Pour comprendre cet exceptionnalisme, il faut s'inscrire dans la longue durée.

Vers le milieu de la décennie 1990, un consensus s'établit parmi les dirigeants chinois. Ils réalisent alors que le régime communiste n'a guère de chances de rivaliser avec le géant américain qui, contrairement aux thèses qui lui prédisaient un déclin inéluctable, n’en finit pas de gagner en puissance. Sous la houlette de Deng Xiaoping, le leadership convient que la réalisation du développement économique devra constituer le premier objectif du pays, s'il entend retrouver le rôle central qui fut le sien dans les affaires du monde.

Beijing entreprit donc de construire son pouvoir économique. Grâce à des réformes drastiques et audacieuses, l'écart abyssal qui séparait les économies chinoise et américaine s'est resserré en un temps record. Certains analystes projettent même que la Chine, forte de ses 1,3 milliard d'habitants, sera au sommet de l'économie mondiale avant $2 \mathrm{O} 2 \mathrm{O}$. 
Tirant les leçons de l'incidence de la course aux armements sur la chute brutale de l'Union soviétique, mais aussi de sa propre histoire, la Chine semble avoir trouvé un équilibre entre la modernisation militaire et le développement économique. Portée par boom économique sans précédent, elle ne se prive pas pour autant de se doter d'un budget militaire à la mesure de ses aspirations. Elle est en train de redresser progressivement ses capacités par l'importation d'équipements sophistiqués et le développement parallèle de sa propre industrie de défense. De fait, son armée est déjà pourvue de capacités défensives et offensives bien meilleures.

Sensibles aux défis stratégiques de l'après guerre froide et à la modernisation militaire qui menace de marginaliser les armées conventionnelles, les chinois se sont investis dans une «révolution militaire avec des caractéristiques chinoises» afin de préparer l'APL aux guerres de haute technologie. À cet effet, la doctrine militaire de la Chine s'est recentrée sur la professionnalisation et l'informatisation accélérées de ses forces armées par l'intégration des technologies de l'information à ses opérations militaires.

Par sa politique étrangère dynamique et efficace, la Chine accomplit un autre objectif essentiel de sa grande stratégie: l'établissement d'un environnement extérieur propice à son émergence. À mi-chemin entre réalisme et pragmatisme, elle va jusqu'à donner les signes d'un certain enthousiasme à l'endroit du multilatéralisme - jadis rejeté -, qu'elle combine avec un bilatéralisme exemplaire au service d'une diplomatie de grande puissance.

Afin de s'assurer un accès aux ressources pétrolières et aux matières premières indispensables à une économie en plein essor, elle établit des partenariats stratégiques 
avec les grandes et moyennes puissances, et s'efforce par de multiples initiatives de renouer avec l'allié traditionnel qu'est le tiers-monde. Ce cocktail économicodiplomatique est généralement assorti d'éléments politiques et militaires qui, par leur ampleur, semblent signaler des velléités expansionnistes. Tout cela provoque une onde de choc ressentie jusque dans l'arrière-cour de Washington, dont l'inquiétude est désormais visible. 


\section{BIBLIOGRAPHIE INDICATIVE}

Bozan, Jian et al., Histoire générale de la Chine, Pékin, Éditions en langues étrangères, 1985.

BRZEZINSKI, Zbigniew, Le grand échiquier. L'Amérique et le reste du monde, Paris, Hachette, 1997.

Cabestan, Jean-Pierre, "Chine, des armes pour quoi faire?», Politique internationale, $\mathrm{n}^{\circ} 110,2005-2006$.

CABESTAN, Jean-Pierre, «European Union-China relations and the United States», Asian Perspective, vol. 30, no 4, 2006, p. 11-38.

CABrillac, Bruno, Économie de la Chine, Paris, PUF, 2003.

Christensen, Thomas J., «Posing problems without catching up: China's rise and challenges for U.S. security policy», International Security, vol. 25, $\mathrm{n}^{\circ}$ 4, 2001, p. 5-40.

Christensen, Thomas J., «Chinese realpolitik: Reading Beijing's world-view», Foreign Affairs, vol. 75, n 5, 1996, p. 37-52.

Cohen, Warren I., «China's rise in historical perspective», Journal of Strategic Studies, vol. 30, nos 4-5, 2007, p. 683-704.

Coulomb, Catherine, Chine: le nouveau centre du monde?, La Tour d'Aigues, Éditions de l'Aube, 2007.

Deng, Yong et Fei-Ling WANG (dir.), China Rising: Power and Motivation in Chinese Foreign Policy, Lanham, Rowman and Littlefield, 2005.

Élisseeff, Danielle, Histoire de la Chine, Paris, Éditions du Rocher, 1997.

Evron, Yoram, «Sino-American relations and the new Administration», Strategic Assessment, vol. 11, n 3, 2009, p. 33-44.

FAIR BANK, John King, La grande révolution chinoise: 1800-1989, Paris, Flammarion, 1989.

FRIEDBERG, Aron L., «The future of U.S.-China relations: Is conflict inevitable?», International Security, vol. 30, nº 2, 2005, p. 7-45. 
Goldstein, Avery, Rising to the Challenge. China's Grand Strategy and International Security, Stanford University Press, 2005.

Goldstein, Avery, «The diplomatic face of China's grand strategy: A rising power's emerging choice», The China Quarterly, $\mathrm{n}^{\circ} 168$, 2001, p. 835-864.

Golub, Philip S., «Quand la Chine et l'Inde dominaient le monde», Manière de voir, vol. 2, $\mathrm{n}^{\circ} 85,2006$.

Hsü, Immanuel C. Y., The Rise of Modern China, New York, Oxford University Press, 2000.

JACQues, Martin, When China Rules the World. The End of the Western World and the Birth of a New Global Order, Londres, Allen Lane, 2009.

JIJUn, Li, Traditional Military Thinking and the Defensive Strategy of China, Carlisle, Strategic Studies Institute, 1997.

Kelly, Jason, «A Chinese revolution in military affairs?», Yale Journal of International Affairs, hiver-printemps 2006, p. 58-71.

Kurlantzick, Joshua, Charm Offensive: How China's Soft Power is Transforming the World, New Haven et Londres, Yale University Press, 2007.

KuRLANTZICK, Joshua, «Cultural Revolution: How China is changing global diplomacy», The New Republic, $\mathrm{n}^{\circ}$ 27, 2005, p. 16-21.

Lampton, David M., The Three Faces of Chinese Power: Might, Money and Minds, Berkeley, University of California Press, 2008.

LAYNE, Christopher, «The unipolar illusion revisited: The coming end of the United States' unipolar moment», International Security, vol. 31, $\mathrm{n}^{\circ} 2,2006$.

LEE, Joseph Tse-Hei, «The dragon and the eagle: China's encounters with the United States in the Third world", Asia Journal of Global Studies, vol. 2, $\mathrm{n}^{\mathrm{o}}$ 1, 2008, p. 1-15.

Lemoine, Françoise, «La montée en puissance de la Chine et l'intégration économique en Asie», Hérodote, $\mathrm{n}^{\circ}$ 125, 2007, p. 62-73.

MeArsheimer, John J., The Tragedy of Great Power Politics, New York, W. W. Norton, 2001.

MEARSHEIMER, John J., «The false promise of international institutions», International Security, vol. 19, $\mathrm{n}^{\circ}$ 3, 1995, p. 5-49.

Menzies, Gavin, 1421. L'année où la Chine a découvert l'Amérique, Paris, Intervalles, 2007.

Mulvenon, James C. et al., Chinese Responses to U.S. Military Transformation and Implications for the Department of Defense, Santa Monica, RAND, MG-340-OSD, 2006.

Needham, Joseph, Science in Traditional China: A Comparative Perspective, Harvard Universty Press, 1981. 
PAU L, T. V., «Soft balancing in the age of U.S. primacy», International Security, vol. 30, $\mathrm{n}^{\circ} 1$, 2005, p. 47-71.

RICHER, Philippe, L'offensive chinoise en Afrique, Paris, Khartala, 2008. Shambaugh, David (dir.), Power Shift: China and Asia's New Dynamics, Berkeley, University of California Press, 2005.

Shambaugh, David, «The new strategic triangle: US and European reactions to China's rise», The Washington Quarterly, vol. 28, $\mathrm{n}^{\circ} 3$, 2005, p. 7-25.

Snow, Philip, The Star Raft. China's Encounter with Africa, Ithaca, Cornell University Press, 1988.

Shirk, Susan L., China: Fragile Superpower. How China's Internal Politics Could Derail Its Peaceful Rise, Oxford University Press, 2007.

Sutter, Robert G., Chinese Foreign Relations: Power and Policy Since the Cold War, Lanham, Rownan and Littlefield, 2008.

SutTeR, Robert G., «Durability in China's strategy toward Central Asia - Reasons for optimism», China and Eurasia Forum Quarterly, vol. 6, $\mathrm{n}^{\circ} 1,2008, \mathrm{p} .3-10$.

Sutter, Robert G., "Why does China matter?», The Washington Quarterly, vol. 27, $\mathrm{n}^{\circ}$ 1, 2003-2004, p. 75-89.

Swaine, Michael D. et Ashley J. Tellis, Interpreting China's Grand Strategy: Past, Present, and Future, Santa Monica, RAND, 2000.

WANG, Jisi, "China's search for stability with America», Foreign Affairs, vol. 84, nº 5, 2005, p. 39-48.

WANG, Yuan-Kang, "China's grand strategy and U.S. primacy: Is China balancing American power?», CNAPS, 2005-2006, p. 1-31.

WALtZ, Kenneth N., Theory of International Politics, Reading, AddisonWesley, 1979.

Wu, Yuan, La Chine et l'Afrique, Beijing, China Continental Press, 2006. 



\section{TABLE DES MATIÈRES}

$\begin{array}{ll}\text { INTRODUCTION } & 7\end{array}$

1 L’ordre mondial bousculé $\quad 11$

2 La puissance chinoise dans la longue durée 33

3 La dimension économique de la stratégie chinoise de puissance $\quad 55$

4 La modernisation militaire conventionnelle de la Chine 69

5 Une révolution militaire à la chinoise 95

6 La dimension politique de la stratégie chinoise

$\begin{array}{ll}\text { CONCLUSION } & 165\end{array}$

BIBLIOGRAPHIE INDICATIVE 169 



\section{DANS LA MÊME COLLECTION}

Comité spécial du Sénat sur les drogues illicites, Le cannabis. Rapport du Comité spécial du Sénat sur les drogues illicites

Normand Baillargeon, Contre la réforme. La dérive idéologique du sytème d'éducation québécois

Charles Blattberg, Et si nous dansions? Pour une politique du bien commun au Canada

Gérard Boismenu et Guylaine Beaudry, Le nouveau monde numérique. Le cas des revues universitaires

Esther Cohen, Les narrateurs d'Auschwitz

Yolande Cohen, Femmes philanthropes. Catholiques, protestantes et juives dans les organisations caritatives au Québec

Joseph Heath, La société efficiente. Pourquoi fait-il si bon vivre au Canada?

Ingo Kolboom, Pièces d'identité. Signets d'une décennie allemande 1989-2000

Armand Mattelart, Pour un regard-monde. Entretiens avec Michel Sénécal

Catherine Mavrikakis, Condamner à mort. Les meurtres et la loi à l'écran

Éric Méchoulan, La culture de la mémoire ou comment se débarrasser du passé?

Alain Noël et Jean-Philippe Thérien, La gauche et la droite. Un débat sans frontières 
